TIAGO DOS SANTOS RAMOS

FORÇA DE RADIAÇÃO ACÚSTICA PRODUZIDA POR ONDAS ESTACIONÁRIAS DE ULTRASSOM

São Paulo

(2017) 
TIAGO DOS SANTOS RAMOS

\title{
FORÇA DE RADIAÇÃO ACÚSTICA PRODUZIDA POR ONDAS ESTACIONÁRIAS DE ULTRASSOM
}

\author{
Tese apresentada à Escola \\ Politécnica da Universidade de \\ São Paulo para obtenção do título \\ de Doutor em Ciências
}

São Paulo

(2017) 


\section{FORÇA DE RADIAÇÃO ACÚSTICA PRODUZIDA POR ONDAS ESTACIONÁRIAS DE ULTRASSOM}

Tese apresentada à Escola Politécnica da Universidade de São Paulo para obtenção do título de Doutor em Ciências

Área de Concentração:

Engenharia de Controle e Automação Mecânica

Orientador: Prof. Dr. Julio Cezar Adamowski

Coorientador: Prof. Dr. Marco Aurélio Brizzotti Andrade

São Paulo

(2017) 
Este exemplar foi revis ado e corrigido em relação à versão original, sob responsabilidade única do autore com a anuência de seu orientador.

São Paulo, de de

As inatura do autor:

Assinatura do orientador

Catalogação-na-publicação

Ramos, Tiago dos Santos

FORCA DE RADIACÃO ACÚS TICA PRODUZIDA POR ONDAS

ESTACIONÁRIAS DE ULTRASSOM/T.S. Ramos -- versão corr. -- São Paulo, 2017.

$125 \mathrm{p}$.

Tese (Doutorado) - Escola Politécnica da Universidade de São Paulo. Departamento de Engenharia Mecânica.

1.Ondas 2.Acústica 3.Ultrassom 4.Atuadores piezoelétricos I.Universidade de São Paulo. Escola Politécnica. Departamento de Engenharia Mecânica II.t. 
Dedico esta tese à minha filha Clara, à minha esposa Maria Gabriela e aos meus pais Severino e Maria de Fátima. 
Agradecimentos

Ao meu orientador, Prof. Dr. Julio Cezar Adamowski, que me aceitou como orientando e em todas as etapas do doutorado me aconselhou, sendo prestativo e atencioso indicou os melhores caminhos contribuindo para meu crescimento acadêmico e pessoal e dando todo o suporte necessário para desenvolver este trabalho.

Ao meu co-orientador, Prof. Dr. Marco Aurélio Brizzotti Andrade, pelas orientações, conselhos pertinentes, pela paciência, pela atenção, sempre presente no desenvolvimento dos estudos e análise dos resultados, pelos ensinamentos e conversas que contribuíram para minha formação acadêmica e pessoal.

Aos professores Dr. Pai Chi Nan, Dr. Flávio Buiochi e Dr. Nicolas Perez, por suas contribuições técnicas e acadêmicas.

Aos meus pais Severino e Maria de Fátima por todo carinho, companheirismo e dedicação ao longo de toda minha trajetória acadêmica e pessoal, sempre de prontidão em todos os momentos.

À minha esposa Maria Gabriela sempre carinhosa, paciente e companheira em todos os momentos, me apoiando e me motivando em minha vida acadêmica e pessoal.

À Clara minha adorável filha, que veio para nossas vidas durante este trabalho alegrando e sempre me esperando com um largo sorriso, que me renovava às energias.

Aos técnicos Gilberto Garcia e Adilson Felix pela confecção das peças utilizadas durante o doutorado Carlos Lima e Fidel de Paula pelas dicas técnicas e conversas.

Aos amigos e colegas de pós-graduação: Timóteo Oliveira, Carlos Mario, Rafael Tavares, Agesinaldo, Dan, Alan Tavares, Rafael Benetti, Thiago Paiva, Estevão Rodrigues, Vivian Costa, Breno Coelho, Hilton Nascimento, Myrian Bronn, Tiago Goto, Gustavo Oliveira, Rogério Yamamoto, Willian Scaff, Renan Pavani, Adriano Santos e Ricardo Farias pelos momentos de descontração, conversas acadêmicas, cafés e almoços ao longo de toda essa trajetória acadêmica. $\mathrm{E}$ a todos que colaboram de forma direta e indireta na execução deste trabalho.

A todos os professores que me inspiraram, incentivaram e contribuíram de alguma forma durante toda a minha formação acadêmica.

As secretarias da Pós-graduação Regianne Amaral e Marisa Lara sempre prestativas e atenciosas.

À CAPES, pela concessão da bolsa de doutorado.

Às agências de fomento CNPq e Petrobrás/ANP. 
As pegadas daqueles que caminham juntos nunca se apagam. (Autor desconhecido) 
Resumo

O estudo da força de radiação acústica é de extrema importância para compreender o fenômeno da levitação acústica, tendo em vista que ela é que permite a levitação de objetos no interior de uma cavidade acústica. A cavidade acústica é uma região do espaço delimitada pelas faces de um transdutor e de um refletor, onde é produzida uma onda estacionária de alta intensidade. Nesta técnica, conhecida como levitação por ondas estacionárias, pequenos objetos são aprisionados nos nós de pressão da onda estacionária. Além desta, também existe uma outra técnica de levitação onde não há a necessidade de se utilizar um refletor, técnica conhecida como levitação de campo próximo, na qual se tem apenas um transdutor e o objeto de face plana que se deseja levitar. Nesta técnica há uma pequena região com ar entre o transdutor e o objeto, sendo que a espessura da camada de ar é muito menor que o comprimento de onda. Neste trabalho foi feito um estudo numérico e experimental da força de radiação acústica em levitadores acústicos de onda estacionária e em levitadores de campo próximo. As simulações foram realizadas no software de elementos finitos COMSOL Mutiphysics. No estudo experimental foi utilizada uma balança eletrônica para medir a força de radiação acústica e uma câmera de alta velocidade para observar o comportamento oscilatório de objetos esféricos no interior da cavidade acústica. O estudo da força de radiação acústica resultou em três principais contribuições. A primeira contribuição está relacionada com a caracterização de efeitos não lineares em um levitador acústico, como o fenômeno de salto (jump phenomenon) e o fenômeno de histerese. A segunda contribuição está relacionada com o estudo numérico e experimental da força de radiação acústica que atua no refletor de um levitador acústico. Por último também foi feito um estudo da força de radiação acústica que atua no refletor para a região do campo próximo. Neste último estudo foi verificado que quando o diâmetro da face do transdutor é pequeno em comparação com o comprimento de onda, surge uma força atrativa sobre o refletor, e esta força pode ser utilizada para levitar um objeto plano em baixo da face do transdutor, sem haver necessidade de utilizar refletores.

Palavras chave: Ondas, Acústicas, Ultrassom, Atuadores piezelétricos. 


\begin{abstract}
The study of the acoustic radiation force is of high relevance to understand the acoustic levitation, since it is responsible for the levitation of small objects in the interior of an acoustic cavity. The acoustic cavity is the region delimited by the surfaces of the transducer and the reflector, where it is generated an acoustic standing wave field of high intensity. In this technique, called standing wave acoustic levitation, small objects are entrapped at the pressure nodes of the standing wave. In addition, there is also another levitation technique where there is no need to use a reflector. This technique is known as near-field levitation, in which there is only one transducer and the flat-faced object to be levitated. In this technique there is a small region with air between the transducer and the object, with the thickness of the air layer being much smaller than the wavelength. In this work, a numerical and experimental study of the acoustic radiation force in acoustic wave levitators and near-field levitators was done. The simulations were performed in the finite element software COMSOL Mutiphysics. In the experimental results, an electronic scale was used to measure the acoustic radiation force and a high speed camera was applied to observe the oscillatory behavior of spherical objects inside the acoustic cavity. The study of acoustic radiation strength resulted in three main contributions. The first contribution is related to the characterization of nonlinear effects in an acoustic levitator, such as the jump phenomenon and the hysteresis phenomenon. The second contribution is related to the numerical and experimental study of the acoustic radiation force that acts on the reflector of an acoustic levitator. Finally, a study of the acoustic radiation force that acts on the reflector for the near field region was also made. In this last study, it was verified that when the transducer is small in comparison with the wavelength, an attractive force appears on the reflector. This force can be used to levitate a flat object below the transducer face, without requiring a reflector.
\end{abstract}

Keywords: Waves, Acoustic, Ultrasound, Piezoelectric Actuators. 


\section{Lista de símbolos}

a Raio da face do transdutor

A Amplitude de pressão

$c_{0} \quad$ velocidade do som no ar

$c_{p} \quad$ velocidade da partícula

d distância

$F \quad$ força

$K \quad$ número de onda

$k \quad$ constate elástica

$Q_{0} \quad$ quantidade de calor

$p \quad$ pressão acústica

$p_{0} \quad$ pressão de equilíbrio do ambiente

$P \quad$ pressão total

$p_{s} \quad$ pressão total sobre uma superfície

$R \quad$ Raio do objeto

$S \quad$ entropia

$t \quad$ tempo

U potencial acústico

$v \quad$ velocidade

w entalpia

$V \quad$ Volume do objeto

z $\quad$ Coordenada do eixo vertical 
Lista de símbolos gregos

$\rho_{0} \quad$ densidade de equilíbrio do fluido

$\rho$ densidade acústica

$\rho_{p} \quad$ densidade da partícula

$\rho_{t} \quad$ densidade total

$\lambda \quad$ comprimento de onda

$\omega \quad$ frequência angular

$\Gamma \quad$ constante

$\varphi \quad$ potencial de velocidade

$\gamma \quad$ relação entre os calor especifico a pressão constante e a volume constante 


\section{Lista de ilustrações}

Figura 1.1- Modelo simplificado de uma cavidade acústica com uma posição de levitação, e as relações do comprimento de onda na cavidade.

Figura 2.1.1- Representação esquemática de uma onda estacionária.

Figura 2.4.1- Aproximação do potencial acústico por uma parábola em torno de uma posição de equilíbrio estável em um mínimo potencial.

Figura 2.5.1- Relação entre os parâmetros acústicos: a-) pressão acústica, b-) velocidade das partículas do meio, c-) potencial acústico e, d-) forção de radiação acústica de uma onda estacionária propagando-se no eixo $z$.

Figura 2.6.1- Curva de histerese e fenômeno de "salto" em uma varredura para uma cavidade acústica.

Figura 3.1- Esquema de um transdutor de Langevin.

Figura 3.2- Modelo de transdutor de Langevin com um amplificador mecânico.

Figura 4.2.1- Imagem do sistema experimental para o transdutor e refletor côncavo

Figura 4.2.2- Diagrama do sistema de aquisição das oscilações das esferas na cavidade acústica e, força de radiação acústica com a balança eletrônica

Figura 4.3.1- Diagrama do transdutor e refletor côncavos e com medidas e eixos de referências. .....50 Figura 4.3.2- Força de radiação acústica em função da distância entre o transdutor e o refletor côncavo.

Figura 4.3.3- Intensidade da força de radiação acústica em função da distância entre o transdutor e o refletor côncavo, para uma varredura de crescente e outra decrescente.

Figura 4.3.4- Força de radiação acústica sobre o refletor em função da distância entre o transdutor e o refletor côncavo, com uma curva de referência, e curvas para as esferas de polipropileno, vidro e aço utilizadas no experimento

Figura 4.3.5- Força de radiação acústica em função da distância entre o transdutor e o refletor côncavo para uma esfera de polipropileno de $3 \mathrm{~mm}$ de diâmetro, com três posições para análise de oscilações.

Figura 4.3.6- Oscilações horizontais e verticais para a esfera de polipropileno e suas respectivas amplitudes e frequências de oscilações, para a posição $A$, da figura 4.3.5.

Figura 4.3.7- Oscilações horizontais e verticais para a esfera de vidro e suas respectivas amplitudes e frequências de oscilações, para a posição $A$, da figura 4.3.5.

Figura 4.3.8- Oscilações horizontais e verticais para a esfera de aço e suas respectivas amplitudes e frequências de oscilações, para a posição $A$, da figura 4.3.5.

Figura 4.3.9- Perfis da a-) Amplitude de pressão e, b-) potencial acústico relativo para a cavidade acústica do transdutor de $20 \mathrm{kHz}$ e refletor côncavos.

Figura 4.3.10- Modelo simplificado de levitação acústica, seguindo um modelo que obedece a lei de Hooke, para um sistema massa mola.

Figura 4.3.11- Oscilações horizontais e verticais para a esfera de polipropileno e suas respectivas amplitudes e frequências de oscilações, para a posição $B$, da figura 4.3.5. 
Figura 4.3.12- Oscilações horizontais e verticais para a esfera de vidro e suas respectivas amplitudes e frequências de oscilações, para a posição $B$, da figura 4.3.5.

Figura 4.3.13- Oscilações horizontais e verticais para a esfera de aço e suas respectivas amplitudes e frequências de oscilações, para a posição $B$, da figura 4.3.5. 68

Figura 4.3.14- Oscilações horizontais e verticais para a esfera de polipropileno e suas respectivas amplitudes e frequências de oscilações, para a posição $C$, da figura 4.3.5. 69

Figura 5.2.1- Modelo do sistema de levitação apresentado no software COMSOL, para um transdutor e refletor de faces planas.

Figura 5.2.2- Modelo numérico do sistema de levitação acústico com o potencial de Gor'kov relativo para a cavidade com transdutor e refletor de faces planas (COMSOL). Nesta figura, tanto o transdutor quanto o refletor possuem $7,5 \mathrm{~mm}$ de raio.

Figura 5.2.3- Modelo numérico para a força de radiação acústica máxima em função de cada raio de refletor de face plana (COMSOL).

Figura 5.2.4- Potencial de radiação acústica relativo, para refletores de faces planas com raios de 8 e $12 \mathrm{~mm}$, com as cavidades acústicas em ressonância.(COMSOL).

Figura 5.2.5- Pressão de radiação acústica qualitativa sobre o refletor de face plana plano com raio de $8 \mathrm{~mm}$. (COMSOL)

Figura 5.2.6- Modelo numérico qualitativo do primeiro termo da força de radiação acústica sobre o refletor de face plana com raio de $8 \mathrm{~mm}$ (energia potencial média temporal). (COMSOL) 80

Figura 5.2.7- Modelo numérico qualitativo do segundo termo da pressão de radiação acústica sobre o refletor de face plana com raio de $8 \mathrm{~mm}$ (energia cinética média temporal). (COMSOL).

Figura 5.2.8- Visão de topo qualitativo do primeiro e do segundo termo sobre o refletor de face plana e raio de $8 \mathrm{~mm}$. (COMSOL)

Figura 5.3.1- Aparato experimental utilizado para medir a força de radiação acústica sobre o refletor em função da distância de separação entre a face do transdutor e o refletor.

Figura 5.4.1- Varredura experimental completa para um refletor de face plana com $11 \mathrm{~mm}$ de raio...86 Figura 5.4.2- Resultado experimental da força de radiação acústica para três refletores de faces planas com diferentes diâmetros na ressonância das respectivas cavidades acústicas.

Figura 5.4.3- Força de radiação acústica máxima experimental para cada raio de refletor de face plana.

Figura 5.4.4- Força de radiação acústica máxima experimental e simulada para cada raio de refletor de face plana.

Figura 6.1.1- Esquema simplificado de levitação de campo próximo, com a face plana emissora direcionada pra cima, amostra de face plana.

Figura 6.1.2- Modelo numérico da força de radiação acústica em função da distância entre o transdutor e 0 anel de faces planas. (COMSOL)

Figura 6.1.3- Modelo numérico qualitativo da pressão de radiação acústica total sobre o raio do anel de face plana. (COMSOL)

Figura 6.1.4- Modelo numérico qualitativo do primeiro termo da pressão de radiação acústica total em função do raio do anel de face plana. (COMSOL). 
Figura 6.1.5- Modelo numérico qualitativo do segundo termo da pressão de radiação acústica em função do raio do anel de face plana. (COMSOL)....

Figura 6.2.1- Esquema simplificado do sistema de aquisição de dados da força de radiação acústica sobre o um anel de face plana, com uma balança eletrônica. 101

Figura 6.3.1- Força de radiação acústica sobre um refletor de face plana, com diferentes amplitudes de deslocamento, para campo próximo, para o transdutor de $31 \mathrm{kHz}$ e $7.5 \mathrm{~mm}$ de raio. (experimental)

Figura 6.3.2- Força de radiação acústica sobre um refletor de face plana, com diferentes amplitudes de deslocamento, para campo próximo, para o transdutor de $20 \mathrm{kHz}$ e $10 \mathrm{~mm}$ de raio. (experimental)

Figura 6.3.3- Força de radiação acústica sobre um refletor com diferentes amplitudes de tensão, para campo próximo, para o transdutor de $25 \mathrm{kHz}$ e $13 \mathrm{~mm}$ de raio. (experimental) 106

Figura 6.4.1- Imagem do experimento de levitação de campo próximo, com a ponta emissora do transdutor direcionada para baixo e um anel ambos com faces planas. 107

Figura 6.4.2- Força de radiação acústica sobre um anel de face plana com diferentes amplitudes de tensão, para campo próximo para o transdutor de $23 \mathrm{kHz}$ e $5 \mathrm{~mm}$ de raio. (experimental) 109 


\section{Sumário}

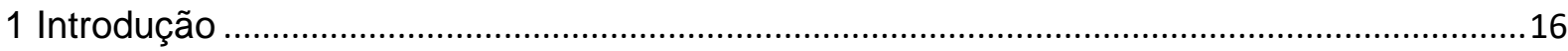

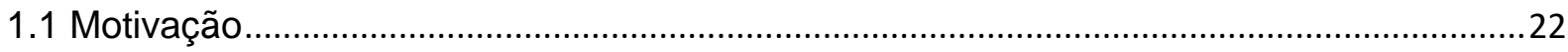

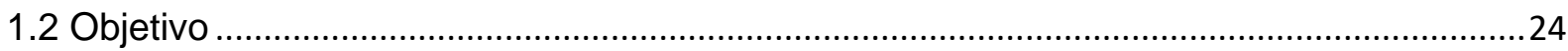

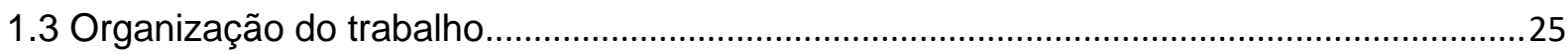

2 Teoria

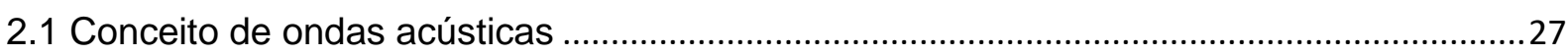

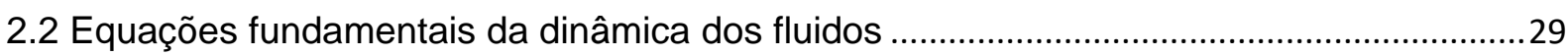

2.3 Pressão de radiação acústica sobre um refletor ................................................................32

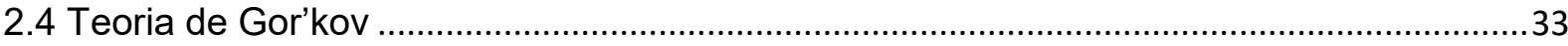

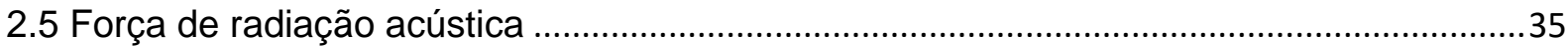

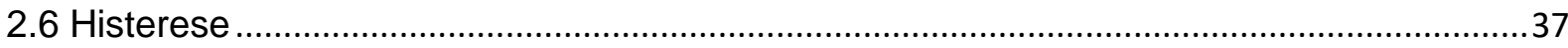

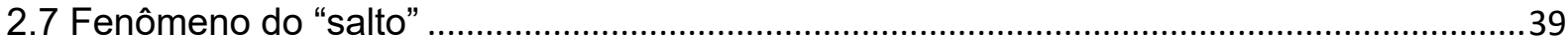

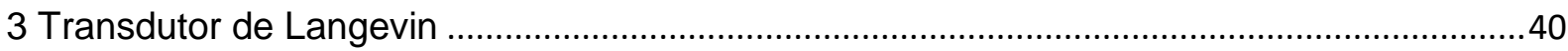

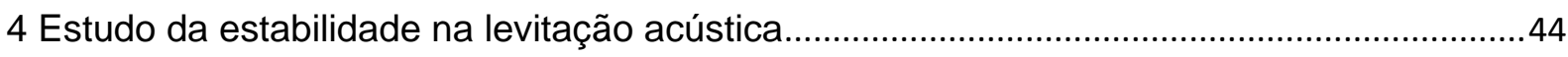

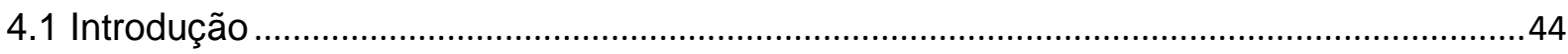

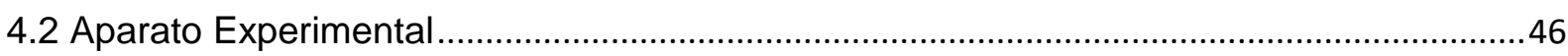

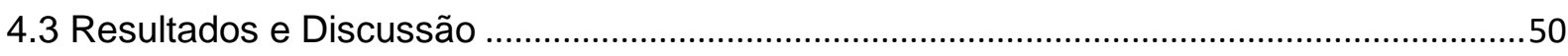

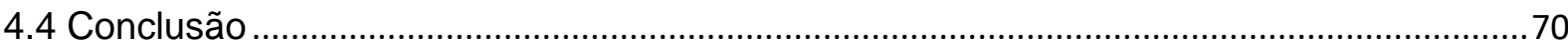

5 Força de radiação acústica no refletor no campo distante ......................................................72

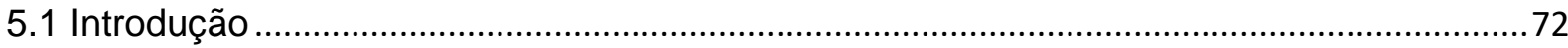

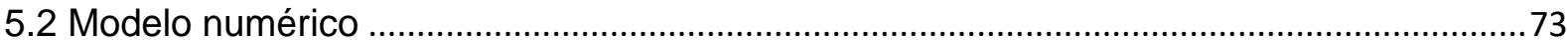

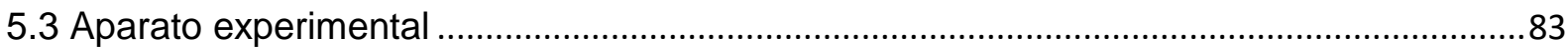

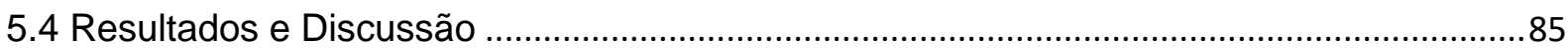

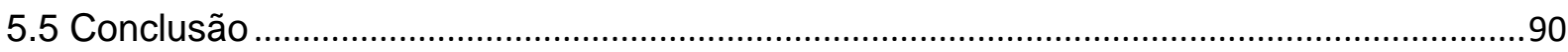

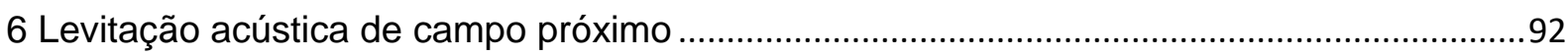

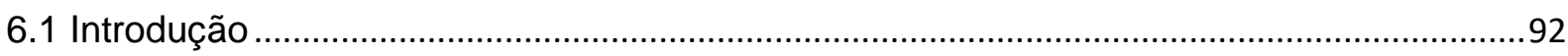

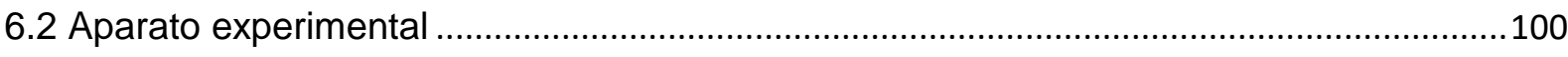

6.3 Campo próximo força de radiação acústica positiva ............................................................ 103

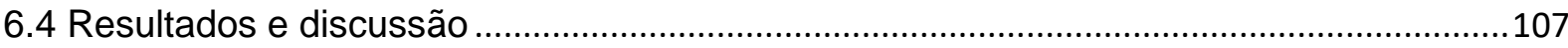

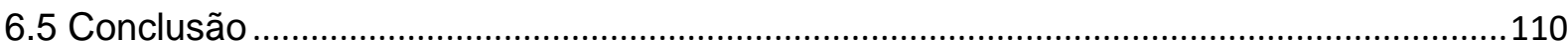

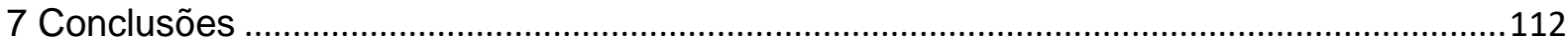

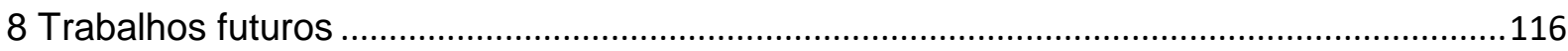

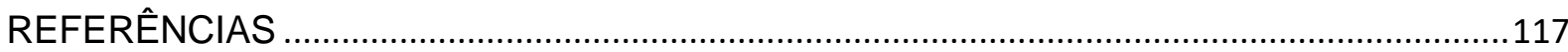




\section{Introdução}

A humanidade sempre foi fascinada por objetos que levitam sem uma causa aparente, ou melhor, sem o apoio ou suporte que possa ser notado facilmente. Em grande parte desses casos, os corpos possuem propriedades elétricas ou magnéticas.

Para que um objeto com as características acima citadas levite pode-se utilizar equipamentos que gerem uma força eletromagnética com uma intensidade igual à força gravitacional. Dentre os elementos capazes de gerar um campo magnético com tal magnitude cita-se o imã permanente ou o eletroímã. Significa dizer, que ao aplicar um campo eletromagnético de intensidade suficiente para contrabalancear a força peso, o objeto poderá levitar.

Acredita-se que desde a Grécia antiga os fenômenos elétricos e magnéticos são conhecidos, porém apenas no século XIX que o eletromagnetismo se desenvolveu a passos largos, em especial, após os trabalhos de André-Marie Ampère, William Sturgeon, Joseph Henry, Georg Simon Ohm, Michael Faraday e de James Clerk Maxwell, que unificou a teoria eletromagnética. A partir destes estudos e o desenvolvimento de pesquisas em eletromagnetismo, a levitação eletromagnética aprimorou-se muito ao longo do tempo, tornando possível levitar e manipular objetos com propriedades eletromagnéticas por meio da força eletromagnética.

Assim como as ondas eletromagnéticas, as ondas acústicas também exercem força sobre objetos que estejam localizados em seu caminho de propagação, transferindo momento aos objetos posicionados na trajetória de propagação da onda. Contudo, o estudo na área de levitação acústica teve início com os trabalhos publicados por Rayleigh no século XIX, que supôs que assim como as ondas eletromagnéticas as ondas acústicas podem exercer força sobre os objetos. O que torna o estudo da levitação acústica promissora é pelo fato do objeto não possuir, necessariamente, propriedades elétricas ou magnéticas. 
Lord Rayleigh, precursor no estudo da pressão de radiação acústica, optou por essa área de pesquisa ao conseguir relacionar o seu estudo em ondas eletromagnéticas com o de ondas acústicas (BEYER, 1995). Nesta época, os pesquisadores acreditavam que as ondas eletromagnéticas se propagavam no vácuo percorrendo um meio conhecido como "éter". Rayleigh realizou uma analogia baseada nesse princípio para afirmar que a propagação da onda sonora ocorre em um meio material - o ar (LEE; WANG, 1993).

Em literaturas de Física com conteúdo voltado para óptica, eletromagnetismo e quântica é familiar encontrar menções sobre feixes de luz unidirecional exercendo força sobre uma determinada superfície, tal força aplicada sobre o objeto é creditada ao momento da onda eletromagnética do feixe. Entretanto, todas as ondas conseguem exercer força sobre os objetos em seu caminho, transferindo momento ao objeto na trajetória da onda. O objeto no qual a onda incide pode absorver ou refletir uma porcentagem da energia de momento incidente sobre sua superfície (TORR, 1984).

Rayleigh considerava que a pressão de radiação acústica ocorria devido à incidência de uma onda plana sobre a superfície do objeto, ambos imersos no mesmo meio gasoso. Rayleigh apresenta uma expressão para pressão de radiação acústica considerando uma onda plana incidente sobre uma superfície, relacionando o calor específico do gás (meio que abrange tanto a onda como o objeto) e a energia média da onda estacionária, uma onda estacionária é formada por uma onda incidente e outra refletida (LEE; WANG, 1993).

Na hipótese da pressão acústica atuando sobre a superfície de um pequeno objeto, este é submetido a uma força conhecida como força de radiação acústica (FORESTI, 2012). Tal força aplicada sobre uma amostra pode ser gerada por ondas acústicas progressivas ou estacionárias. Em geral, as aplicações envolvendo o uso de força de radiação acústica utilizam, predominantemente, ondas estacionárias (ANDRADE, 2010), que são geradas pelas múltiplas reflexões de uma onda acústica que ocorrem entre o transmissor e o refletor (ANDRADE; PEREZ; ADAMOWSKI, 2015). 
Na prática, a força de radiação acústica é muito fraca em comparação com a força eletromagnética, segundo Lee e Wang (LEE; WANG, 1993). Apesar disso, em determinadas condições, é possível contrabalancear a força gravitacional, permitindo a levitação de pequenos objetos.

Partindo do princípio que uma onda acústica exerce força sobre um objeto, pode-se utilizar a força de radiação acústica para contrabalancear a força gravitacional e, assim, suspender pequenos objetos em ar (MARZO et al., 2017). A suspensão de um objeto em ar através de uma onda acústica é um fenômeno conhecido como levitação acústica.

Altberg, em 1903, mediu a força de radiação acústica exercida por ondas sonoras (ALTBERG, 1903, apud TORR, 1984). Em 1934, King apresentou em seu trabalho expressões para força de radiação acústica sobre uma esfera incompressível e para ondas estacionárias (KING, 1934); Em 1955, efeitos de compressibilidade da partícula foram introduzidos por Yosioka e Kawasima (YOSIOKA; KAWASIMA, 1969). No modelo apresentado por King há duas equações, uma válida para caso em que o produto entre o número de onda e o raio da esfera é menor que $1, K R<<1$ , e outra para quando o produto é $K R=1$. Quando o produto $K R<<1$ as teorias de King e Hasegawa e Yosioka se equiparam, mesmo considerando condições diferentes para as partículas (ANDRADE, 2010).

Gor'kov, em 1962, apresentou uma expressão para uma esfera compressível em campo acústico arbitrário, sua expressão se tornou semelhante à proposta por King (KING, 1934) para o caso de uma onda plana estacionária (GOR'KOV, 1962). A partir destes modelos, uma série de estudos e pesquisas veio a aprimorar-se nos últimos anos baseados nestes trabalhos.

Uma configuração simplificada de um sistema de levitação acústica é composta de um transdutor, emissor de ondas acústicas, em que toda a face emissora vibra harmonicamente em uma determinada frequência, e um refletor que é utilizado para gerar as múltiplas reflexões da onda emitida pelo transdutor. Nesta configuração, 
temos uma onda do tipo estacionária, delimitada pelas faces planas do transdutor e do refletor, esta região é conhecida como cavidade acústica.

Para que ocorra a levitação de um objeto na cavidade acústica, região onde a onda é confinada, o transdutor e o refletor devem ficar espaçados entre si, por um múltiplo inteiro de meio comprimento de onda. Esse espaçamento é calculado com base na frequência da onda emitida pelo transdutor, e na velocidade de propagação da onda no meio em que o sistema está imerso.

No modelo apresentado na figura 1.1 observa-se um transdutor e um refletor, ambos cilíndricos, com suas superfícies emissoras e refletoras planas, onde existe apenas um nó, neste caso uma posição de levitação para um objeto. Uma condição que cabe ressaltar, nesse modelo ora apresentado, é de que a relação de distância entre o refletor e o transdutor deve ser de um múltiplo inteiro de meio comprimento de onda ( $d=n \lambda / 2, n=1,2,3, \ldots)$, onde: $d$ é a distância de separação entre o transdutor $\mathrm{e}$ o refletor; $n$ é um número inteiro; e $\lambda$ é o comprimento de onda emitida pelo transdutor, e o objeto deve ter o raio muito menor que o comprimento de onda emitida, $R<<\lambda$. No canto inferior direito da figura em questão, mostram-se os eixos de referência que serão adotados como padrão nesta tese, onde o eixo $z$ indica a coordenada vertical, e o eixo $x$ indica a coordenada horizontal ou radial para 0 modelo cilíndrico em questão.

Figura 1.1- Modelo simplificado de uma cavidade acústica com uma posição de levitação, e as relações do comprimento de onda na cavidade.

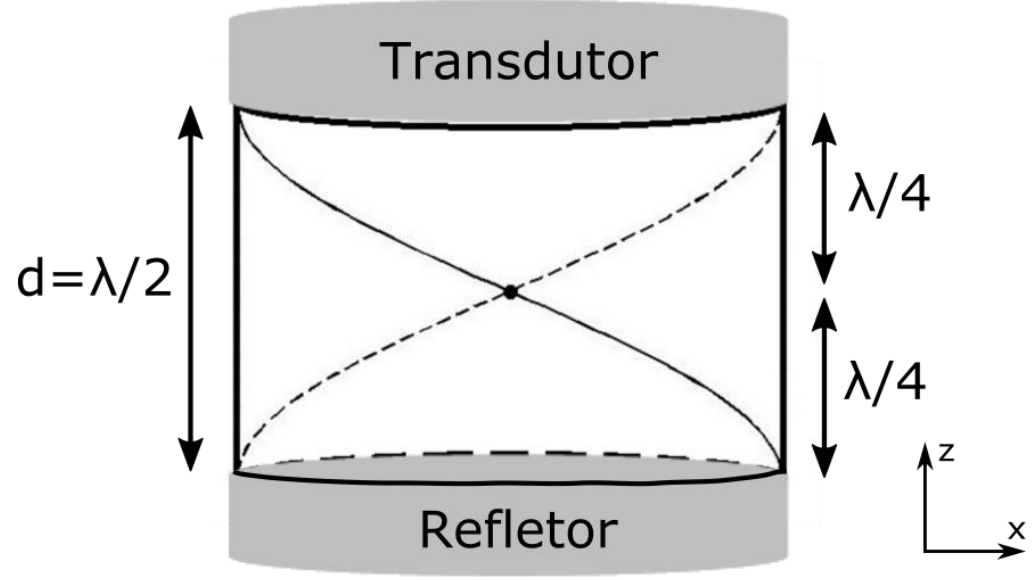

Fonte: Autor 
No caso da figura 1.1 temos $n=1$. Nesta configuração existe apenas um ponto de levitação na cavidade acústica, neste ponto, o potencial acústico (energia gerada pelo campo acústico) é mínimo, que é condição necessária para levitar um objeto com raio muito menor que o comprimento de onda. Aumentando a distância entre transdutor e refletor é possível posicionar outros objetos nos nós. Considerando apenas um objeto por nó, para um caso em que a configuração do sistema forneça três nós, ou seja, $n=3$, sendo possível levitar três objetos, um por nó.

Essa técnica permite levitar objetos sem exigir características físicas especificas do material, tais como propriedades elétricas ou magnéticas (GAO; CAO; WEI, 1999). A levitação acústica estimulou a comunidade científica a investigar as características desta técnica como: as propriedades e caraterísticas geométricas dos transdutores e refletores; os parâmetros como força de radiação acústica; do potencial acústico; da pressão de radiação acústica; os tipos de objetos que esta técnica tem a capacidade de levitar; além de aprimorar estudos que desejam observar as características geométricas e propriedades físico-químicas dos objetos/substâncias; bem como as vantagens desta técnica de levitação.

A levitação acústica é uma técnica relevante, principalmente em processos que envolvem materiais frágeis, os quais, em geral, são compostos por componentes sensíveis ou por microcomponentes (VANDAELE; LAMBERT; DELCHAMBRE, 2005). A técnica da levitação acústica possui importante aplicação em processos que requerem um alto grau de pureza (GAO; CAO; WEI, 1999), permitindo o desenvolvimento de estudos que visam investigar as propriedades físicas ou químicas de substâncias sem contaminação.

Em razão das particularidades da técnica da levitação acústica observam-se diversas aplicações. Dentre estas se destaca a manipulação e transporte de pequenas amostras sólidas e líquidas (TJOTTA, 2000). O transporte e a manipulação de objetos e gotas é um dos grandes desafios do campo de levitação acústica (HAAKE; DUAL, 2005) (FORESTI et al., 2011), (FORESTI; NABAVI; POULIKAKOS, 2012), processamento de material sem contato evitando sua 
contaminação (LÖFSTEDT; PUTTERMAN, 1991), (BAER et al., 2011) e medida de tensão superficial (PERÉZ et al., 2014).

Portanto, a levitação acústica tem potencial para ser aplicada em diversos ramos do conhecimento científico, tais como: biologia, química, farmácia, entre outras (BENMORE; WEBER, 2011), (KOYAMA; NAKAMURA, 2010), (ANDRADE et al., 2014). A levitação acústica também pode ser utilizada para o estudo de espectroscopia Raman, processos de coagulação (COLLAS; BARMATZ, 1987), efeitos de viscosidade (XIE; WEI, 2002), simulação de microgravidade (FORESTI; POULIKAKOS, 2014), (SANTILLÁN et al.,2007), (RUDNICK; BARMATZ, 1989), análises biomédicas (BRUUS, 2011), separação de células vermelhas do plasma sanguíneo (GLYNNE-JONES et al., 2012).

A força de radiação acústica possui aplicação em processos que necessitam de manipulação ou transporte de objetos sem contato, contudo, a força deve possuir intensidade que permita levitar uma amostra de líquido ou um objeto frágil, sem que a força danifique o objeto levitado. Exemplificando, em levitação de líquidos, ao mesmo tempo em que a força tem que ser intensa o suficiente para sustentar o volume da amostra deve possuir uma intensidade que não rompa a tensão superficial do líquido levitado (FORESTI, 2012).

O escopo desta tese de doutorado é investigar quais parâmetros interferem sobre a força de radiação acústica e como estes parâmetros influenciam na estabilidade do objeto levitado. Estudos mostram que efeitos não lineares afetam a estabilidade das amostras levitadas em um sistema de levitação acústica (BEYER, 1995), (GAITAN; ATCHLEY, 1993) e (HAMILTON; BLACKSTOCK 1998). Tais sistemas são constituído por transdutores de ultrassom do tipo Langevin (PERÉZ, et al., 2015) e por um refletor, que confinam entre si uma onda estacionária.

Para compreender as técnicas de levitação acústica, levitação no campo distante e no campo próximo, e os efeitos sobre um objeto é necessário entender como as ondas interagem se comportam na cavidade acústica na presença de um objeto, ou seja, compreender como se dá a distribuição do campo de pressão acústica e o 
campo de velocidade. Para obter o potencial acústico da cavidade que se deseja trabalhar.

\subsection{Motivação}

A levitação acústica é uma técnica relevante para aplicações em que se deseja manipular e transportar objetos sem contato. A levitação acústica proporciona a levitação de objetos frágeis que requerem uma pequena força sobre a sua superfície, pois necessita manter sua integridade física ou química, durante a manipulação ou transporte. Este cuidado se deve com substâncias com as quais se deseja manipular e separar como exemplo com células sanguíneas e lipídios (BARNKOB, 2009), micro-organismos (THALHAMMER, et al., 2011).

A força aplicada sobre os objetos na levitação acústica deve ser bem conhecida, para caracterizar, quais as dimensões e formas dos objetos que são possíveis levitar, e como será seu comportamento do ponto de vista de estabilidade. As dificuldades na previsão do comportamento da levitação decorrem do fato do campo acústico gerado pela onda estacionária na cavidade ter um comportamento não linear, produzindo efeitos como histerese e fenômeno de salto que ocorrem em algumas configurações.

Na levitação acústica deve se ter o cuidado de configurar e montar corretamente o sistema de levitação em função do objeto que se deseja levitar. A levitação pode ser de campo distante com uma onda estacionária, onde se utiliza um transdutor e um refletor, ou de campo próximo onde se utiliza um transdutor e um objeto de face plana. Para cada configuração a onda acústica possui uma característica especifica que irá afetar o comportamento do objeto levitado.

Neste trabalho são utilizados modelos analíticos, numéricos e verificações experimentais para caracterizar sistemas específicos de levitação. São observados os comportamentos experimentais de tais sistemas que são comparados com os 
modelos analíticos e numéricos verificando suas validades no que se refere à atuação força de radiação acústica e o comportamento do objeto levitado.

Os modelos preveem com boa precisão a posição de levitação. No entanto, os modelos não preveem o comportamento do objeto, como seu movimento oscilatório, na cavidade acústica.

Neste trabalho observam-se os comportamentos numéricos e experimentais de três experimentos, nos quais: $O$ primeiro tem o objetivo de observar experimentalmente $o$ comportamento da força de radiação acústica sobre o refletor e sobre três esferas, o comportamento numérico deste transdutor é apresentado nos trabalhos desenvolvidos por Andrade em seu doutorado (ANDRADE, 2010). O transdutor desta configuração experimental possui a face emissora côncava, frequência de trabalho de $20340 \mathrm{~Hz}$, o refletor também possui a face côncava, as esferas utilizadas são de polipropileno, vidro e aço, as esferas possuem o mesmo diâmetro de $3 \mathrm{~mm}$.

O segundo experimento tem como objetivo observar o comportamento da força de radiação acústica sobre o refletor (HONG et al, 2014), neste experimento o refletor tem seu raio variado desde 5 até $52 \mathrm{~mm}$, o transdutor possui a face emissora plana com raio fixo de $7,5 \mathrm{~mm}$ e frequência de $31380 \mathrm{~Hz}$. Neste experimento a distância entre o transdutor e o refletor é alterada, com o objetivo de encontrar a região de ressonância de cada cavidade acústica, para os respectivos refletores.

O terceiro experimento tem como objetivo observar no campo próximo, como a força de radiação acústica altera sua magnitude com a variação do raio de transdutor, ou seja, para quais transdutores tem-se a força de radiação acústica negativa para atrair o objeto para junto da face do transdutor e quais são positivas afastando o objeto da face do transdutor (TAKASAKI et al., 2010), as faces dos transdutores são planas, os raios dos transdutores são de: 5; 7,5; 10 e $13 \mathrm{~mm}$, as frequências são de 23090, 31380, 25250 e $20440 \mathrm{~Hz}$ respectivamente.

Por fim, o propósito deste trabalho é desenvolver e apresentar elementos que contribuam na determinação e escolha do aparato experimental, como o transdutor e 
o refletor para experimentos em campo distante. Além disso, facilitar o procedimento de definição do diâmetro do transdutor que será utilizado em experimentos de campo próximo, e em ambos os casos controlar a amplitude a ser aplicada ao transdutor. Partindo destas premissas, determinar o comportamento do potencial de radiação acústica, a pressão de radiação acústica e, da força de radiação acústica, que sofrem forte influência da geometria do sistema acústico.

\subsection{Objetivo}

O objetivo deste trabalho é identificar como os parâmetros geométricos do transdutor e do refletor afetam a força de radiação acústica que atua sobre refletores e objetos levitados, e como interferem na estabilidade deste durante a levitação. Para tanto, o estudo de campo distante foi investigado em torno da região de ressonância das respectivas cavidades acústicas, para determinar as características dos seguintes parâmetros a serem explorados:

- A força de radiação acústica sobre o refletor côncavo e plano;

- Efeitos não lineares em sistemas acústicos;

- O espalhamento que um objeto esférico gera sobre o campo de radiação acústica no refletor;

- A frequência de oscilação particular do objeto e a sua amplitude;

- Relação ótima entre diâmetro do transdutor e do refletor no campo distante;

- O diâmetro da ponta do transdutor no campo próximo;

- A amplitude de deslocamento do transdutor.

Para determinar a força de radiação acústica, a intensidade da força no campo próximo, e o espalhamento que as esferas produzem no campo acústico sobre os refletores é utilizada uma balança eletrônica, sobre a qual os refletores são posicionados. Para determinar as frequências de oscilação e as amplitudes, uma câmera de alta velocidade é utilizada para gravar vídeos das esferas levitando na cavidade acústica. A amplitude de deslocamento da face do transdutor é controlada para avaliar como a amplitude de deslocamento do transdutor afeta a intensidade da força de radiação acústica. 
Este estudo tem a intenção de obter resultados que ajudem a refinar os modelos computacionais e matemáticos que descrevam o comportamento do sistema de levitação acústico, visando à compreensão dos fenômenos lineares e não lineares que atuam sobre a força de radiação acústica.

\subsection{Organização do trabalho}

O presente trabalho é distribuído em 8 capítulos. No capítulo 1 foram expostos conceitos de levitação acústica, a motivação para este presente trabalho e os objetivos do desenvolvimento deste trabalho. O capítulo 2 apresenta conceitos de campo distante e campo próximo, teoria de ondas acústicas, propagação linear e não linearidade, modelos analíticos para pressão de radiação acústica sobre um refletor, teoria do potencial de Gor'kov, força de radiação acústica, histerese e fenômeno de salto. O capítulo 3 apresenta o transdutor de Langevin e os equipamentos utilizados para excitar o transdutor e realizar a leitura das respostas do sistema. O capítulo 4 apresenta o estudo e os resultados de uma cavidade acústica com o transdutor e o refletor com faces côncavas e a estabilidade de três esferas levitando dentro da cavidade em questão, e os efeitos não lineares de histerese e de salto; A partir dos resultados deste trabalho, foram elaborados dois artigos, sendo que um deles foi publicado nos Proceedings do congresso IEEE International Ultrasonics Symposium, em 2014, com o titulo "Influence of Nonlinear Effects on the Acoustic Levitation of Small Spheres". O segundo foi publicado na revista internacional a Review of Scientific Instruments em 2014 com o titulo "Nonlinear characterization of a single-axis acoustic levitator". Estes trabalhos foram desenvolvidos, pois não encontramos na literatura trabalhos apresentando os efeitos de histerese e salto que observamos nos experimentos. O capítulo 5 apresenta os resultados simulados e experimentais da força de radiação no campo distante alterando a geometria da cavidade acústica com refletores que possuem diferentes diâmetros, observando que há uma relação ótima entre o diâmetro do transdutor e do refletor. O capítulo 6 apresenta os resultados simulados e experimentais alterando os diâmetros dos transdutores para o estudo da levitação de campo próximo, observa-se que para determinado diâmetro de transdutor a força de 
radiação acústica é negativa, sendo atrativo, fato que também decorre do objeto levitado ser um anel. O capítulo 7 apresenta as conclusões gerais do trabalho. $O$ capítulo 8 apresenta as propostas/sugestões para trabalhos futuros e as referências bibliográficas. 


\section{Teoria}

Neste capítulo serão apresentados os modelos utilizados para determinar a pressão de radiação acústica, o potencial da força de radiação acústica em uma cavidade e a força de radiação acústica que atua sobre refletores e esferas, a fim de comparar os dados numéricos/simulados com os dados obtidos nos experimentos realizados.

\subsection{Conceito de ondas acústicas}

As ondas acústicas podem percorrer diversos meios materiais sejam eles: sólidos, líquidos ou gasosos, sendo que cada um dos meios apresentados possuem propriedades acústicas especificas, tais como: impedância, velocidade de propagação da onda e atenuação (KINO, 1987).

Como premissa deste trabalho, a onda emitida pelo transdutor irá se propagar em um fluido (ar), que será considerado homogêneo, não viscoso e sem perdas. Admitese que a onda acústica irá se propagar em um meio gasoso gerando ondas longitudinais, que são ondas que apresentam regiões de compressão e rarefação do meio, com as partículas do meio oscilando na mesma direção de propagação da onda. Deste modo, para descrever o campo acústico, pode-se utilizar o potencial de velocidade $\varphi$, com o qual é possível determinar o campo de velocidade e o campo de pressão das partículas do meio, através das seguintes expressões:

$$
\begin{gathered}
\mathbf{u}(r, t)=\nabla \varphi(r, t) \\
p(r, t)=-\rho_{0} \frac{\partial \varphi(r, t)}{\partial t}
\end{gathered}
$$

onde $\mathbf{u}$ é a velocidade, $\varphi$ é o potencial de velocidade que é dado em função do tempo e do espaço, $p$ é a pressão das partículas do meio, $\rho_{0}$ é a densidade do meio e os parâmetros $r$ e $t$ representam as coordenadas de posição e tempo, respectivamente. 
O potencial de velocidade utilizado nas expressões 2.1.1 e 2.1.2 deve ser solução da equação da onda, que é dada por:

$$
\nabla^{2} \varphi=\frac{1}{c_{0}^{2}} \frac{\partial^{2} \varphi}{\partial t^{2}}
$$

onde $\nabla^{2}$ é o operador laplaciano e $c_{0}$ é a velocidade do som no meio.

As ondas acústicas que se propagam em um meio material podem ser classificadas em progressivas ou estacionárias. Em uma onda progressiva todas as partículas do meio contidas na direção de propagação da onda irão oscilar entre os máximos e os mínimos de deslocamento da mesma.

Por outro lado, as ondas estacionárias são formadas pela superposição de no mínimo duas ondas com mesma frequência, amplitude e comprimento de onda, porém propagando-se em sentidos opostos. Em geral, tais ondas são confinadas em uma determinada região de espaço como, por exemplo, entre um transdutor e um refletor, a onda emitida pelo transdutor é refletida pelo refletor, esta sofre múltiplas reflexões gerando assim uma onda estacionária entre ambos.

Um modo simples de entender o comportamento de uma onda estacionária é imaginá-la como o número oito (8), em que as extremidades superior e inferior, assim como o seu centro, onde as linhas se interceptam, são considerados como os nós da onda. Vale ressaltar, ainda, que o ponto médio entre dois nós consecutivos são regiões onde os deslocamentos podem ser máximos, denominados de anti-nós ou ventres.

Uma representação esquemática de uma onda estacionária é apresentada na figura 2.1.1. Nesta figura observa-se a existência de cinco nós (indicados pela letra N) e quatro ventres (indicados pela letra V), assim como a distância entre dois nós consecutivos, e entre dois anti-nós consecutivos, o que se caracteriza como meio comprimento de onda $(\lambda / 2)$, a distância entre um nó e um anti-nó é de $\lambda / 4$. 
Figura 2.1.1- Representação esquemática de uma onda estacionária.

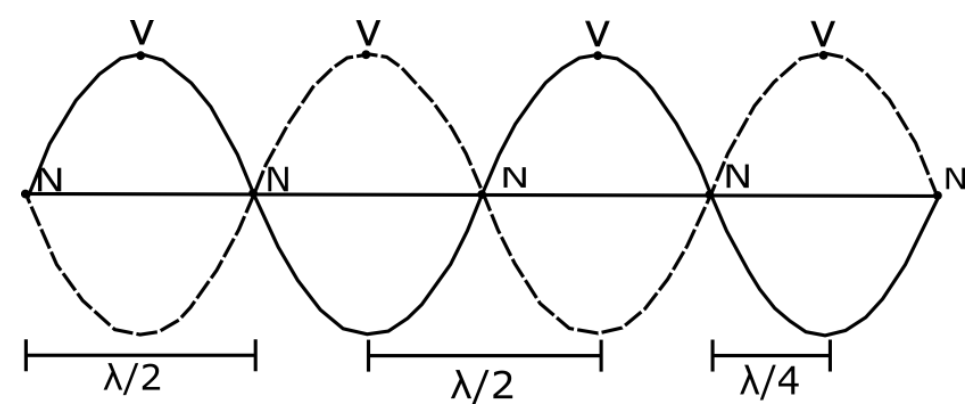

Fonte: Autor

\subsection{Equações fundamentais da dinâmica dos fluidos}

Para chegar às equações e modelos que descrevam a força de radiação acústica, autores como King (KING, 1934), Gor'kov (GOR'KOV, 1962) e Lee e Wang (LEE; WANG, 1993), iniciam o desenvolvimento dos modelos a partir de equações fundamentais da dinâmica dos fluidos. No desenvolvimento destas equações, algumas considerações são feitas como: o objeto está imersa em um fluido ideal, não viscoso e que se deforma continuamente sob a ação de uma força (MANNEBERG, 2009). Alguns autores consideram a transferência de calor e viscosidade em seus modelos (TJOTTA, 2000), porém, estes efeitos não são considerados neste trabalho. Em seu artigo de 1998, Ilinskii considera as equações de conservação de massa, conservação do momento e equações de estado do fluido, em um sistema viscoso, unidimensional, e o ressonador com uma forma arbitrária e axissimétrica (ILINSKII, 1998). Há outros trabalhos com uma linha de raciocínio bem semelhante como os de Chun e Kim (CHUN; KIM, 2000), e de Hamilton e Blackstock (HAMILTON; BLACKSTOCK 1998). Após definirem as condições de contorno, os mencionados autores definem se o modelo utilizado será Euleriano ou Lagrangeano, linearizando as equações.

$\mathrm{Na}$ descrição Lagrangeana, a referência deste modelo refere-se a um objeto que segue o seu movimento no fluxo de um fluido. Nesta descrição há uma simbologia especifica para representar a derivada em relação ao tempo. Já no modelo Euleriano, refere-se a um ponto fixo no espaço no interior do fluxo de um fluido. 
Nesse último modelo, a descrição também requer uma simbologia especifica para representar a derivada em relação ao tempo diferente da Lagrangeana.

Apesar das equações serem bem conhecidas e, em alguns casos, modelos lineares e não lineares possuem soluções analíticas, é comum empregar métodos numéricos para encontrar soluções para os modelos de propagação de ondas (MEURER; QU; JACOBS, 2002). Chun e Kim utilizam métodos numéricos para analisar as oscilações ressoantes não lineares (CHUN; KIM, 2000), Vanhille e Campos-Pozuelo utilizam tais métodos para estudarem ondas de ultrassom propagando-se em um fluido (VANHILLE; CAMPOS-POZUELO, 2004), ambos aplicam métodos numéricos também para a análise de ondas estacionárias não lineares (VANHILLE; CAMPOSPOZUELO, 2005), e em 2006, ambos apresentam um trabalho de análise numérica no domínio do tempo (VANHILLE; CAMPOS-POZUELO, 2006).

Os modelos que descrevem a propagação de ondas acústicas não lineares são obtidos a partir das equações da dinâmica dos fluidos, sendo que os valores característicos de parâmetros como, por exemplo, a densidade do meio depende das condições de temperatura e pressão do meio. Entre essas equações, têm-se a equação da continuidade:

$$
\frac{\partial \rho}{\partial t}+\nabla \cdot(\rho \mathbf{u})=0
$$

E a equação da conservação do momento:

$$
\rho\left[\frac{\partial \mathbf{u}}{\partial t}+(\mathbf{u} \cdot \nabla) \mathbf{u}\right]=-\nabla P
$$

Além das equações acima, também temos a equação de estado do fluido, que é utilizada por Lee e Wang (LEE; WANG, 1993):

$$
P-p_{0}=Q_{0}\left[\left(\rho_{t} / \rho_{0}\right)^{\Gamma}-1\right\rfloor
$$

onde $p_{0}$ é a pressão ambiente, $P=p_{0}+p_{a c}$, onde $p_{a c}$ é a pressão acústica, $Q_{0}=\rho_{0} c_{0}^{2} / \Gamma, Q_{0}$ é a quantidade de calor, $\rho_{0}$ é a densidade ambiente, $\rho=\rho_{0}+\rho^{\prime}$, onde $\rho$ 'é a densidade acústica, $c_{0}$ é a velocidade do som, onde $c_{0}^{2}=\eta_{0} / \rho_{0}$, assim, 
$Q_{0}=p_{0}$, $\Gamma$ é uma constante, para o caso do gás ideal $\Gamma=\gamma$ onde $\gamma$ é a razão entre o calor especifico de um gás a pressão constante e o calor específico a volume constante. Reescrevendo a equação de conservação do momento 2.2.2 com o potencial de velocidade:

$$
\nabla\left(\frac{\partial \varphi}{\partial t}+\frac{1}{2}|\nabla \varphi|^{2}\right)=-\frac{\nabla P}{\rho}
$$

Utilizando a primeira lei da termodinâmica $d w=T d S+d P / \rho$, onde $T$ é a temperatura, $s$ é a entropia por unidade de massa e $w$ é a entalpia por unidade de massa do fluido, considerando que o fluido é adiabático tem-se $d w=d P / \rho$ expandindo a pressão total $P$ em serie de Taylor com relação à $w$. A partir da equação de estado considerada, expande-se a mesma em série de Taylor até sua segunda ordem. Para expoentes maiores, os termos se tornam muito pequenos, sendo, portanto desprezíveis, as considerações e substituições para chegar a equação 2.2.5 são apresentadas no artigo de Lee e Wang (1993).

O valor médio da pressão para o modelo Euleriano é dado por:

$$
\left\langle P-p_{0}\right\rangle=\left(\frac{\left\langle p^{2}\right\rangle}{2 \rho_{0} c_{0}^{2}}\right)-\frac{1}{2} \rho_{0}\langle\mathbf{u} \cdot \mathbf{u}\rangle+C
$$

onde \langle\rangle representa a média temporal em um período, o primeiro termo do lado direito representa a densidade de energia potencial média no tempo, o segundo termo representa a densidade de energia cinética com $\mathbf{u}$ representando a velocidade das partículas do meio, $C$ é uma constante no espaço e no tempo dado por: $C=\rho_{0}\left\langle C^{\prime}\right\rangle$, essa constante, $C^{\prime}$, aparece a partir da integração da equação (2.2.4), $C$ pode ser assumir qualquer que satisfação as condições de contorno, no entanto para satisfazer as restrições consideradas, $C$ será igual a zero (HONG et al., 2014). 


\subsection{Pressão de radiação acústica sobre um refletor}

Segundo King (KING, 1934) a pressão de radiação acústica gerada por uma onda estacionária é devido à interferência entre as ondas incidentes e espalhadas pelo objeto (LÖFSTEDT; PUTTERMAN, 1991), (WETERVELT, 1957).

A pressão de radiação acústica é uma perturbação do campo acústico em fluido sobre uma superfície (BRUUS, 2012), sendo essa pressão aplicada sobre a superfície de um objeto. A onda incidente sobre o objeto pode ser refletida parcialmente ou completamente pela face do objeto, este efeito é bem observado para objetos no campo distante (KARLSEN; BRUUS, 2015).

Hong e coautores (HONG et al., 2014) utilizam a equação determinada por Lee e Wang (LEE; WANG, 1993) para determinar a pressão de radiação acústica sobre um refletor onde o parâmetro $C$ será igual a zero como apresentado previamente. Assim:

$$
p_{a c}=\frac{\left\langle p^{2}\right\rangle}{2 \rho_{0} c_{0}^{2}}-\frac{\rho_{0}\langle\mathbf{u} \cdot \mathbf{u}\rangle}{2}
$$

onde $p_{a c}$ é a pressão de radiação acústica sobre o refletor (Hong et al., 2014).

É importante notar que na equação 2.3.1 há apenas parâmetros relacionados ao fluido, não existindo nenhum parâmetro relacionado ao objeto que pode ser levitado na cavidade acústica, razão pela qual se utilizou da equação 2.3.1 para calcular a pressão de radiação acústica sobre refletores. Integrando a pressão de radiação acústica sobre a superfície de um refletor de face plana obtêm-se a força de radiação acústica que atua sobre este refletor.

A equação 2.3.1 foi utilizada nas simulações realizadas em COMSOL para estimar como a força atua sobre diferentes diâmetros de refletores, sendo que os resultados das simulações e experimentais serão apresentados no capítulo 5 deste trabalho. 


\subsection{Teoria de Gor'kov}

O potencial da força de radiação acústica que atua sobre uma esfera de raio $R$ imersa em um fluido com densidade $\rho_{0}$ e velocidade da onda $c_{0}$ pode ser calculado através da equação desenvolvida por Gor'kov (GOR'KOV, 1962). Essa equação é válida para uma esfera com o raio muito menor que o comprimento de onda (onda estacionária arbitrária), com densidade diferente da densidade do meio no qual o objeto está imerso, e o fluido é ideal e não viscoso. A equação proposta por Gor'kov é dada por:

$$
U=2 \pi R^{3}\left(\frac{\left\langle p^{2}\right\rangle}{3 \rho_{0} c_{0}^{2}} f_{1}-\frac{\rho_{0}\langle\mathbf{u} \cdot \mathbf{u}\rangle}{2} f_{2}\right)
$$

onde $\left\langle p^{2}\right\rangle$ e $\left\langle\mathbf{u}^{2}\right\rangle$ são as médias quadráticas temporais da pressão e da velocidade, respectivamente. Os fatores $f_{1}$ e $f_{2}$ que aparecem na equação representam a relação entre as densidades do objeto que se pretende levitar e do fluido, a relação é dada por:

$$
\begin{aligned}
& f_{1}=1-\frac{\rho_{0} c_{0}^{2}}{\rho_{o b} c_{o b}^{2}} \\
& f_{2}=\frac{2\left(\rho_{o b}-\rho_{0}\right)}{\left(2 \rho_{o b}+\rho_{0}\right)}
\end{aligned}
$$

onde $\rho_{o b}$ é a densidade do objeto e $c_{o b}$ é a velocidade do objeto.

Para modelar o potencial acústico do sistema de levitação é necessário analisar previamente as equações 2.4 .2 e 2.4.3 que são conhecidas por determinar o fator de contraste entre o meio e o objeto que se deseja levitar. Como a densidade dos objetos utilizados neste trabalho serão muito maior que a densidade do meio, ar, conclui-se que $f_{1}=f_{2}=1$, logo a equação 2.4.1 pode ser reescrita como:

$$
U=2 \pi R^{3}\left(\frac{\left\langle p^{2}\right\rangle}{3 \rho_{0} c_{0}^{2}}-\frac{\rho_{0}\langle\mathbf{u} \cdot \mathbf{u}\rangle}{2}\right)
$$

Com a equação de Gor'kov é possível determinar as posições (nós) de levitação, região em que o potencial acústico é mínimo e estável para levitar um objeto. Em torno de uma posição de equilíbrio estável, pode-se aproximar o potencial $U$, por meio de uma parábola que possui a forma de um "poço potencial" em torno do 
mínimo potencial na posição de equilíbrio (NUSSENZVEIG, 2005). A partir deste potencial acústico é possível calcular a força restauradora sobre o objeto que oscila na posição de equilíbrio e a constante elástica da cavidade.

$\mathrm{Na}$ figura 2.4.1, há um exemplo de um sistema oscilante regido por um potencial acústico senoidal, em que o objeto se posiciona em um local de equilíbrio estável, nesta posição o potencial deve ser mínimo. O potencial acústico não é parabólico em torno do mínimo potencial, contudo, por meio das series de Taylor é plausível aproximar por uma parábola (ANDRADE; PERÉZ; ADAMOWSKI, 2015).

Figura 2.4.1- Aproximação do potencial acústico por uma parábola em torno de uma posição de equilíbrio estável em um mínimo potencial.

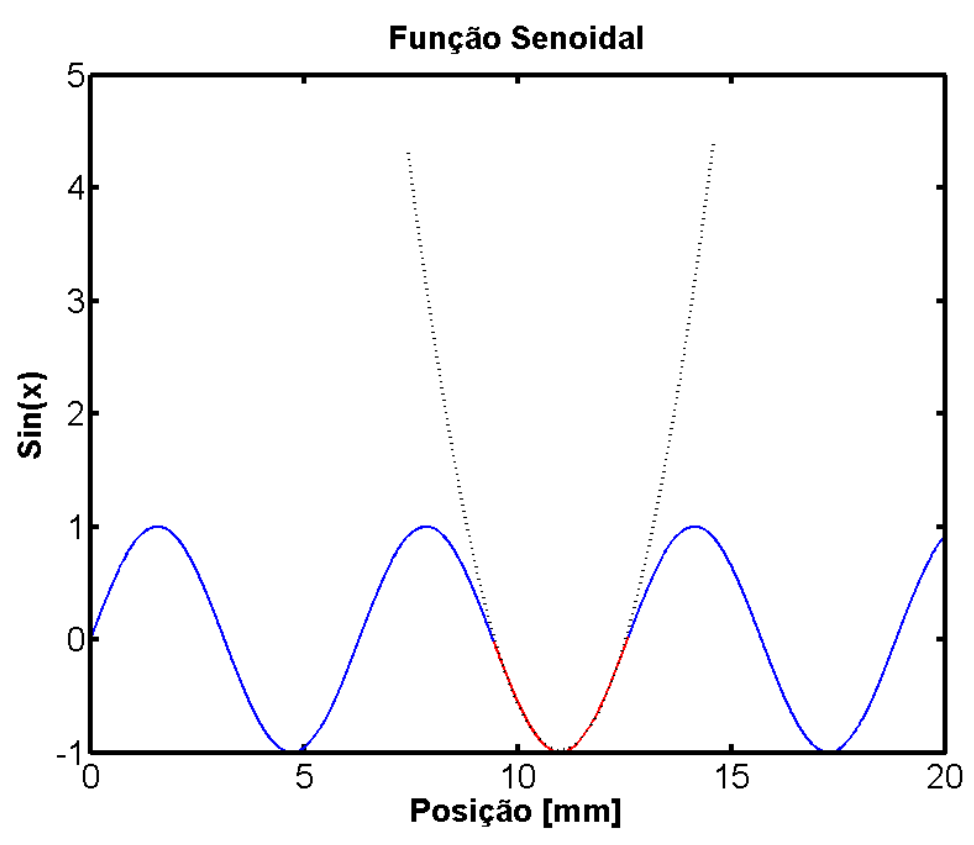

Fonte: Autor

$\mathrm{Na}$ equação apresentada por Gor'kov observam-se termos que representam um objeto imerso no campo acústico, bem como os fatores de contraste entre o meio e o raio do objeto que também aparecem na equação. Utilizou-se a equação de Gor'kov para calcular o potencial acústico da cavidade e as posições de levitação de esferas, conforme serão apresentados nos capítulos de resultados deste trabalho. 


\subsection{Força de radiação acústica}

No geral, é senso comum entre a maioria das pessoas que é sempre desejável uma força de grande intensidade atuando sobre os objetos, mas nem sempre uma grande intensidade de força é sinônimo de que é a ideal. Uma grande intensidade de campo eletromagnético para obter uma grande intensidade de força sobre células vivas ou pequenos aninais pode trazer consequências negativas. Contudo, a força de radiação acústica gerada por um campo acústico é ideal em situações onde as características do sistema que se deseja levitar requer uma força de intensidade suficiente para transportar ou manipular substâncias sem danificar a estrutura do objeto, como em processos bioquímicos e farmacêuticos (FORESTI, 2012).

No trabalho apresentado por Westervelt sobre pressão de radiação acústica, o autor a força de radiação acústica possui dois termos, sendo um em função da onda incidente sobre o objeto em sua trajetória e o outro devido à onda espalhada por este objeto (WESTERVELT, 1956), estes termos são provenientes do potencial acústico. A força de radiação acústica é dada pelo gradiente do potencial acústico, como segue na equação 2.5.1.

$$
\mathbf{F}=-\nabla U
$$

onde $\mathbf{F}$ é a força restauradora e $U$ é o potencial acústico da cavidade.

Uma onda sonora que incide sobre a superfície de uma esfera pode ser refletida completamente ou parcialmente, o que irá configurar um modo de espalhamento (VORONOV; KOROBOV; RUDENKO, 1992). Para calcular a força total exercida por uma onda sonora é necessário integrar a pressão de radiação acústica exercida pela onda sobre a superfície do objeto ou do refletor. Desta forma teremos a força de radiação acústica exercida sobre a superfície desejada, porém tal processo não é fácil de ser mensurado devido aos efeitos não lineares (HONG et al., 2014).

$\mathrm{Na}$ figura 2.5.1, a seguir, observam-se as curvas características de parâmetros importantes para a levitação acústica como: a pressão de radiação acústica indicada com o índice (a), a velocidade das partículas do meio com o índice (b), o potencial acústico com o índice $(c)$ e força de radiação acústica com o índice $(d)$. $O$ índice z indica a direção de referência adotada, coordenada vertical do eixo referencial. 
Na figura 2.5.1, a curva da força de radiação acústica apresentada com o índice (d) têm-se algumas circunferências posicionadas em regiões onde ocorre a levitação de um objeto. Nesta posição, a força de radiação acústica consegue contrabalancear a força gravitacional. As setas na figura (d) indicam a posição de equilíbrio estável, direção para onde a força empurra o objeto. Apresentadas as posições de levitação foram traçadas retas tracejadas, verticais, para identificar o perfil de cada variável em tal posição de levitação.

Portanto, na figura 2.5.1 as posições de levitação são definidas pela linha tracejada, tal linha é empregada respeitando as características necessárias para realizar a levitação de um objeto. A linha tracejada intercepta a curva da força de radiação acústica $(d)$, em determinadas posições de nó, posição de equilíbrio estável, para levitação. Nos outros nós da força de radiação acústica não é possível levitar, pois o potencial de radiação acústica para a posição é máximo, configurando uma região de equilíbrio instável para a levitação. $\mathrm{Na}$ curva (c), a linha tracejada intercepta o perfil do potencial de radiação acústico nas posições de mínimo potencial. Na curva (b), a linha tracejada intercepta o perfil de velocidade das partículas do fluido nos anti-nós da curva que em módulo são regiões de grande velocidade. Na curva (a), a linha tracejada intercepta o perfil de pressão de radiação acústica nos nós de pressão, posição em que a pressão é zero (ANDRADE; PERÉZ; ADAMOWSKI, 2015). 
Figura 2.5.1- Relação entre os parâmetros acústicos: a-) pressão acústica, b-) velocidade das partículas do meio, c-) potencial acústico e, d-) forção de radiação acústica de uma onda estacionária propagando-se no eixo $z$.

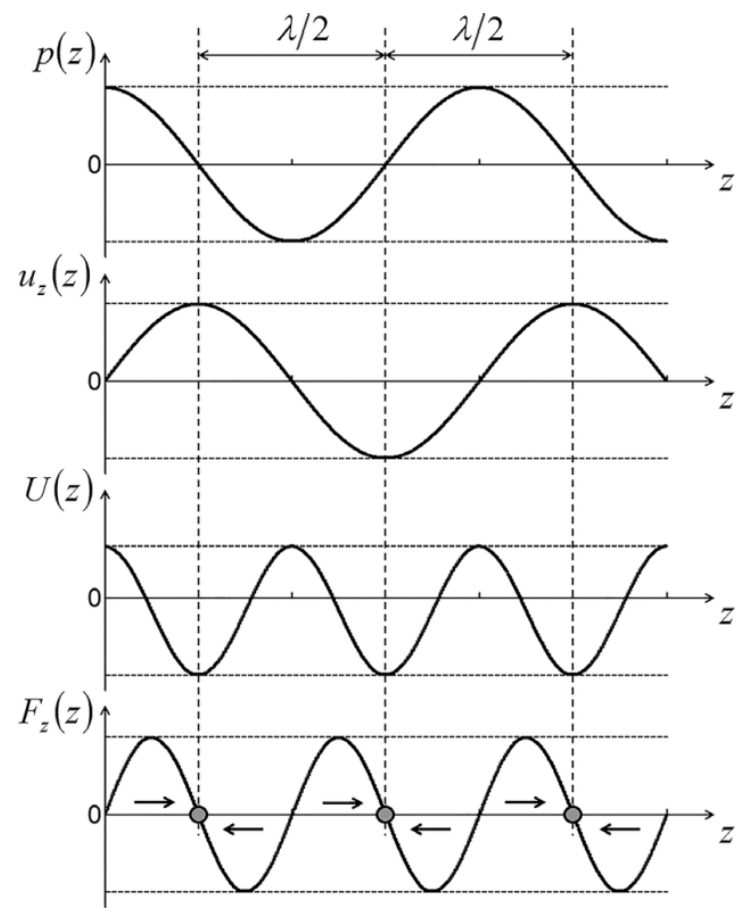

(a)

(b)

(c)

(d)

Fonte: Andrade et al., 2015

Como previamente apresentado neste trabalho é possível compreender que na cavidade acústica, a onda estacionária estará sujeita a efeitos não lineares tais como a histerese e o fenômeno do "salto". Fenômenos estes que interferem na estabilidade de uma amostra levitando (ANDRADE, et al., 2014).

\subsection{Histerese}

A histerese é um retardo transitório do sistema, ou seja, o sistema possui respostas diferentes ao efeito da força de radiação acústica sobre a face de um refletor no deslocamento do transdutor, deslocamento que pode ser aproximando ou afastando o transdutor do refletor. A histerese em geral, está ligada a sistemas não lineares onde o comportamento depende tanto do estado atual quanto de seu estado anterior. Este tipo de fenômeno pode ser observado em diversas áreas como: magnetismo, elasticidade, plasticidade, sistemas de spins, oscilações em redes cristalinas etc (ALMEIDA; COSTA 2000). 
Quando se realiza uma varredura com pequenos deslocamentos, ou seja, com pequenos incrementos ou decrementos de deslocamento do transdutor com relação ao refletor, no sistema de levitação que possui faces côncavas, nota-se que em regiões próximas à ressonância do sistema, fenômenos não lineares interferem de forma crucial, principalmente na forma da curva obtida. O formato da curva dependerá também do sentido da varredura. A figura 2.6.1 apresenta um esquema de curvas de histerese que apresenta dependência do sentido da varredura, se a mesma for realizada no sentido crescente de afastamento entre o transdutor e o refletor, o sistema encontra-se em ressonância na posição $B$ e com um pequeno incremento no deslocamento, a curva cai abruptamente para o ponto C. Caso o deslocamento realizado seja decrescente, a curva passa da posição $D$ para a posição $A$ com um pequeno decremento na distância, posição de ressonância da cavidade acústica neste caso encontra-se no ponto $A$. Pela figura nota-se que a posição de ressonância é deslocada e a intensidade máxima da força também é alterada, isto significa dizer que, dependendo do sentido de deslocamento do sistema, a resposta para cada deslocamento será diferente para o mesmo conjunto (ANDRADE, et al., 2014).

Figura 2.6.1- Curva de histerese e fenômeno de "salto" em uma varredura para uma cavidade acústica.

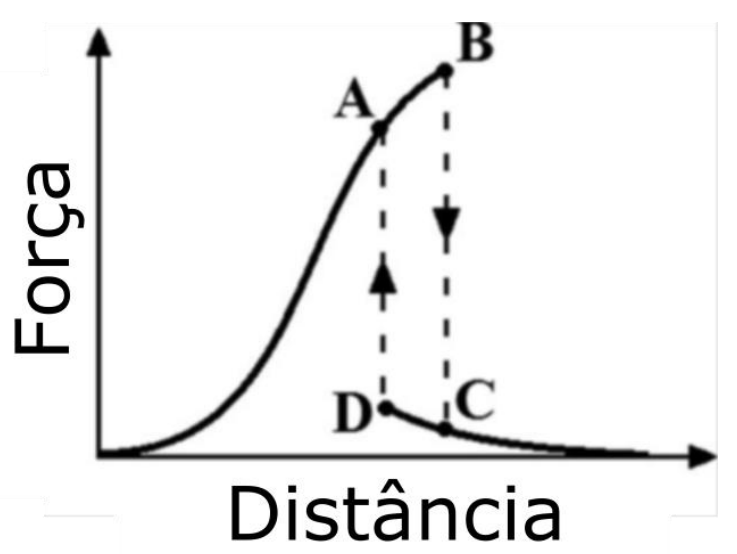

Fonte: Andrade et al., 2014 modificada. 


\subsection{Fenômeno do "salto"}

O Fenômeno do "salto" é a queda ou o aumento de forma abrupta da força de radiação acústica devido a um pequeno incremento na distância entre o transdutor e o refletor ou de uma aproximação, diminuindo a distância no sistema acústico, levando a força de uma força mínima até uma força muito maior rapidamente (ANDRADE et al., 2014).

Sistemas não lineares possuem caminhos particulares, significa que a forma da equação diferencial parcial que rege o movimento, possui uma variação que pode ser mutua entre os parâmetros que regem o sistema, ou podem variar de forma diferente de uma situação para outra.

Este efeito é de extrema importância quando se trabalha em torno da região de ressonância da cavidade acústica, pois dependendo do deslocamento do sistema o objeto que esta sendo levitado pode-se perder, sendo este ejetado ou mesmo caindo sobre a face do refletor. 


\section{Transdutor de Langevin}

Transdutores são dispositivos que convertem um tipo de energia em outro (GALLEGO-JUÁREZ, 1989). Há diversos tipos de transdutores, porém, os mais comuns são do tipo axissimétrico. Os transdutores encontrados com certa facilidade no mercado são do tipo: eletromagnético, capacitivo, magnetostritivo e o piezelétrico.

Os transdutores piezelétricos, os quais foram utilizados neste trabalho, são conhecidos como sendo do tipo Langevin (FIELD; SCHEELINE, 2007). Este modelo de transdutor possui uma variedade de aplicações industriais (IULA et al., 2002).

Um transdutor do tipo Langevin consiste de um conjunto de pares de cerâmicas piezoelétricas ligadas em paralelo, que são conectadas a uma fonte de energia elétrica. Em um transdutor de Langevin, as cerâmicas são pré-tensionadas entre duas massas metálicas por meio de um parafuso central. As cerâmicas piezoelétricas tem a capacidade de transformar a energia elétrica em mecânica e vice-versa. Assim existe a possibilidade de enviar um sinal elétrico a cerâmica que irá transformar o sinal em energia mecânica que fará o sistema vibrar. Neste sistema busca-se que a cerâmica vibre em seu modo de espessura, ou seja, no sentido longitudinal de propagação da onda.

A figura 3.1 representa um transdutor de Langevin, que possui duas cerâmicas piezoelétricas. As cerâmicas são posicionadas com as suas polarizações invertidas entre si, como apresentado na figura, de forma que o eletrodo positivo das cerâmicas seja conectado a uma fonte, e os eletrodos negativos são conectados ao fio terra. Os eletrodos conectados ao fio terra estão em contato com as massas metálicas do transdutor, deste modo evita-se que usuário corra o risco tomar choque. Na configuração apresentada na figura 3.1, há apenas duas cerâmicas piezoelétricas, mas existem transdutores que possuem mais de duas cerâmicas piezoelétricas em sua configuração. 
Figura 3.1- Esquema de um transdutor de Langevin.

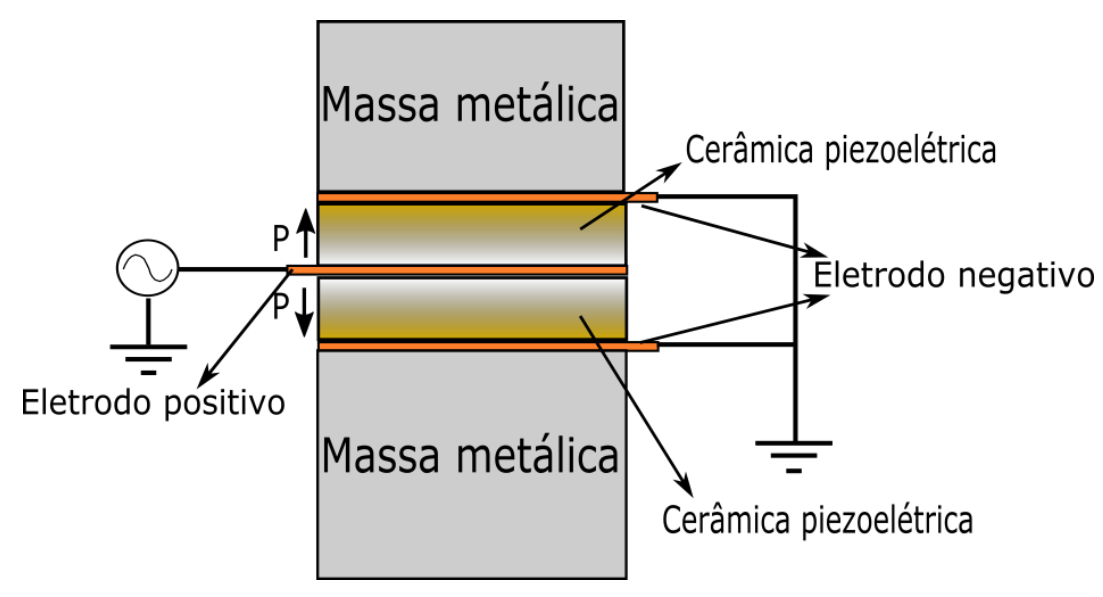

Fonte: Autor

Este tipo de transdutor é projetado para que as cerâmicas e as massas vibrem de forma harmônica e longitudinalmente (SHUYU, 2006). A forma geométrica das massas metálicas que serão utilizadas no sistema são determinadas em função da frequência em que se deseja trabalhar. Inicialmente é feita uma análise modal de cada peça metálica separadamente para encontrar o modo de vibração longitudinal das mesmas e garantir que o conjunto vibre harmonicamente na mesma frequência de ressonância.

Neste trabalho é feita uma análise modal das peças separadamente no software COMSOL (COMSOL AB, Stockholm, Sweden) através do método de elementos finitos. Como os transdutores possuem geometria circular, é possível utilizar elementos axissimétricos, de tal modo que a reduzir um problema tridimensional em um problema bidimensional.

A geometria do levitador e do refletor interferem na estabilidade do objeto que se deseja levitar na cavidade acústica (STINDT et al., 2014), (COLLAS; BARMATZ; SHIPLEY, 1989). As esferas podem ter comportamento oscilatório devido a geometria da cavidade acústica (ANDRADE et al., 2014). Em função das referidas oscilações, foram realizadas três pesquisas com o fim de compreender como força de radiação acústica atua sobre o refletor e, consequentemente, sobre um objeto. 
Na figura 3.2 há um modelo de um transdutor de Langevin com um amplificador mecânico de ondas acústicas. Este é o modelo de transdutor utilizado neste trabalho, todas as vezes em que aparecer no texto menções sobre alterações no raio ou no diâmetro do transdutor, deve-se entender como alterações na face emissora de ondas acústicas do amplificador mecânico. Sendo que, o transdutor é o conjunto completo, no entanto as alterações são realizadas apenas na face do amplificador mecânico.

Figura 3.2- Modelo de transdutor de Langevin com um amplificador mecânico.

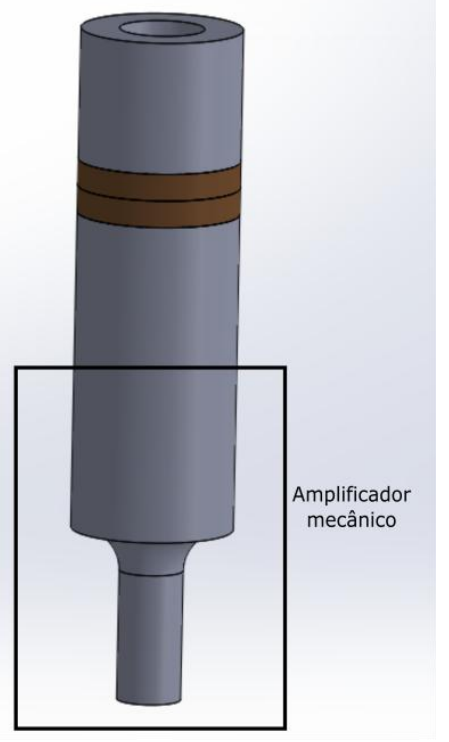

Para excitar as cerâmicas piezoelétricas utiliza-se um sinal elétrico senoidal produzido por um gerador de funções (33250A, Agilent Technology INC., Santa Clara, CA) e um amplificador de potência (800A3A, Amplifier Research Corp., Souderton, PA), que amplifica o sinal, enviado-o às cerâmicas. Com o intuito de manter o sistema funcionando com uma amplitude de deslocamento constante, um sensor de fibra óptica (MTI-2100, MTI Instruments, Inc., Albany, NY) foi utilizado para monitorar o sistema por meio da face transeira do transdutor, que envia o sinal para um osciloscopio (DSO 5012A Agilent Technologies, $100 \mathrm{MHz}-2 \mathrm{Ga} / \mathrm{s}$ USA), onde se pode fazer a leitura instantânea do sinal da amplitude de deslocamento da face do transdutor.

O osciloscópio é utilizado tanto para monitorar o sinal que chega aos contatos do transdutor como para indicar a amplitude de deslocamento da face traseira do 
transdutor e da face dianteira do respectivo transdutor, isso se faz necessário para obter a relação de deslocamento entre as duas faces.

O sensor de fibra ótica (MTI) é utilizado para obter as medidas da amplitude de deslocamento das faces do transdutor. A obtenção das medidas das faces do transdutor, as faces traseira e dianteira do transdutor devem estar bem limpas e polidas para que se tenha uma boa reflexão da luz emitida pelo equipamento.

Antes de iniciar a medição da amplitude de deslocamento das faces do transdutor, é necessário calibrar o equipamento. A calibração deve ser realizada sem a aplicação de tensão nas cerâmicas, ou seja, o deslocamento do sistema durante a calibração deve ser zero. Este aparelho também é utilizado para identificar qual a relação de amplitudes de deslocamento entre as faces traseiras e dianteiras dos transdutores. O MTI possui duas pontas o que permite a utilização simultânea de ambas, permanecendo cada uma em um canal específico de recepção existente no aparelho, neste caso possibilitando obter a relação das amplitudes de deslocamento das faces dianteira e traseira do transdutor.

Durante os experimentos realizados neste trabalho se observou ser inviável monitorar diretamente a vibração da face dianteira do transdutor, pois a agulha não pode ser acomodada na cavidade, uma vez que altera o campo acústico, afetando de forma direta a levitação dos objetos, e a força de radiação acústica que como veremos adiante é sensível a grandes mudanças na geometria da cavidade acústica. A partir da relação entre as amplitudes das faces do transdutor, basta monitorar a amplitude de deslocamento da face traseira, que teremos a amplitude da face dianteira de forma indireta. 


\section{Estudo da estabilidade na levitação acústica}

\subsection{Introdução}

Os modelos numéricos normalmente empregados para se determinar a força de radiação acústica utilizam equações linearizadas para calcular os campos de pressão e de velocidade entre o transdutor e o refletor. Esses campos são inseridos na equação de Gor'kov para calcular a força de radiação acústica sobre o objeto levitado. De acordo com os modelos baseados na equação de Gor'kov, o objeto é levitado nas posições de mínimo potencial do campo acústico. Isso significa que ao deslocar o objeto da posição de equilíbrio, o objeto apresenta um movimento oscilatório, similar ao comportamento de um sistema massa-mola. Devido às forças dissipativas, é de se esperar que o objeto oscile até que as forças de arrasto hidrodinâmico façam com que o objeto pare de oscilar, permanecendo em repouso na posição de mínimo potencial. Entretanto, observações experimentais mostram que o objeto oscila espontaneamente em torno da posição de equilíbrio, o que não é previsto pelos modelos normalmente utilizados.

$\mathrm{Na}$ levitação acústica, quando temos uma onda com baixa amplitude, pode-se utilizar a teoria linear para explicar o seu comportamento. No entanto, quando as amplitudes envolvidas são elevadas, a teoria linear deixa de ser válida e então é necessário utilizar modelos de propagação não lineares.

Alguns pesquisadores observaram alguns efeitos não lineares em cavidades acústicas (GAITAN; ATCHLEY, 1993) associado a um intenso campo acústico em um fluido dissipativo (TJOTTA, 2000). Entre os efeitos causados por não linearidades do sistema, podemos destacar a histerese (ILINSKII et al.,1998), correnteza acústica e o fenômeno de salto (ANDRADE; PERÉZ; ADAMOWSKI., 2014). 
De acordo com a literatura, a instabilidade pode estar relacionada com a posição de levitação do objeto, variação da amplitude de pressão ou pela geometria do levitador (SANTILLÁN et al., 2007). Além disso, grandes amplitudes podem causar a distorção da forma da onda, acarretando alterações nas propriedades do fluido, formando ondas de choque. Tais ondas podem ser relevantes, pois podem afetar os limites de pressão de forma considerável (LAWRENSON, et al., 1998).

Em 1989, Rudnick e Barmatz verificaram que, em determinadas condições, o objeto começa a oscilar espontaneamente em torno da posição de equilíbrio. Os autores argumentam que a instabilidade se dá através de oscilações ou rotações que podem chegar até um estado de saturação, fazendo com que o objeto caia, ou seja ejetado da cavidade acústica.

De acordo com Rudnick e Barmatz, as possíveis causas do fenômeno de instabilidade podem ser atribuídas a dois fatores: 1 - a frequência de ressonância da cavidade depende do tamanho e posição do objeto no interior da cavidade, e 2 - a diferença de fase existente entre a velocidade de oscilação do objeto e a força de radiação acústica atuando sobre o mesmo (RUDNICK; BARMATZ, 1989).

O objetivo deste trabalho é medir experimentalmente a força de radiação acústica atuante no refletor em uma cavidade acústica formada por um transdutor e um refletor, ambos côncavos, bem como investigar a oscilação de esferas levitadas no interior da cavidade. Observa-se neste experimento o espalhamento da onda acústica pelas esferas afetando a força de radiação acústica sobre o refletor e como a densidade da amostra interfere na levitação e no comportamento oscilatório destas esferas na cavidade acústica. 


\subsection{Aparato Experimental}

Neste trabalho foi utilizado um levitador acústico formado por um transdutor de face côncava que opera numa frequência de $20340 \mathrm{~Hz}$ e um refletor côncavo. O transdutor possui um diâmetro de $36 \mathrm{~mm}$ e a face côncava do transdutor possui raio de curvatura de $35 \mathrm{~mm}$, enquanto que o refletor possui um diâmetro de $40 \mathrm{~mm}$ e raio de curvatura da face côncava é de $33 \mathrm{~mm}$, a onda acústica emitida por este transdutor no ar, tem comprimento de onda de 16,7 $\mathrm{mm}$. Este transdutor foi construído por Andrade (ANDRADE, 2010). Com este transdutor foram realizados experimentos para se determinar a força de radiação acústica sobre um refletor de face côncava, como apresentado na figura 4.2.1. Este levitador também é utilizado para estudar o comportamento oscilatório de três esferas que possuem o mesmo diâmetro, porém de materiais diferentes.

No esquema apresentado na figura 4.2.1, há uma guia linear motorizada com passo de $5 \mu \mathrm{m}$, que é utilizada para controlar a posição vertical do transdutor. Um código desenvolvido em Matlab é utilizado para controlar o motor de passo, e consequentemente, a posição vertical do transdutor em relação ao refletor. $O$ refletor, por sua vez, está posicionado sobre uma balança eletrônica, que é utilizada para medir a força de radiação acústica sobre o refletor em função da distância de separação entre o transdutor e o refletor. Após cada deslocamento do transdutor a balança envia aproximadamente 20 valores de força de determinada posição ao computador, e a média destes valores é a utilizada para construir os gráficos de força que serão apresentados. 
Figura 4.2.1- Imagem do sistema experimental para o transdutor e refletor côncavo.

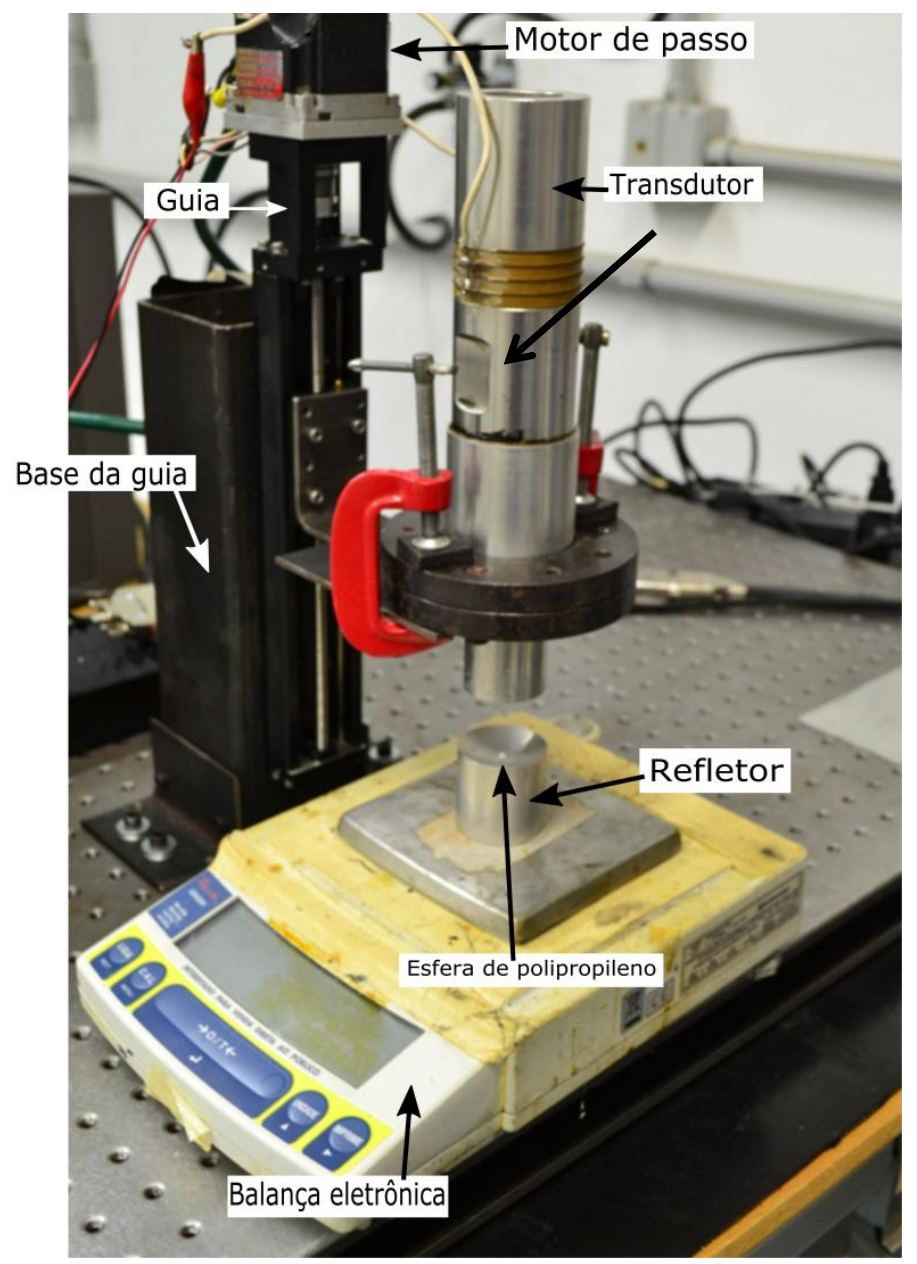

Fonte: Autor

Uma balança eletrônica (Shimadzu UX420H, Kyoto, Japan) foi utilizada para medir a força exercida pela onda estacionária sobre o refletor. A balança é conectada ao computador, sendo que a comunicação é realizada por meio de uma porta USB (Universal Serial Bus) com o mesmo computador, com o qual o motor de passo é controlado. A balança é controlada por um código em Matlab. Como a balança e o motor são conectados ao mesmo computador e controlados por algoritmos distintos, há um terceiro código em Matlab com a função de gerenciar o funcionamento destes códigos que controlam os equipamentos citados.

O computador envia a informação para o motor realizar um incremento ou decremento de deslocamento, gerando a movimentação do transdutor, o sistema aguarda alguns segundos para entrar em equilíbrio. A partir deste equilíbrio o computador começa a receber os valores de forças medidos pela balança. Após 
receber a quantidade de dados solicitados, o envio dos dados, pelo computador, é interrompido e o processo é reinicializado até que se finalize as repetições desejadas.

A figura 4.2.2 apresenta o diagrama do sistema de levitação acústica com a câmera de alta velocidade para gravar as oscilações das esferas na cavidade acústica, conforme o apresentado esquematicamente.

Figura 4.2.2- Diagrama do sistema de aquisição das oscilações das esferas na cavidade acústica e, força de radiação acústica com a balança eletrônica.

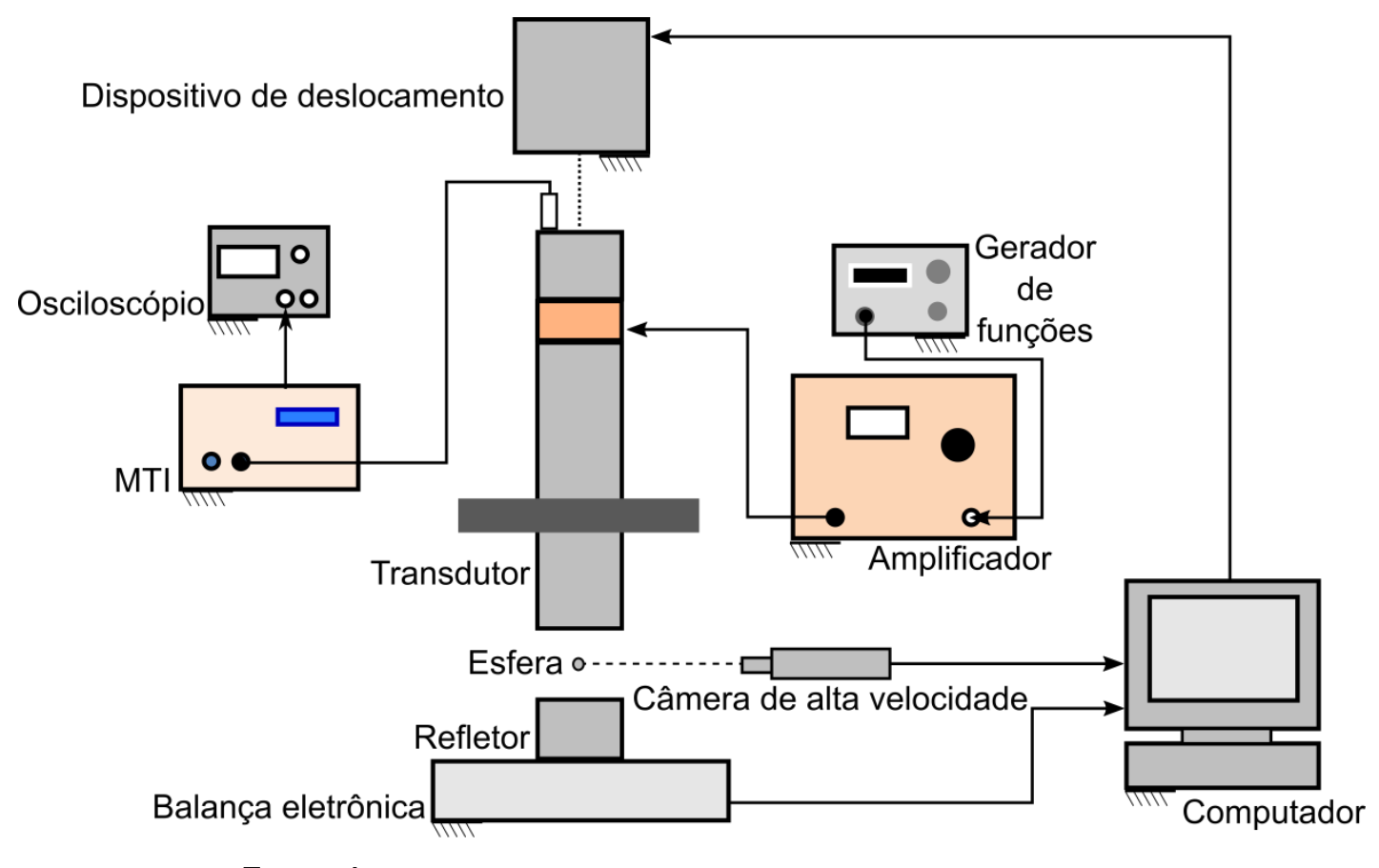

Fonte: Autor

Nos experimentos para verificar as oscilações das esferas durante a levitação foi utilizada uma câmera de alta velocidade (Fastec Inline 1000 monochrome, Fastec Imaging Corp., San Diego, CA). A câmera é conectada ao computador que tem como função armazenar os vídeos para posterior análise do comportamento das esferas na cavidade acústica, em cada uma das posições de equilíbrio do sistema, nestas posições de equilíbrio esperava-se um tempo para fazer os vídeos, pois de um ponto para outro pode apresentar efeitos transientes não esperados, pois a ideia é levitar um objeto na posição de equilíbrio e mantendo-o de forma estável. Durante 
a captura dos videos, a balança eletrônica envia os dados da força sobre o refletor para o computador.

A partir dos vídeos com o movimento oscilatório das esferas é utilizado um código em Matlab para encontrar o centro de massa das esferas e, a partir da localização deste ponto de referência, é possivel observar as posições horizontais e verticais das esferas em função do tempo e a amplitude de oscilação em função da frequência de oscilação da esfera, aplicando a transformada rápida de Fourier (FFT), conforme as figuras 4.3.6 à 4.3.14.

Este experimento foi desenvolvido ao longo de 5 meses e diversas varreduras foram conduzidas nesse período, afim de eliminar todo o tipo de interferência, refinando o experimento até obter respostas repetitivas do sistema. A cada varredura foram verificados o alinhamento vertical e horizontal do levitador acústico, e o alinhamento entre transdutor e o refletor que deve ser perfeitamente concêntrico. Para manter a amplitude de deslocamento da face do transdutor constante, a ampllitude do sinal enviado as cerâmicas foi controlado manualmente através do ganho no amplificador que excita as cerâmicas. Notou-se durante os experimentos que existe uma temperatura de regime de trabalho, nesta temperatura há pouca variação da amplitude de deslocamento da face do transdutor, assim todos os experimentos foram realizados em condições semelhantes para obter a repetitividade coerente do sistema acústico.

Durante o experimento, levantou-se a suspeita de que algumas ondas acústicas emitidas pelo transdutor poderiam chegar ao prato da balança, alterando o valor da força de radiação acústica sobre a face do refletor. Para evitar que as ondas emitidas pelo transdutor atingissem o prato da balança, foi colocada uma espécie de proteção em torno do refletor. Este sistema de proteção não encosta na face lateral do refletor para não gerar resistência sobre o mesmo, e o apoio desta proteção é em torno da balança eletrônica. Este sistema de proteção não encosta no prato da balança, e portanto, não interfere no resultado da força de radiação acústica sobre a face do refletor. 
Com estes aparatos funcionando corretamente foi possível obter as relações entre a força exercida sobre o refletor concâvo e a posição vertical do transdutor e as oscilações das esferas.

\subsection{Resultados e Discussão}

No experimento, o transdutor e o refletor são posicionados conforme apresentado na figura 4.3.1, que mostra as características geométricas da cavidade acústica como: os diâmetros do transdutor e do refletor, e os raios de curvatura das faces $R_{c 1}=35 \mathrm{~mm}$ e $R_{c 2}=33 \mathrm{~mm}$ do transdutor e do refletor, respectivamente, e o ponto zero de referência para varredura, localizado na borda superior da face do refletor. $A$ figura 4.3.1 também mostra a distância $d$ entre o transdutor e o refletor. Quando as bordas das faces do transdutor e refletor estão alinhadas, com as linhas horizontais de referência sobrepostas, a distância $d$ é zero, de modo que a varredura possa ser iniciada.

Figura 4.3.1- Diagrama do transdutor e refletor côncavos e com medidas e eixos de referências.

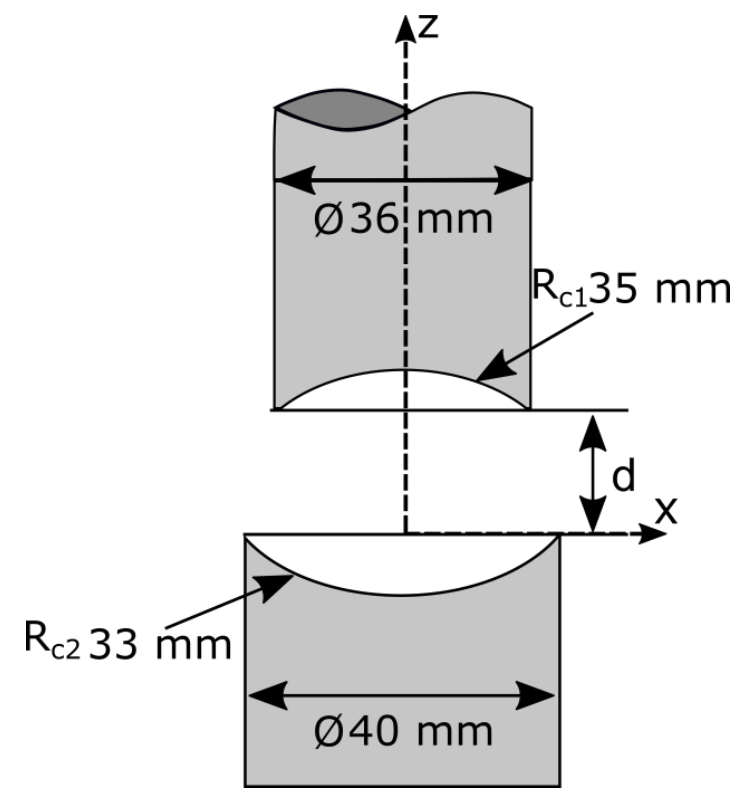

Fonte: Autor 
A figura 4.3.2 apresenta a curva da força de radiação acústica sobre o refletor em função da distância entre o transdutor e o refletor. Para obter a figura 4.3.2, o transdutor é posicionado próximo ao refletor, como descrito anteriormente. A partir desta posição, inicia-se o deslocamento do transdutor de zero até uma distância de aproximadamente $65 \mathrm{~mm}$, posição um pouco maior que a última posição de ressonância da cavidade (menor pico que ocorre em $d \approx 58 \mathrm{~mm}$ ), o incremento de cada ponto é de $0,5 \mathrm{~mm}$. Este experimento foi realizado sem a ultilização das esferas, o que permitiu encontrar as regiões de ressonância da cavidade acústica. Nestas regiões a força sobre o refletor é máxima, porém possuem valores diferentes para cada região, com a varredura é possivel observar o comportamento da força de radiação acústica em torno das regiões de ressonância e em todas as posições de deslocamento entre o transdutor e o refletor.

Na figura 4.3.2, nota-se que em algumas posições ocorrem picos da força de radiação acústica sobre o refletor. Tais posições são distâncias em que o transdutor e o refletor estão espaçados entre si em aproximadamente um múltiplo inteiro de meio comprimento de onda. Este valor não é exato, pois o refletor e o transdutor neste caso possuem as faces côncavas, fazendo com que a relação de distância entre ambos não siga exatamente essa relação. No entanto, o primeiro pico que aparece na figura, ocorre em uma posição não esperada em torno de $16 \mathrm{~mm}$. Essa posição é aproximadamente igual ao comprimento de onda, da onda emitida. Provavelmente o sistema acústico, comporta-se de forma semelhante ao de um sistema de levitação acústico de faces planas. Os demais picos são dominados pela geometria da cavidade acústica.

Devido as faces côncavas do transdutor e do refletor, este conjunto gera uma força de radiação acústica de máxima intensidade em um determinado ponto, que é definido pelas curvaturas das faces. Neste sistema constata-se que a força com maior intensidade ocorre no terceiro pico. A confirmação deste ponto está no fato que para uma varredura com passos de $5 \mu \mathrm{m}$, a intensidade da força máxima do pico se mantém em torno do mesmo valor de $15 \mathrm{gf}$, como pode ser observado nas figuras 4.3.2 e 4.3.3. Por sua vez, examinando os dados obtidos em um conjunto em que 0 transdutor e o refletor possuem faces planas, o pico de maior intensidade 
ocorrerá no primeiro pico, posição onde o transdutor e o refletor estão próximos, mas não encostados. No capítulo seguinte, será apresentado o experimento com a demonstração deste efeito.

Figura 4.3.2- Força de radiação acústica em função da distância entre o transdutor e o refletor côncavo.

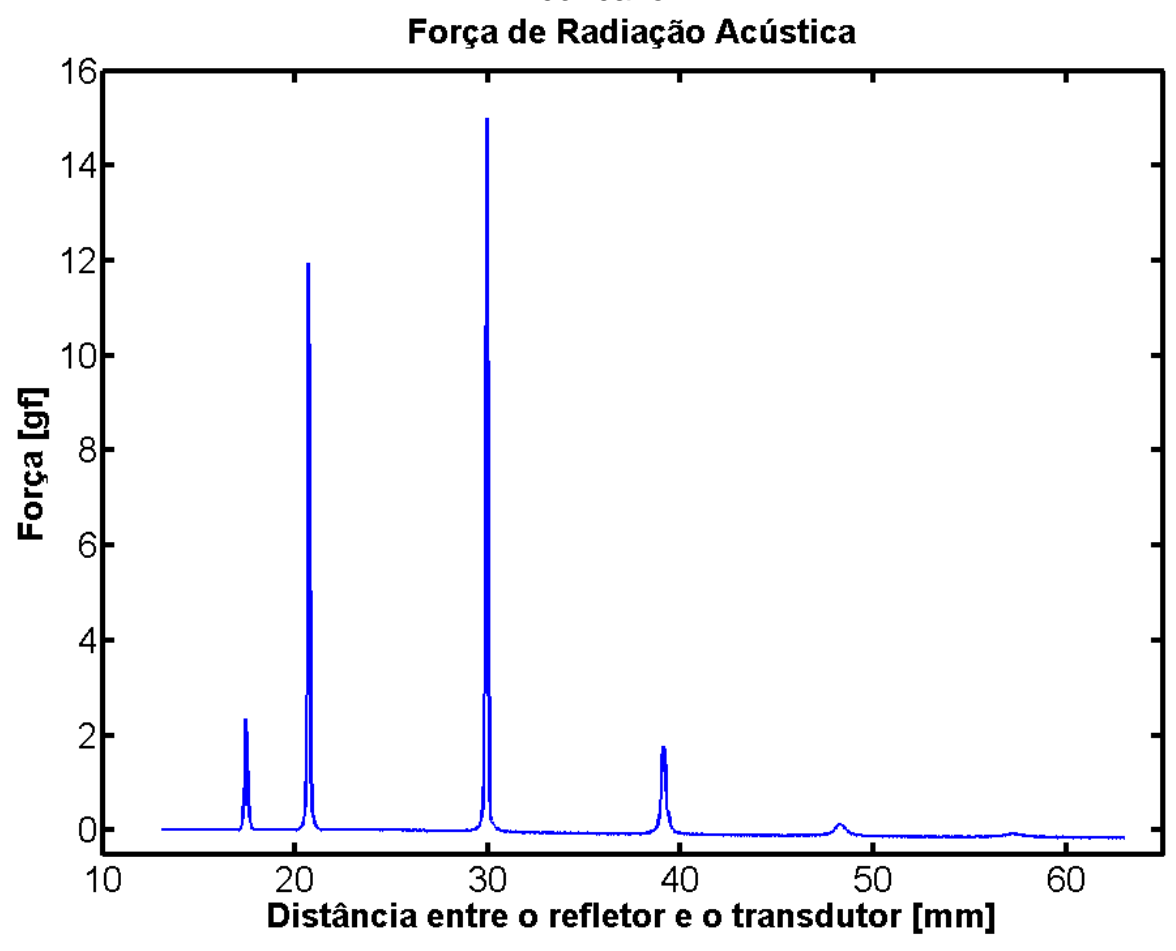

Fonte: Autor

Considerando o terceiro pico da figura 4.3.2, foram realizadas duas varreduras em torno deste pico. Na primeira varredura, a distância $d$ foi alterada de $28,9 \mathrm{~mm}$ até 29,9 mm (subida), e na segunda varredura, a distância foi reduzida de 29,9 $\mathrm{mm}$ até $28,9 \mathrm{~mm}$ (descida). A força obtida com essas duas varreduras são apresentadas na figura 4.3.3, que evidenciam dois fenômenos: 1- o fenômeno de salto (jump phenomenon), que é a queda abrupta da força em uma determinada posição; e 2- a histerese que ocorre quando se percorre o mesmo caminho, porém com condições iniciais diferentes de deslocamento. Estes dois fenômenos indicam que há um comportamento não linear do sistema. 
Figura 4.3.3- Intensidade da força de radiação acústica em função da distância entre o transdutor e o refletor côncavo, para uma varredura de crescente e outra decrescente.

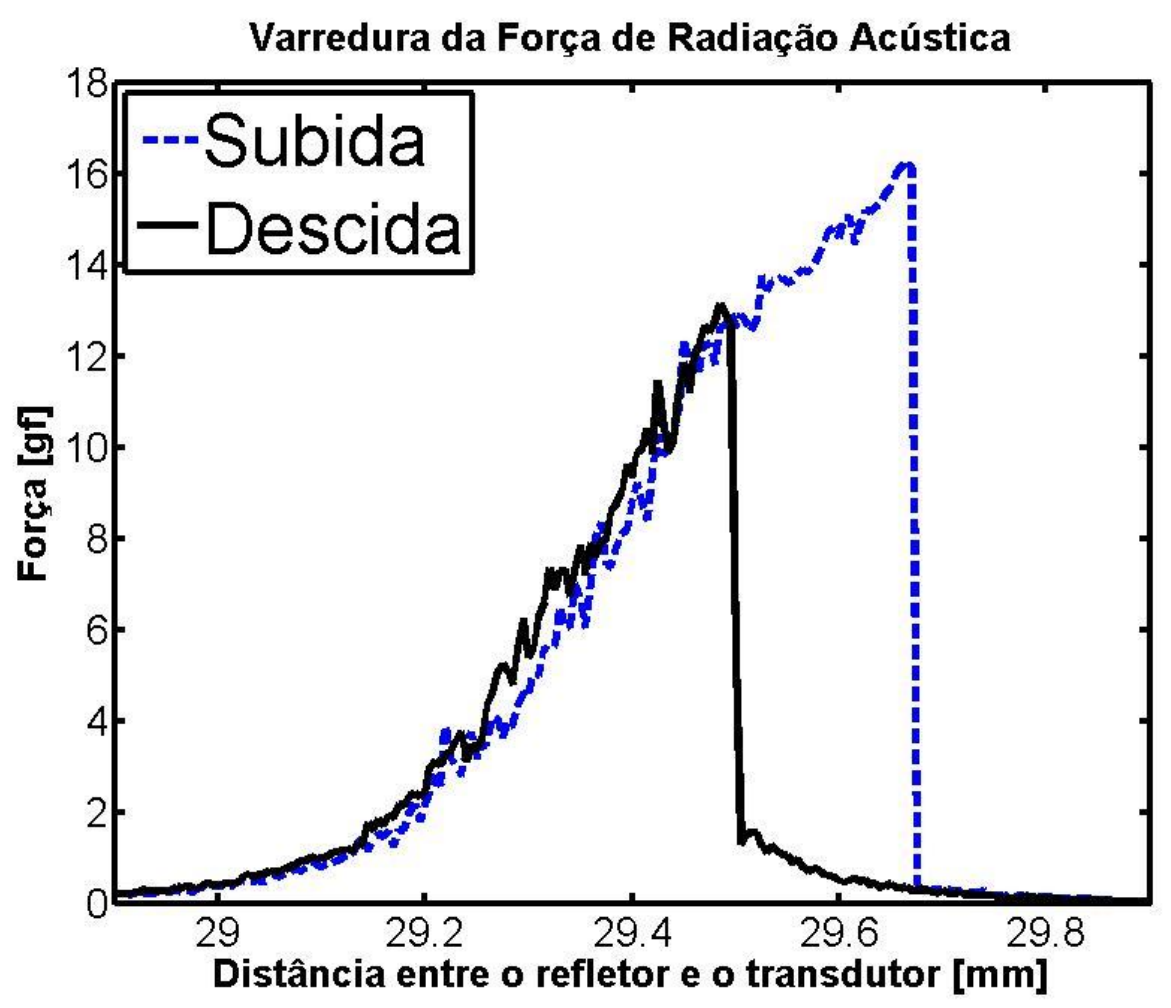

Fonte: Autor

$\mathrm{Na}$ figura 4.3.3, a varredura teve seu início em torno do terceiro pico, em uma posição onde o sistema não está em ressonância. A partir deste ponto, a varredura passa pela posição de ressonância e desloca-se novamente para uma posição fora da ressonância da cavidade acústica. Constatou-se que na posição de ressonância da cavidade acústica a intensidade da força de radiação acústica sobre o refletor é máxima. Nesta posição, um pequeno incremento na distância entre o transdutor e o refletor, em uma varredura na qual foi ampliada a distância entre o transdutor e o refletor resultou na queda abrupta da força de radiação acústica, queda da amplitude de pressão da cavidade. A curva azul tracejada representa este efeito.

A mencionada queda abrupta é conhecida como fenômeno do "salto" (ANDRADE et al., 2014), (RAMOS; ANDRADE; ADAMOWSKI, 2014). Dependendo do sentido da varredura, o pico máximo é deslocado como apresentado nas curvas da figura 2.6.1, curva de histerese, se a varredura é realizada com a diminuição da distância entre 0 transdutor e o refletor, a força resultante será muito baixa inicialmente, todavia, essa 
força aumentará de forma brusca, em razão do repentino aumento da amplitude de pressão da cavidade. Este efeito é representado pela curva preta continua. Apesar das condições de trabalho serem mantidas as mesmas, este deslocamento do pico de intensidade máxima ocorre devido ao fenômeno conhecido como histerese, que também ocorre em osciladores harmônicos não lineares.

Os efeitos de hiterese e salto são respostas do sistema a efeitos não lineares que ocorrem na cavidade acústica, que possivelmente ocorre devido ao comportamento do meio fluido da cavidade acústica.

Na figura 4.3.4 observa-se quatro curvas. A curva de referência é obtida realizandose a varredura na ausência de esferas no interior da cavidade acústica, e as outras três curvas são obtidas com as esferas levitando na cavidade, na região em torno do terceiro pico. As três esferas possuem o mesmo diâmetro, de $3 \mathrm{~mm}$, e o que as diferem, é apenas o material que as constituem.

Uma das esferas é de vidro, outra é de polipropileno, e a terceira é de aço. Apesar de serem de diferentes materiais, as curvas para as esferas são muito semelhantes. Como a geometria das esferas são idênticas, elas produzem 0 mesmo espalhamento para o campo acústico incidente sobre o refletor (MANNEBERG, 2009).

$\mathrm{Na}$ figura 4.3.4 nota-se que a força para a cavidade sem a esfera (curva azul e continua), utilizada como referência, a intensidade da força sobre o refletor é um pouco maior que para a cavidade com as esferas de vidro (curva pontilhada e preta), polipropileno (curva vermelha tracejada) e aço (curva pontilhada e verde). Isso indica que a geometria das esferas produzem o mesmo espalhamento sobre a força de radiação acústica na cavidade, independente do material utilizado. Vale ressaltar que as curvas das respectivas esferas é para a força de radiação acústica sobre o refletor e a força de radiação acústica sobre a esfera não é apresentada na figura em questão. 
Deste modo, é possivel afirmar que o espalhamento do campo acústico que as três esferas geram sobre o refletor são iguais. No entanto, o ponto inicial de levitação de cada amostra é diferente devido a densidade específica das esferas, uma vez que quanto maior a densidade, maior deve ser a intensidade da força de radiação acústica.

Figura 4.3.4- Força de radiação acústica sobre o refletor em função da distância entre o transdutor e o refletor côncavo, com uma curva de referência, e curvas para as esferas de polipropileno, vidro e aço utilizadas no experimento.

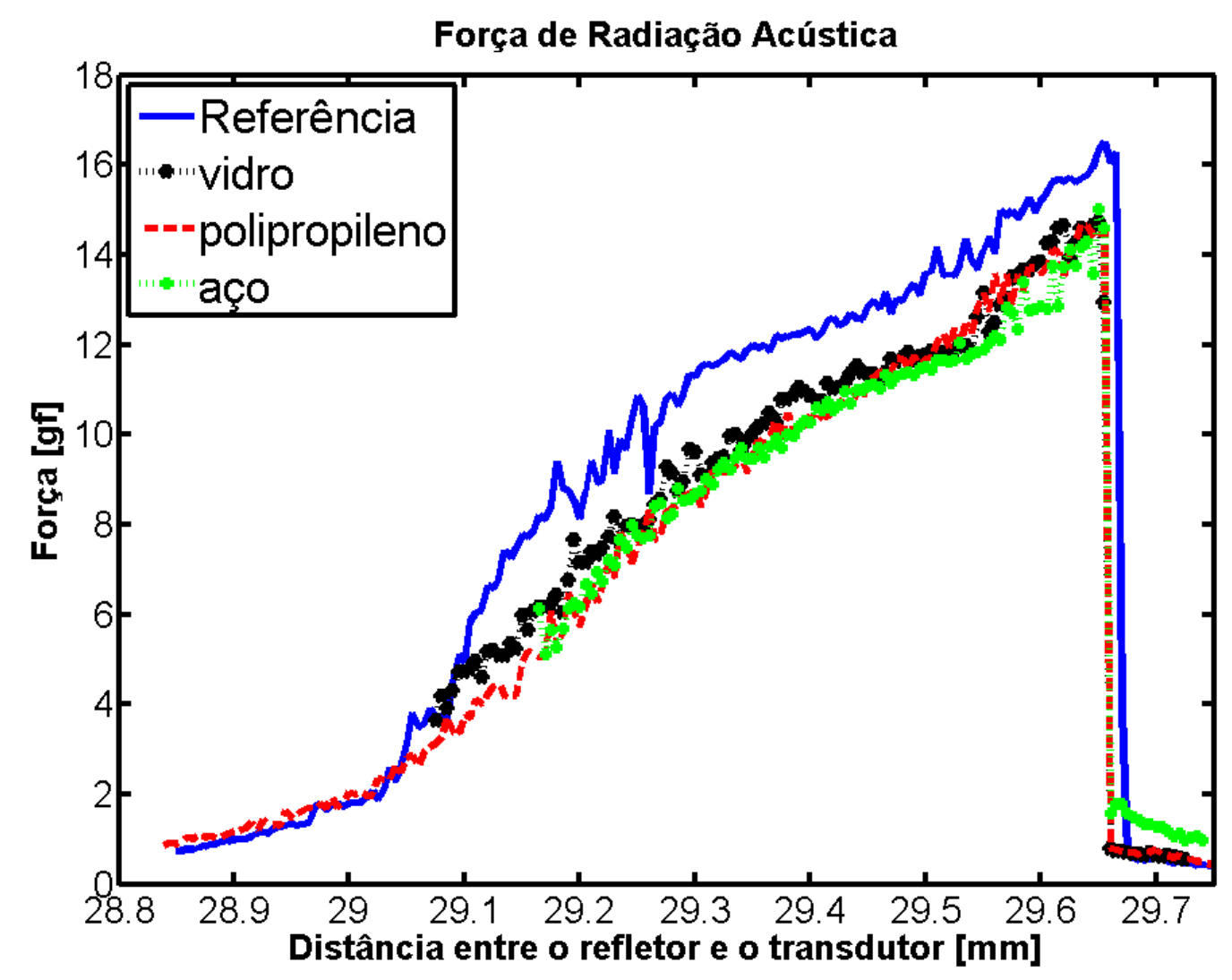

Fonte: Autor

A partir da figura 4.3.4 pode-se constatar que as respostas do sistema para as três esferas são semelhantes entre si, o que possibilitou eleger a curva da esfera de poliproleno para gerar a figura 4.3.5. A esfera de polipropileno foi escolhida por possuir menor densidade em relação as demais esferas, o que permite analisar o comportamento da esfera em uma região mais ampla em torno da ressonância. Sendo assim, com a determinação da curva a ser utilizada, foram selecionados três pontos de levitação para análise, os quais estão indicados na figura 4.3.5. 
O ponto $A$ está localizado em torno da região onde a esfera de aço inicia a sua levitação. Este ponto é comum para todas as esferas, pois a esfera de vidro inicia sua levitação em uma posição onde a força é menor que para a esfera de aço devido a densidade. No ponto $B$, posição em que a cavidade acústica encontra-se em ressonância, todas as esferas estão levitando na cavidade. O ponto $C$ é uma posição em que a força é menor que no ponto $A$. Do ponto $B$ para o ponto $C$, há uma queda brusca da força de radiação devido ao fenômeno do "salto".

Enquanto realiza-se a medida da força de radiação acústica sobre o refletor em função da distância entre o transdutor e o refletor, uma câmera de alta velocidade é utilizada para filmar as oscilações das esferas durante a levitação. Nos pontos $A$ e $B$ obteve-se as respostas das três esferas levitando, mas, para o ponto $C$, observou apenas a resposta da esfera de polipropileno, pois para as demais esferas, a força de radiação acústica não era intensa o suficiente para mantê-las levitando.

Figura 4.3.5- Força de radiação acústica em função da distância entre o transdutor e o refletor côncavo para uma esfera de polipropileno de $3 \mathrm{~mm}$ de diâmetro, com três posições para análise de oscilações.

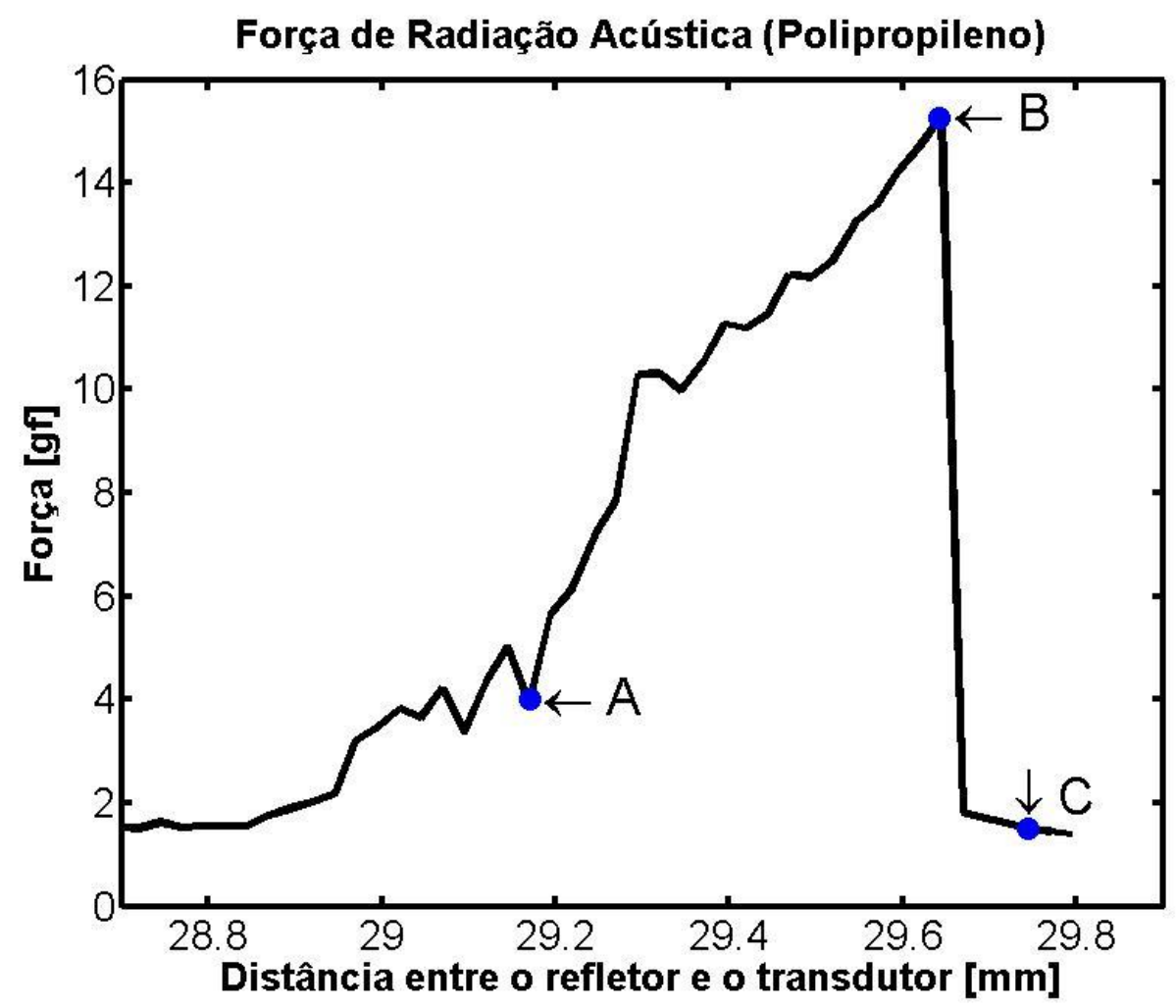

Fonte: Autor 
Para cada posição indicada na figura 4.3 .5 serão apresentadas as oscilações verticais e horizontais das esferas e suas respectivas frequências de oscilação para as posições em destaque.

A figura 4.3.6 apresenta as oscilações horizontais e verticais da esfera de polipropileno para a posição $A$, em torno da posição de início de levitação da esfera de aço. Nesta figura, nota-se que a esfera de polipropileno possui uma frequência de oscilação maior na vertical que na horizontal. Isso ocorre pois a força de radiação acústica na vertical é maior que na horizontal (BAER et al., 2011), sentido de propagação da onda acústica. Na horizontal, a esfera de polipropileno, a sua amplitude de deslocamento é alta para frequência em torno de $11 \mathrm{~Hz}$, já, na vertical, a frequência de oscilação da esfera é de aproximadamente $42 \mathrm{~Hz}$.

Figura 4.3.6- Oscilações horizontais e verticais para a esfera de polipropileno e suas respectivas amplitudes e frequências de oscilações, para a posição $A$, da figura 4.3.5.
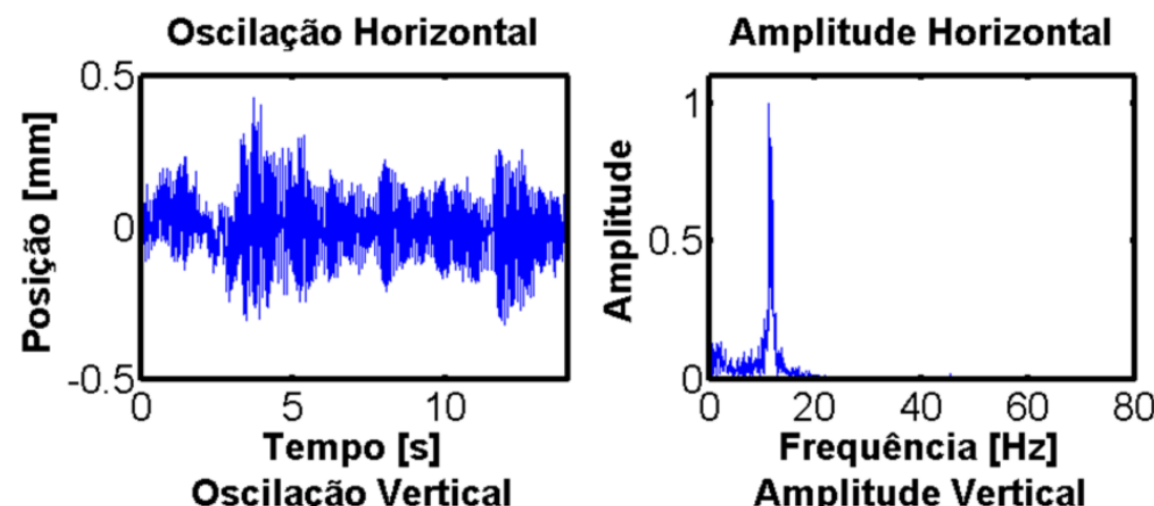

$11 \mathrm{~Hz}$
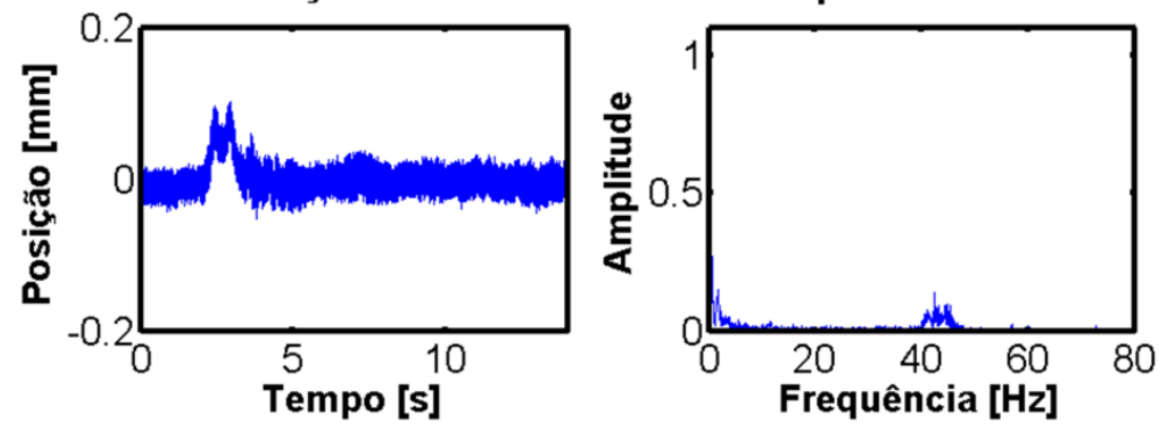

$42 \mathrm{~Hz}$

Fonte: Autor 
A figura 4.3.7 mostra as oscilações horizontais e verticas da esfera de vidro para a posição $A$, posição em torno do inicio de levitação da esfera de aço. Nesta figura é possivel observar que a frequência de oscilação horizontal é menor que a frequência de oscilação vertical, também devido a força de radiação acústica ser mais intensa na vertical. A frequência de oscilação vertical é maior que na horizontal, assim como para a esfera de polipropileno, e a frequência de oscilação horizontal da esfera de vidro fica em torno de $8 \mathrm{~Hz}$ e a vertical em torno de $31 \mathrm{~Hz}$. Como esperado, com o aumento da densidade da amostra, a frequência de oscilação diminui, tanto no eixo vertical como no eixo horizontal.

Figura 4.3.7- Oscilações horizontais e verticais para a esfera de vidro e suas respectivas amplitudes e frequências de oscilações, para a posição $A$, da figura 4.3.5.
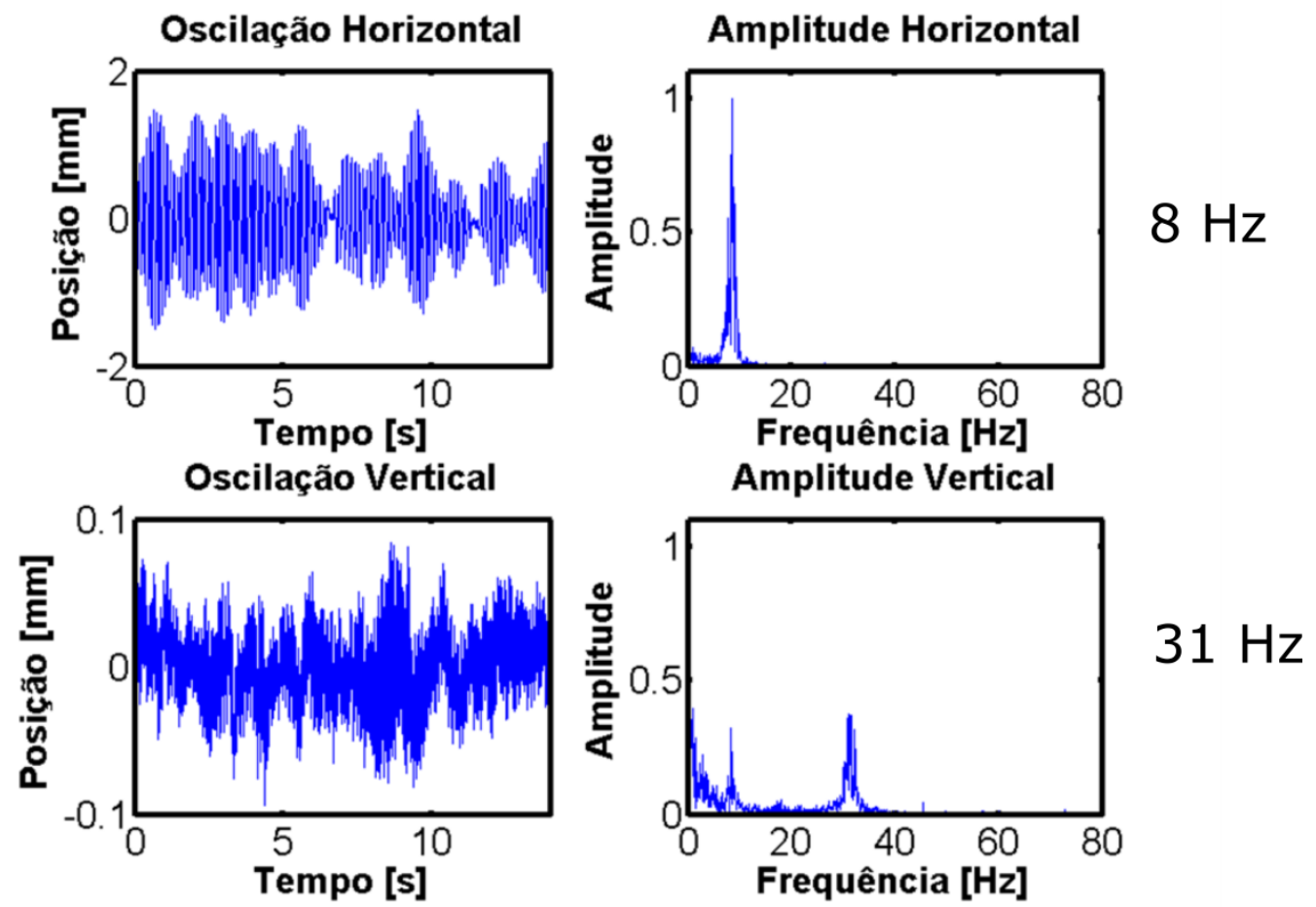

Fonte: Autor 
A figura 4.3.8 apresenta as amplitudes de deslocamento horizontais e verticais para a esfera de aço para posição $A$, em torno da posição onde a esfera começa a levitar. Assim, como nas figuras anteriores, a frequência de oscilação horizontal é menor que a frequência de oscilação vertical. A frequência de oscilação no eixo horizontal fica em torno de $5 \mathrm{~Hz}$ e a frequência de oscilação no eixo vertical em torno de $20 \mathrm{~Hz}$. Comparando a frequências de oscilação das três esferas com o aumento da densidade da esfera verificou-se a diminuição das frequências de oscilação.

Figura 4.3.8- Oscilações horizontais e verticais para a esfera de aço e suas respectivas amplitudes e frequências de oscilações, para a posição $A$, da figura 4.3.5.
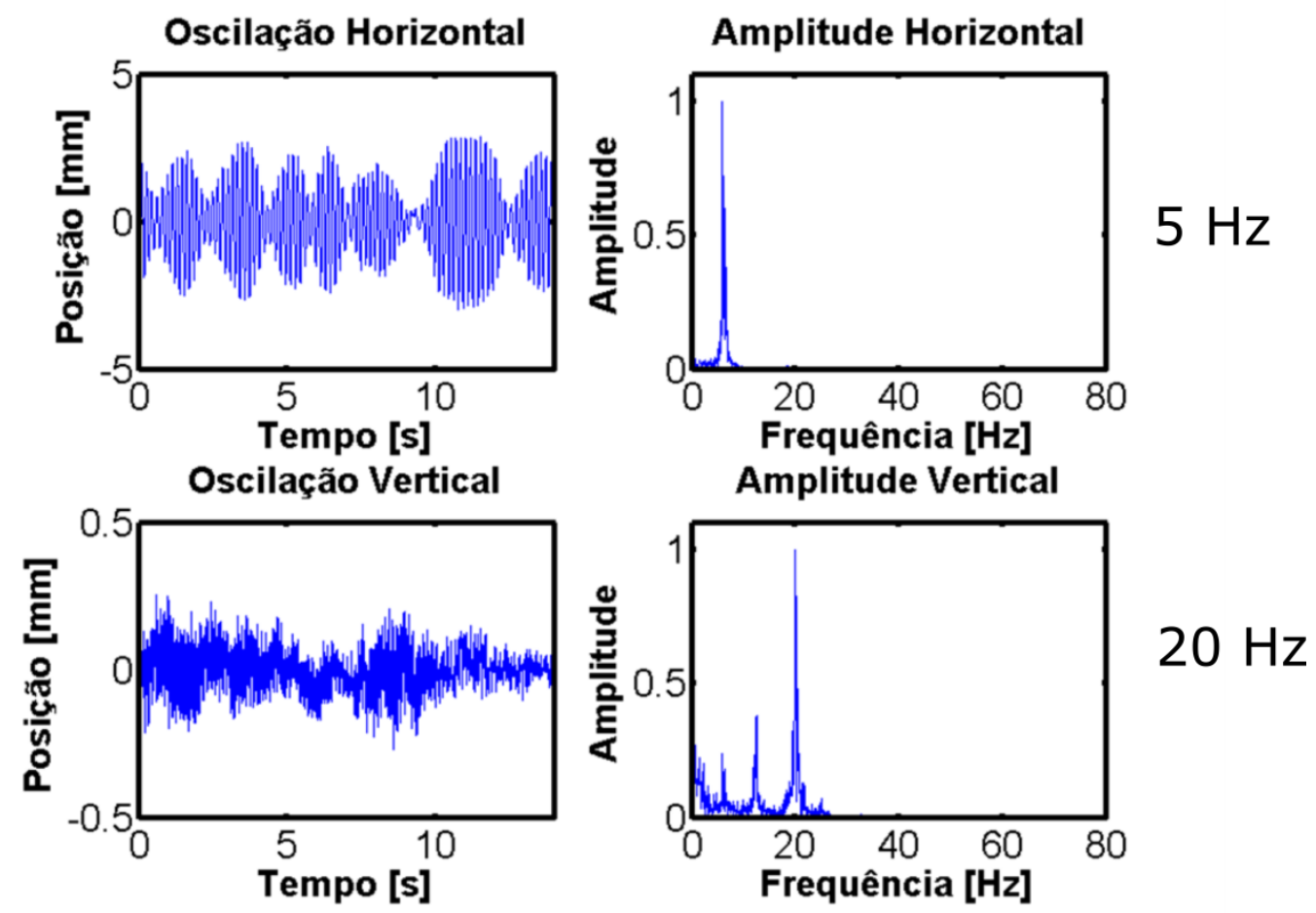

Fonte: Autor

Como a densidade do aço é maior que das amostras de vidro e de polipropileno, as respostas das oscilações de cada esfera para as mesmas posições são diferentes. Densidade do aço $7700 \mathrm{~kg} / \mathrm{m}^{3}$, densidade do vidro $2500 \mathrm{~kg} / \mathrm{m}^{3}$, densidade do polipropileno $946 \mathrm{~kg} / \mathrm{m}^{3}$. Quanto maior a densidade da amostra, menor a frequência de oscilação da esfera. A equação 4.3.1 apresenta a relação entre a frequência natural da esfera e a densidade do material para um oscilador harmônico unidimensional. 
Considerando que as esferas estão na mesma posição $A$ na cavidade acústica, a distância entre o transdutor e refletor são iguais para as três esferas. Admitindo que as esferas são submetidas a mesma constante elástica e na mesma configuração de levitação. Como as esferas possuem o mesmo diâmetro de $3 \mathrm{~mm}$, considerou-se que as esferas possuem o mesmo volume. Portanto, o que justifica os diferentes valores de frequências obtidas entre as esferas para a mesma posição, com relação ao eixo de oscilação, foram as densidades das esferas, resultando na equação 4.3.1.

$$
\omega=2 \pi f \Rightarrow f=\frac{1}{2 \pi} \sqrt{\frac{k}{\rho_{o b} V}}
$$

onde $k$ é a constante elástica, $\rho_{o b}$ é a densidade do objeto, e $V$ é o volume da esfera.

No ponto $A$ as esferas são submetidas a uma força de radiação acústica proporcional a força peso da esfera. A força de radiação acústica possui maior intensidade no eixo vertical, eixo de propagação da onda acústica, que na horizontal, essa verificação pode ser notada pelas figuras que foram analisadas desde a figura 4.3.6 até a 4.3.8. Sendo assim, notou-se que as maiores frequências de oscilação ocorrem no eixo vertical e as menores frequências ocorreram no eixo horizontal, devido a intensidade da força restauradora, considerando um sistema semelhante ao de massa mola.

O deslocamento das esferas são menores no eixo vertical que no eixo horizontal, visto que, quanto maior a intensidade da força restauradora, menor a amplitude de deslocamento da esfera, a força tende a trazer a amostra para posição de equilibrio.

$\mathrm{Na}$ equação 4.3.2, há a relação entre a força restaudora, o deslocamento da esfera e a constante elástica que é dada pela amplitude de pressão que será apresentado a seguir. Pela lei de Hooke têm-se:

$$
F=-k z
$$

onde $F$ é a força e $z$ é o pequeno deslocamento da esfera em torno da posição de equilíbrio. 
A fim de obter a constante elástica da mola na cavidade acústica na posição de levitação das esferas é necessário conhecer o potencial da força de radiação acústica na cavidade. Na vizinhança de um mínimo de potencial acústico, o comportamento de um objeto é semelhante ao de um sistema massa mola. Neste caso tem-se que a constante elástica é dada pela derivada segunda do potencial de radiação acústico em relação ao eixo desejado (ANDRADE, 2010). Assim, a constante elástica é dada pela equação 4.3.3.

$$
k=\frac{\partial^{2} U}{\partial z^{2}}
$$

Como apresentado por Andrade em sua tese de doutorado em 2010, quanto maior a constante elástica, mais denso pode ser o objeto, posicionado no nó da onda estacionária. A constante elástica também determina a capacidade do levitador manter o objeto na posição de equilíbrio (ANDRADE, 2010).

No trabalho apresentado por Andrade e coautores (ANDRADE; PERÉZ; ADAMOWSKI, 2015) foi demonstrado que a constante elástica efetiva de uma mola acústica em uma cavidade depende do quadrado da amplitude da pressão. Desta forma, a equação que determina a constante elástica em cada posição de mínimo potencial da cavidade acústica é dada pela expressão 4.3.4.

$$
k=\frac{5 \pi R^{3} K^{2}}{3 \rho_{0} c_{0}^{2}} A^{2}
$$

onde $A$ é a amplitude de pressão, e $K$ é o número de onda dado por: $K=2 \pi / \lambda$ (ANDRADE; PERÉZ; ADAMOWSKI, 2015). Na expressão 4.3.4, considera-se que a onda estacionária é plana.

Na figura 4.3.9 (a) nota-se o perfil da amplitude de pressão, para a cavidade acústica em questão. A posição de levitação da amostra ocorre nas posições indicada por um sinal branco de positivo. Pela figura, também pode-se notar que a posição onde a esfera levita, a amplitude de pressão é baixa e a amostra posiciona-se entre duas regiões consecutivas de alta amplitude de pressão. 
Na figura 4.3.9 (b), apresenta o potencial acústico relativo para a configuração do sistema de levitação acústica. Nesta figura constata-se que segundo o potencial acústico relativo há três posições de levitação para uma esfera, que pelo diagrama da figura ocorre em uma região de mínimo potencial acústico. Os sinais de positivo de cor branca nas figuras (a) e (b) localizam-se na mesma posição em ambas as figuras. O potencial acústico relativo não leva em consideração o raio da esfera como na equação de Gor'kov. Para calcular o potencial relativo da figura 4.3.9 (b), a equação de Gor'kov deve se tornar independente do raio da esfera, logo:

$$
\tilde{U}=\frac{U}{2 \pi R^{3}}=\left(\frac{\left\langle p^{2}\right\rangle}{3 \rho_{0} c_{0}^{2}}-\frac{\rho_{0}\langle\mathbf{u} \cdot \mathbf{u}\rangle}{2}\right)
$$

Figura 4.3.9- Perfis da a-) Amplitude de pressão e, b-) potencial acústico relativo para a cavidade acústica do transdutor de $20 \mathrm{kHz}$ e refletor côncavos.

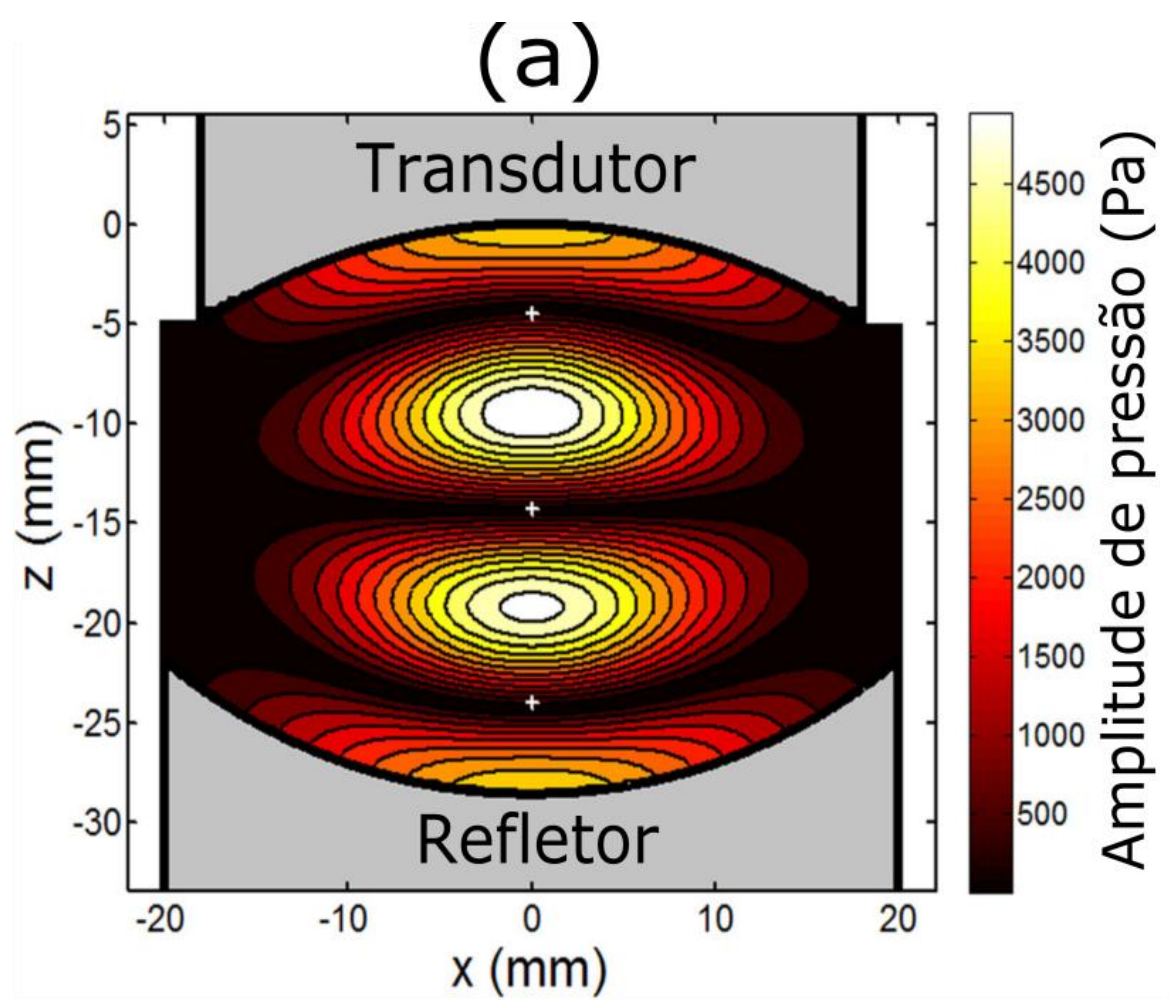

Fonte: Adaptado de Andrade, et al., 2014 


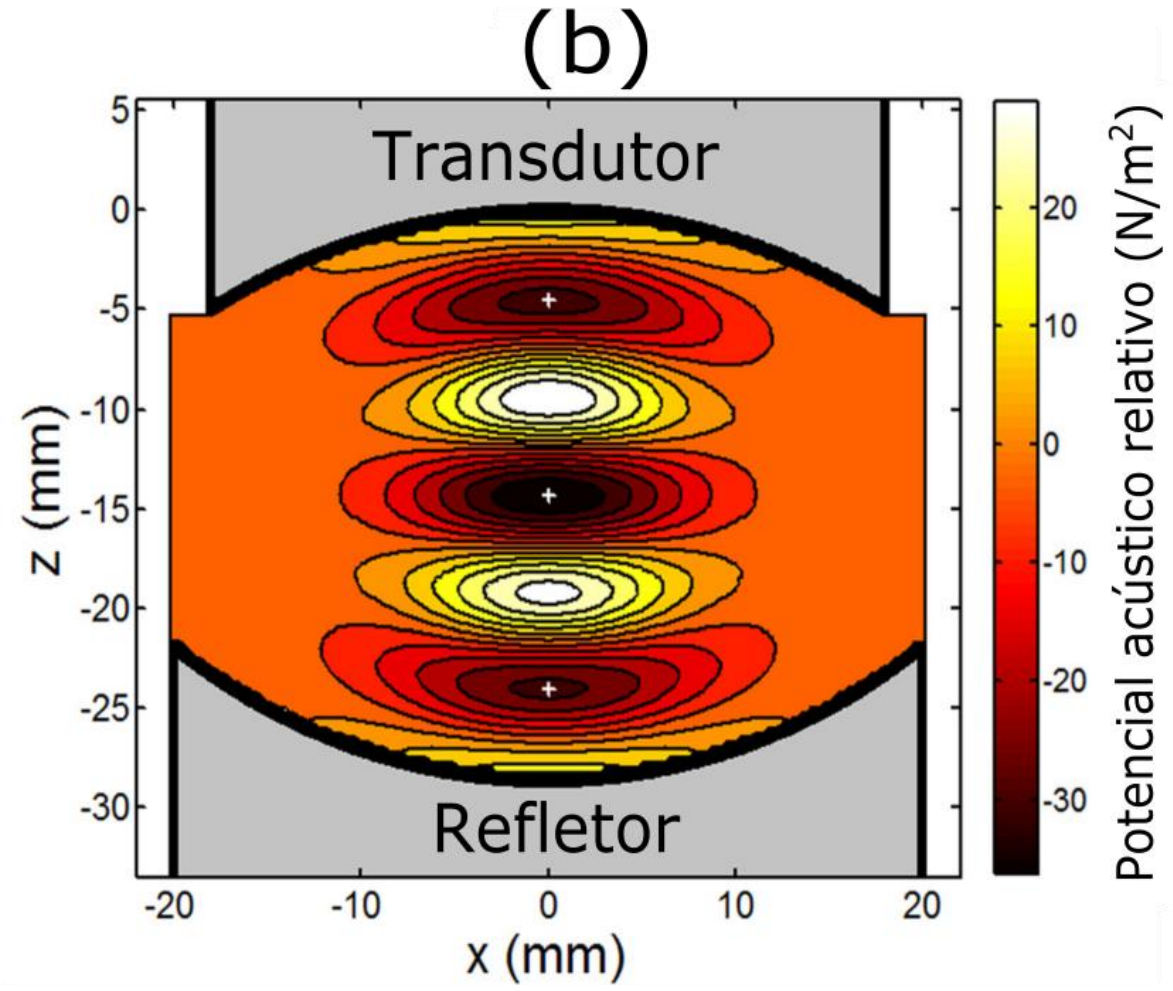

Fonte: Adaptado de Andrade, et al., 2014 
Na figura 4.3.10 há um modelo simplificado do comportamento das esferas na cavidade acústica obedecendo às características de um sistema massa mola dadas pela lei de Hooke.

A mola, para os casos apresentados a seguir, é ideal, de massa desprezível e presa na extremidade superior a um suporte fixo rígido. As densidades das esferas deslocam o sistema da posição de equilíbrio, caso (a) da figura 4.3.10. Ao deslocar o sistema da posição de equilíbrio uma força restauradora $F$, age no sentido contrário ao do deslocamento, tal força irá atuar sobre a esfera, com magnitude proporcional a amplitude de deslocamento da esfera.

Figura 4.3.10- Modelo simplificado de levitação acústica, seguindo um modelo que obedece a lei de Hooke, para um sistema massa mola.

(a)

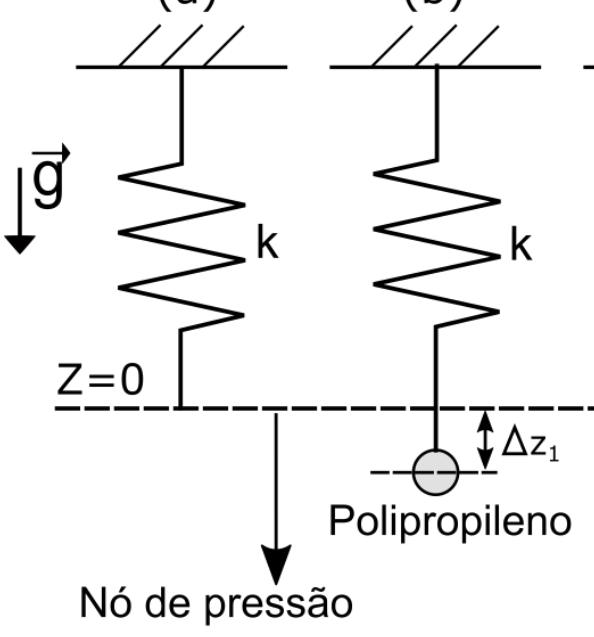

Fonte: Autor (c)

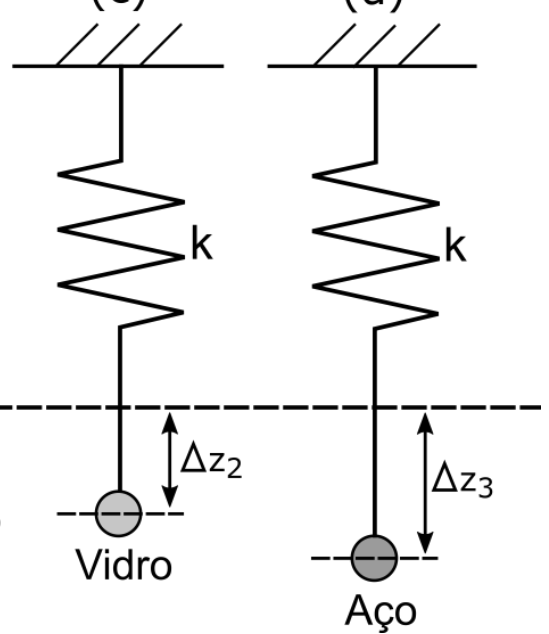

(d)

A figura 4.3.10 apresenta quatro condições - (a), (b), (c) e (d). A mola, para as quatro condições, possui a mesma constante elástica $k$, o que difere uma condição da outra são as densidades das esferas e força aplicada devido à densidade do respectivo material da esfera. Para a condição (a), a mola não apresenta deformação, não há a aplicação de força sobre essa mola, caso semelhante ao da cavidade acústica sem as esferas.

No caso (b), com uma esfera de polipropileno presa a extremidade livre da mola, que se desloca suavemente da posição de equilíbrio do sistema gerando um pequeno 
deslocamento $\Delta z_{1}$; No caso (c), com a esfera de vidro presa a extremidade livre da uma mola o deslocamento $\Delta z_{2}$ do sistema é maior que $0 \Delta z_{1}$ da esfera de polipropileno, devido a densidade do vidro ser maior; No caso (d), com uma esfera de aço presa na extremidade livre da mola apresenta um deslocamento ainda maior com relação ao eixo de referência, onde temos o nó de pressão, o deslocamento que a esfera de aço proporciona ao sistema é $\Delta z_{3}$, que é maior que para as demais esferas. Os deslocamentos das esferas com relação à posição de equilíbrio se dão devido as densidades de cada material que são diferentes, uma vez que quanto maior a densidade, maior o deslocamento, assim maior deve ser a força de radiação acústica para manter a esfera levitando.

Nos pontos destacados $A, B$ e $C$ da figura 4.3 .5 há uma constante elástica específica para cada ponto, pois cada ponto corresponde a uma amplitude de pressão distinta, devido a configuração da cavidade acústica, ou seja, para cada posição entre o transdutor e o refletor há um sistema de levitação específico diferente de posição para posição. 
A figura 4.3.11 apresenta as amplitudes de deslocamento horizontais e verticais da esfera de polipropileno da posição $B$ da figura 4.3.5. Nesta posição, a cavidade se encontra em ressonância, sendo o comportamento de oscilação da esfera semelhante ao do que acontece no ponto $A$, em que a frequência de oscilação é maior no eixo vertical do que no horizontal.

A frequência de oscilação horizontal no referido ponto $B$ não é bem definida para a esfera de polipropileno, que fica em torno dos $20 \mathrm{~Hz}$, diferentemente do ponto $A$, em que a frequência era de $11 \mathrm{~Hz}$. Por sua vez, a frequência de oscilação vertical, no referido ponto $A$, aumenta de $42 \mathrm{~Hz}$ para aproximadamente $66 \mathrm{~Hz}$ no ponto $B$. Isso ocorre em razão do aumento da amplitude de pressão na cavidade, fazendo com que a constante elástica e a força de radiação acústica aumentem na cavidade acústica. Consequentemente, ocorre o aumento da frequência de oscilação da esfera, uma vez que a densidade da esfera permanece constante.

Figura 4.3.11- Oscilações horizontais e verticais para a esfera de polipropileno e suas respectivas amplitudes e frequências de oscilações, para a posição $B$, da figura 4.3.5.
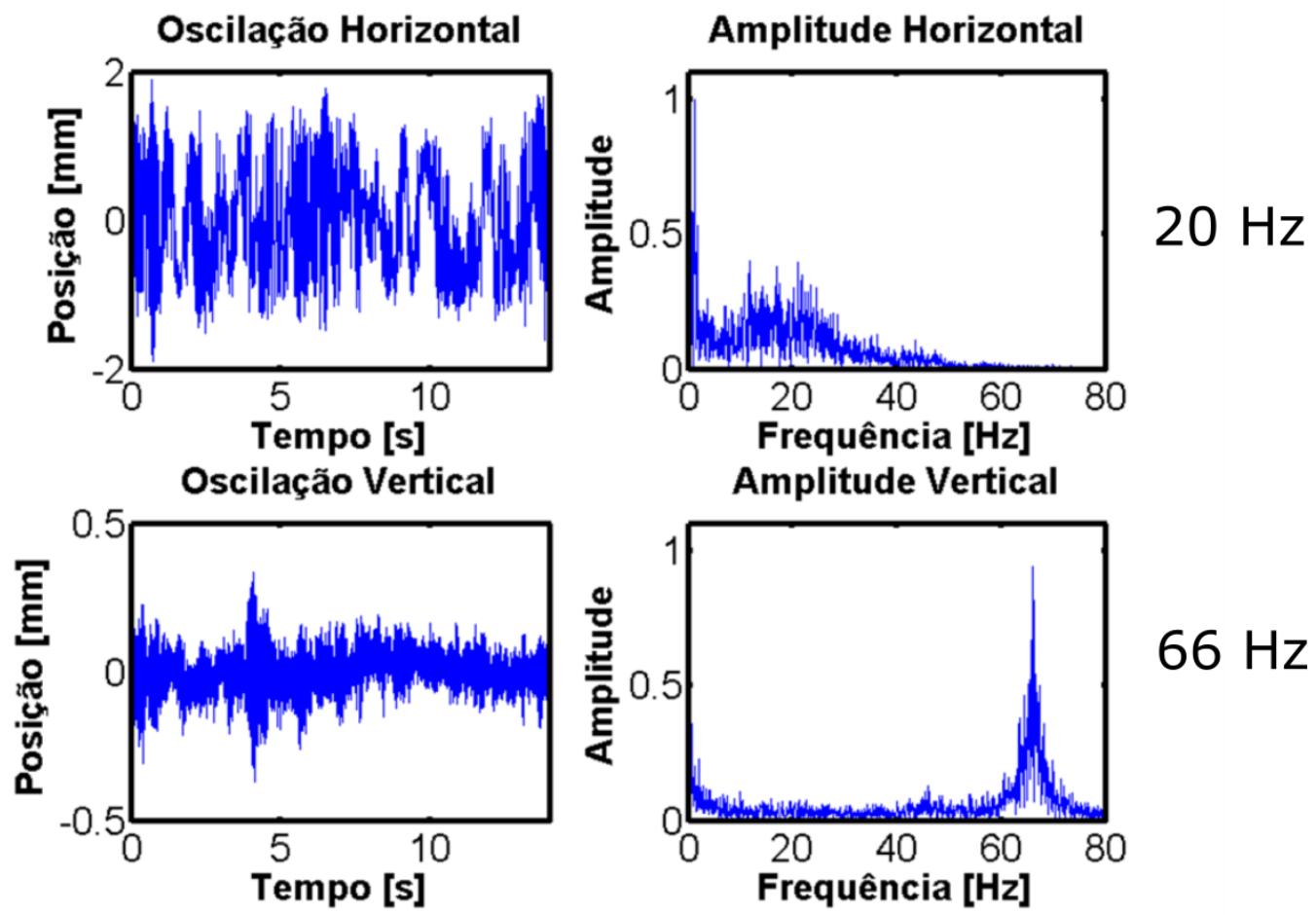

Fonte: Autor 
A figura 4.3.12 apresenta as oscilações horizontais e verticais da esfera de vidro para a posição $B$ da figura 5.3.5. Assim como ocorre com a esfera de polipropileno, as frequências de oscilações horizontais e verticais aumentaram, passando de $8 \mathrm{~Hz}$ na posição $A$, para $14 \mathrm{~Hz}$ na posição $B$, no eixo horizontal e, no eixo vertical, passou de $31 \mathrm{~Hz}$ na posição $A$, para $40 \mathrm{~Hz}$ na posição $B$. Esse aumento acontece devido ao aumento da intensidade da força de radiação acústica na ressonância da cavidade.

Figura 4.3.12- Oscilações horizontais e verticais para a esfera de vidro e suas respectivas amplitudes e frequências de oscilações, para a posição $B$, da figura 4.3.5.
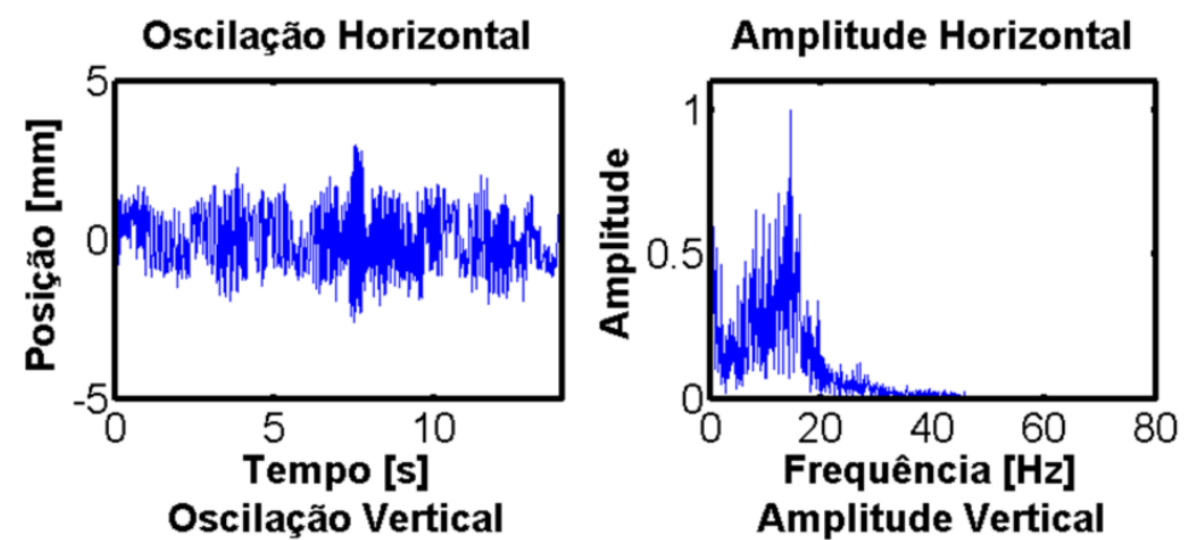

$14 \mathrm{~Hz}$
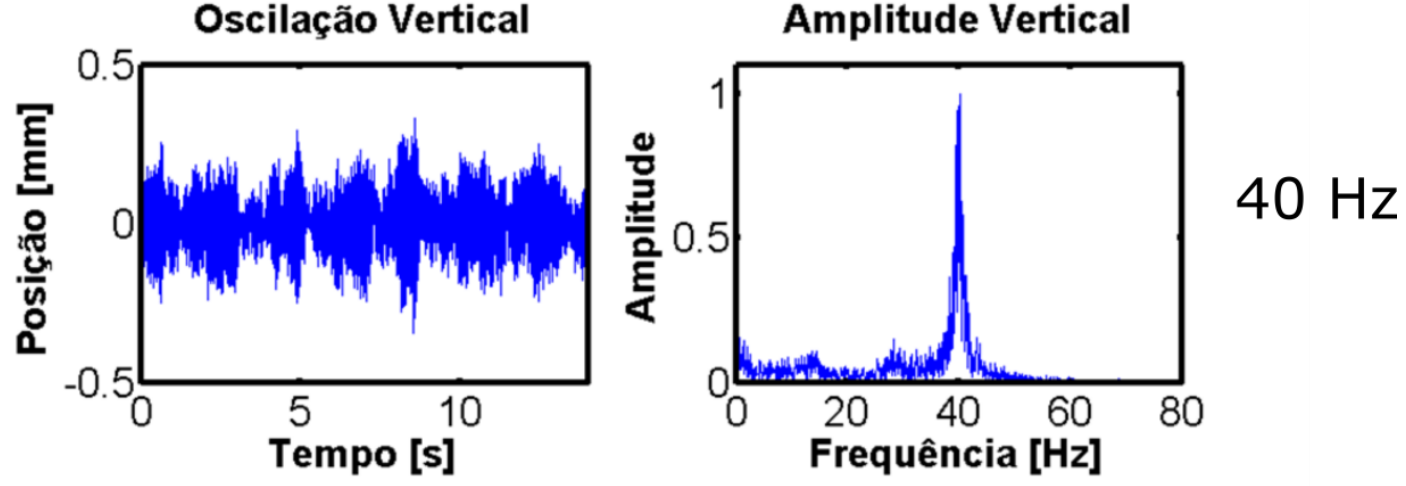

Fonte: Autor 
A figura 4.3.13 apresenta as oscilações da esfera de aço para a posição $B$ da figura 4.3.5. Como nas esferas de polipropileno e de vidro, as frequências de oscilações horizontais e verticais também aumentaram, passando de $5 \mathrm{~Hz}$ na posição $A$, para 8 $\mathrm{Hz}$ na posição $B$, no eixo horizontal e, para o eixo vertical, passou de $20 \mathrm{~Hz}$ na posição $A$, para $23 \mathrm{~Hz}$ na posição $B$.

Figura 4.3.13- Oscilações horizontais e verticais para a esfera de aço e suas respectivas amplitudes e frequências de oscilações, para a posição $B$, da figura 4.3.5.
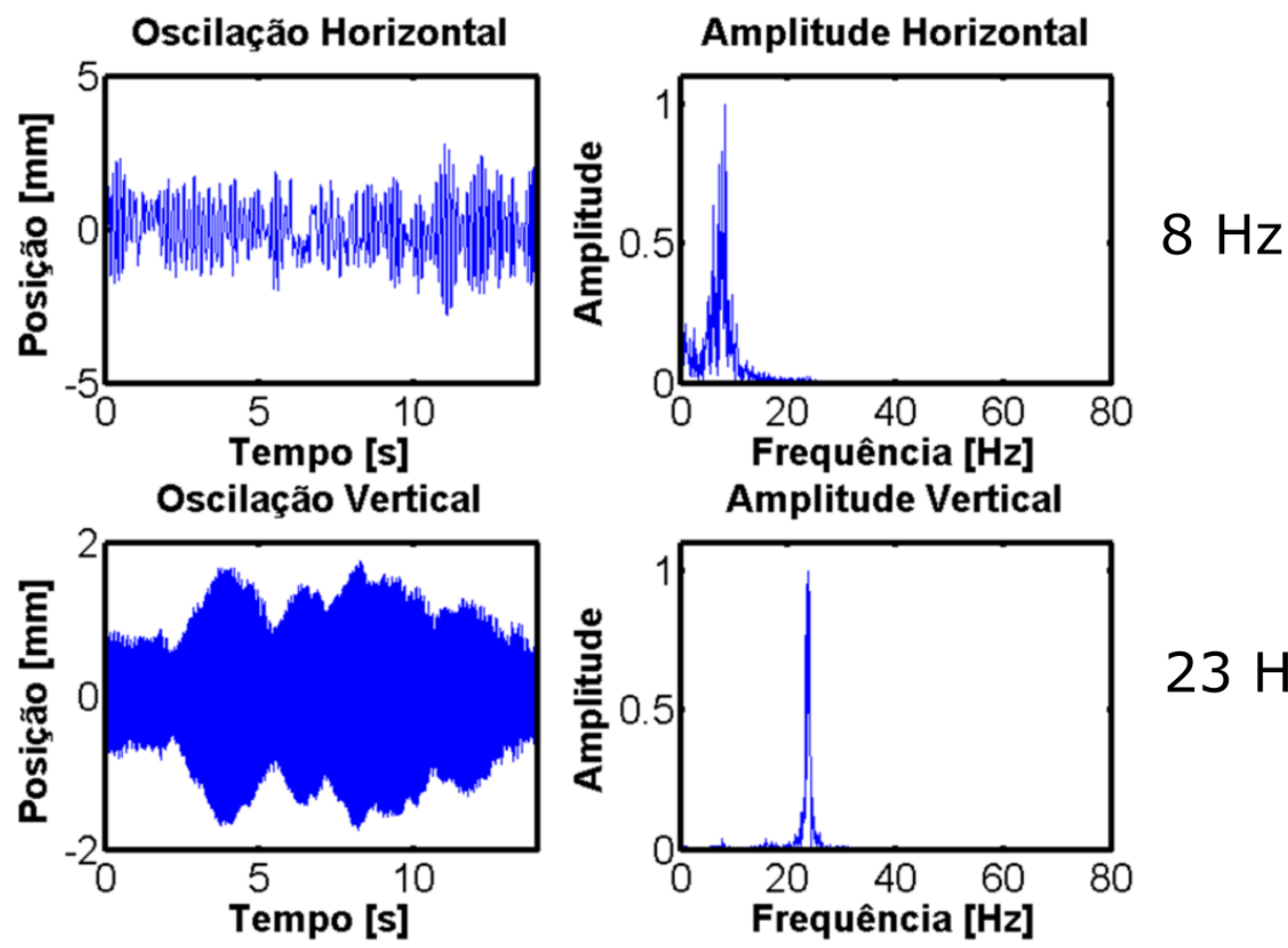

Frequência [Hz]

Amplitude Vertical

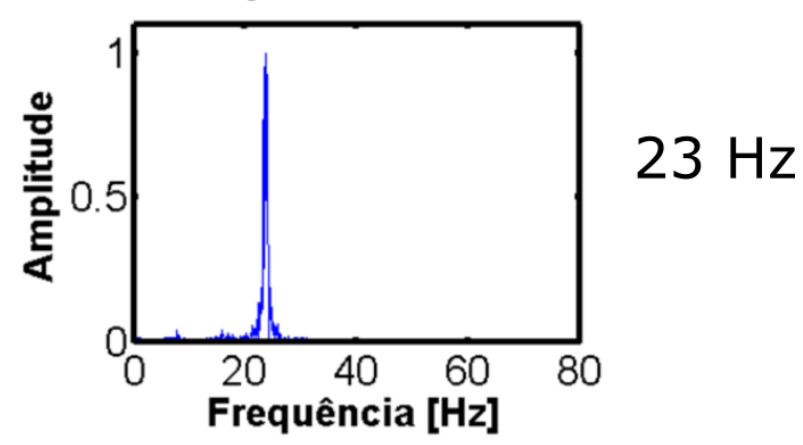

Fonte: Autor

Das figuras das oscilações apresentadas, é possível identificar que a densidade do material, e a distância entre o transdutor e o refletor, interferem na frequência de oscilação da esfera na cavidade acústica. Significa dizer que quanto maior a densidade menor será a variação da frequência de oscilação com relação à posição. Deve-se ressaltar que o deslocamento realizado foi no sentido crescente, ou seja, aumentando a distância entre o transdutor e o refletor e, devido ao aumento da amplitude de pressão, constatou-se que para cada ponto da figura 4.3.5 há uma constante elástica específica para cada posição, independente da natureza do material do objeto que se esta levitando. 
A figura 4.3.14 apresenta as frequências de oscilações horizontais e verticais da esfera de polipropileno para o ponto $C$ da figura 4.3 .5 e suas respectivas amplitudes. Nesta configuração, apenas a esfera de polipropileno continuou levitando após a queda abrupta (fenômeno do "salto") da força de radiação acústica. Este fato se deu devido a sua baixa densidade em relação às demais esferas, de aço e de vidro. No ponto $C$, a frequência de oscilação horizontal é de $7 \mathrm{~Hz}$, enquanto que no ponto $A$, a frequência era de $11 \mathrm{~Hz}$ no eixo horizontal, e a frequência de oscilação vertical é de $21 \mathrm{~Hz}$ para o ponto $C$ e, no ponto $A$, a frequência de oscilação era de $42 \mathrm{~Hz}$. As frequências de oscilação no ponto $C$ foram menores que as frequências de oscilação no ponto $A$ em razão da intensidade da amplitude de pressão ser menor no ponto $C$. As esferas de vidro e de aço caíram sobre o refletor, tendo em vista que a força de radiação acústica neste ponto não teve intensidade suficiente para contrabalancear a força peso das respectivas esferas, podendo, em determinadas condições ejetar a esferas da cavidade acústica.

Figura 4.3.14- Oscilações horizontais e verticais para a esfera de polipropileno e suas respectivas amplitudes e frequências de oscilações, para a posição $C$, da figura 4.3.5.
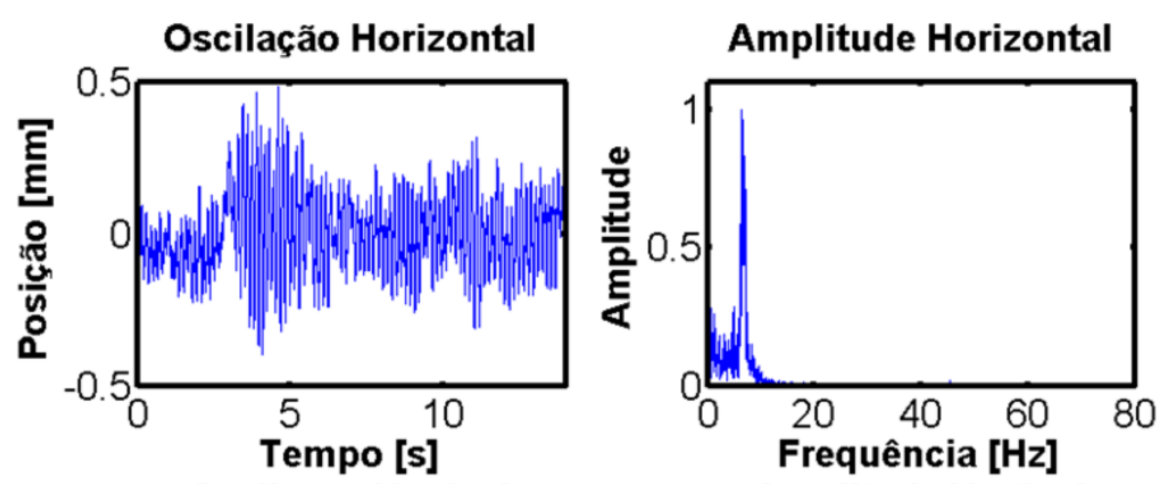

$7 \mathrm{~Hz}$
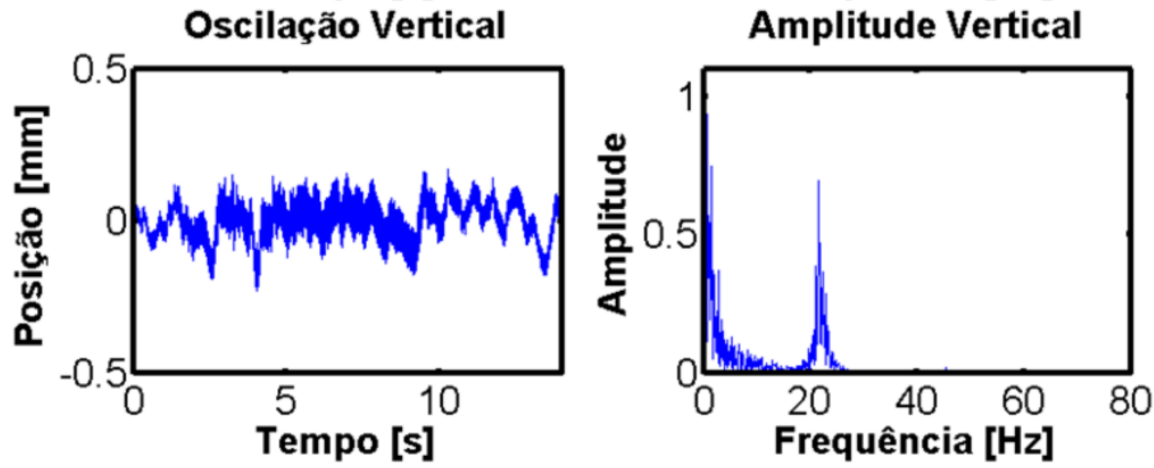

$21 \mathrm{~Hz}$

Fonte: Autor 


\subsection{Conclusão}

O conjunto transdutor/refletor neste experimento apresenta 5 regiões de ressonância, nessas regiões a força de radição acústica sobre a face do refletor apresenta-se em forma de picos. Para o primeiro pico o sistema age de forma semelhante ao de um conjunto de transdutor/refletor de faces planas e para os demais picos a geometria da cavidade intefere na posição de ressonância da cavidade acústica, e na intensidade da força de radiação acústica sobre o refletor.

Pelos experimentos aqui apresentados foi possível constatar que as esferas de mesmo diâmetro produzem o mesmo espalhamento do campo acústico sobre o refletor, independente da densidade do seu material, aqui apresentado. A densidade interferirá no ponto de início de levitação, fato que exige do sistema a aplicação de uma força de radiação acústica específica para cada esfera, proporcional à sua força peso.

Assim, quanto maior a densidade da esfera, maior será a força e, consequentemente, será maior o deslocamento com relação ao eixo de referência, neste caso o eixo de referência é dado com relação a cavidade sem as esferas. Por sua vez, menor será a frequência de oscilação com relação as demais esferas de menor densidade e, ao mesmo tempo, menor será a diferença da frequência de oscilação de uma posição para outra da mesma esfera.

Os resultados dos experimentos realizados permitiu observar que o comportamento das oscilações das esferas se altera conforme a disposição da distância entre o transdutor e o refletor, pois em cada configuração existe uma amplitude de pressão específica. Com base nos resultados apresentados, nota-se que no ponto $A$ da figura 4.3.5, a amplitude de pressão é menor que no ponto $B$ da mesma figura, posição em que a cavidade encontra-se em ressonância, neste ponto tem-se a maior rigidez elástica para a cavidade acústica e a força de radiação acústica de maior intensidade para o dado sistema de levitação.

Com o sistema em ressonância, maior o potencial de radiação acústica o que implica em uma maior rigidez elástica da mola acústica, que aumenta em função do 
quadrado da amplitude de pressão, para a posição. Nesta posição tem-se a maior força de radiação acústica sobre o refletor, a força restauradora nesta posição é maior e, tende a trazer a esfera para a posição de equilíbrio, fazendo com que a esfera oscile em torno da posição de equiíbrio do sistema de levitação acústica.

A oscilação da esfera é dado por efeitos não lineares como correnteza acústica, efeito não estudado, lembrando que a esfera esta sob a ação da força de radiação acústica que atua sobre sua superfície.

Após a região de ressonância, apenas a esfera de polipropileno continuou levitanto, já as demais esferas cairam sobre o refletor.

Portanto:

- O primeiro ponto de ressonância ocorre para uma posição semelhante a um conjunto transdutor/ refletor de faces planas;

- Em torno da região de ressonância da cavidade acústica, nota-se a presença de efeitos não lineares como: histerese e fenômeno de "salto", mostrando que o sistema é sensível a pequenas mudanças na geometria da cavidade (deslocamento);

- A força aplicada sobre a esfera é diferente da força aplicada sobre o refletor;

- A frequência de oscilação da esfera diminui com o aumento da densidade. Caso em que a densidade do material é muito maior que o meio, como o apresentado neste trabalho;

- A oscilação da esfera pode se dá pelo efeito de correnteza acústica na cavidade;

- A rigidez elástica da cavidade acústica é dada pelo quadrado da amplitude de pressão da cavidade. 


\section{Força de radiação acústica no refletor no campo distante}

\subsection{Introdução}

Um fator que interfere de forma crucial sobre a força de radiação acústica é a geometria da cavidade acústica. Uma forma de alterar a geometria da cavidade acústica é alterar o diâmetro do refletor ou do transdutor. Neste trabalho, foi feita uma investigação de como a força de radiação acústica sobre o refletor é afetada pela alteração do diâmetro do refletor. Para calcular a força de radiação acústica que atua sobre um refletor é necessario ter o conhecimento prévio dos campos de pressão e velocidade da cavidade acústica, que são necessários para calcular a pressão de radiação acústica sobre a face do refletor. A partir da integração da pressão de radiação acústica sobre a superfície do refletor, obtém-se a força de radiação acústica total sobre o mesmo.

Para obter o campo de pressão e o de velocidade da cavidade acústica é necessário utilizar métodos numéricos, pois não existem soluções analiticas. Neste trabalho, foi utilizado o software COMSOL para calcular os campos de pressão e de velocidade na cavidade acústica. De posse dos valores numéricos dos campos de pressão e velocidade, é utilizada a equação de Gor'kov para calcular o potencial da força de radiação acústica na cavidade. Equação essa utilizada para obter o potencial de radiação acústico, a posição de levitação de um objeto, a força de radiação acústica e a rigidez elástica da mola na cavidade. Estes resultados numéricos obtidos são utilizados como referência para o que deve ser esperado como resultado experimental.

Os trabalhos apresentados por Hong e coautores (HONG et, al., 2014), Xei e Wei (XEI; WEI, 2002 ), Barmatz e Collas (BARMATZ; COLLAS, 1987) e Li e coautores (LI, et al., 2004) procuraram desenvolver estudos analisando os efeitos da geometria da cavidade acústica sobre a força de radiação acústica. Estes autores desenvolveram modelos numéricos e/ou analíticos para realizar as investigações. 
Com essa linha de raciocínio, pretende-se apresentar os resultados simulados e experimentais para um conjunto de refletores com diversos diâmetros.

Neste capítulo, o sistema de levitação é constituído por um transdutor de ultrassom de $31 \mathrm{kHz}$ com face circular plana de $7,5 \mathrm{~mm}$ de raio e por um refletor plano, cujo raio pode variar de $5 \mathrm{~mm}$ a $28 \mathrm{~mm}$. Neste sistema de levitação, é produzida uma onda estacionária entre o transdutor e o refletor, com comprimento de onda de 10,8 $\mathrm{mm}$.

\subsection{Modelo numérico}

O sistema de levitação acústica é modelado no software comercial COMSOL Multiphysics. Devido a simetria do sistema de levitação, o modelo numérico empregado é axissimétrico e é ilustrado na figura 5.2.1. Neste modelo, o transdutor e o refletor possuem faces planas e a face do transdutor vibra harmonicamente na frequência de $31380 \mathrm{~Hz}$ e com amplitude de deslocamento de $2 \mu \mathrm{m}$. Tanto o transdutor quanto o refletor estão imersos no ar. Na região com ar, foi considerada uma velocidade do som de $340 \mathrm{~m} / \mathrm{s}$ e um valor de densidade de $1,2 \mathrm{~kg} / \mathrm{m}^{3}$. Nas extremidades do domínio do ar, aplicou-se um tipo de elemento conhecido como perfectly matched layer (PML) (ANDRADE; ADAMOWSKI, 2016), que é utilizado para absorver as ondas acústicas que atingem as extremidades do domínio, evitando-se assim, reflexões indesejadas. 
Figura 5.2.1- Modelo do sistema de levitação apresentado no software COMSOL, para um transdutor e refletor de faces planas.

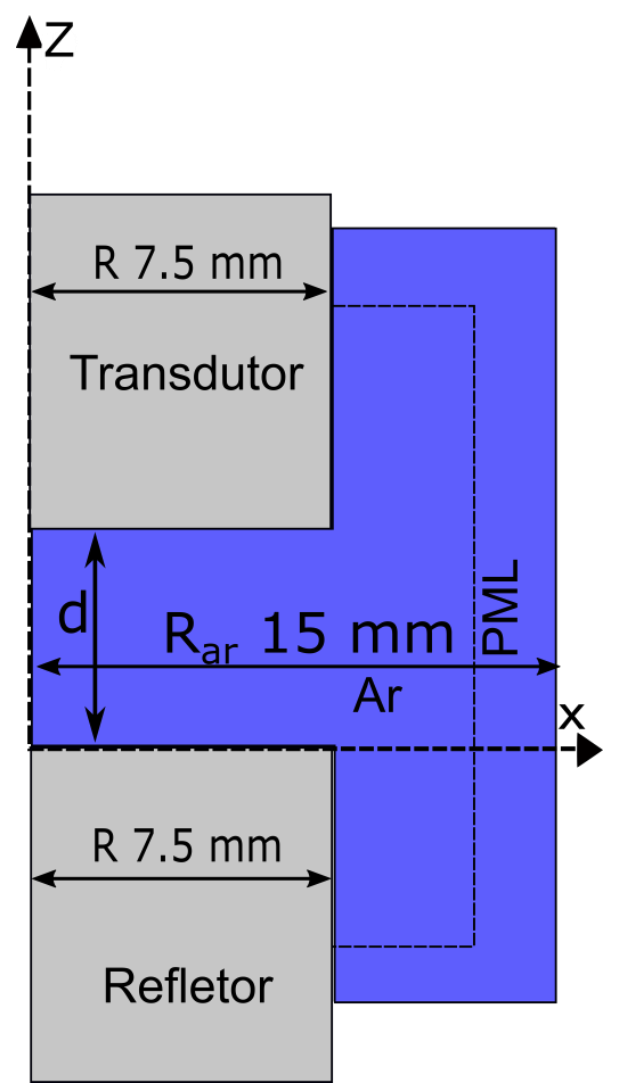

Fonte: Autor

A figura 5.2.2 mostra o perfil do potencial de radiação acústica obtido com o software COMSOL. Na figura nota-se que nas regiões próximas do transdutor e do refletor, têm-se regiões da cor vermelha. Nestas posições, o potencial possui os maiores valores obtidos para a configuração dada. Já para a região de cor azul, posição onde o potencial acústico é mínimo, região onde é possível levitar um objeto. Lembrando que na figura apresenta-se, apenas uma região de levitação para a cavidade acústica, lembrando que este resultado é axissimétrico, ou seja, pode-se rebater este perfil para o lado esquerdo do eixo $z$. Nas demais regiões, longe da região central da cavidade acústica, o potencial acústico tem a cor esverdeada, região onde a onda acústica possui pouca influência. O potencial de radiação acústica apresentado é dado sem o parâmetro geométrico de uma esfera. Portanto, tem-se o potencial de radiação acústico relativo na cavidade. Deste modo, a equação de Gor'kov relativa é dada por: 


$$
\widetilde{U}=\frac{U}{2 \pi R^{3}}=\left(\frac{\left\langle p^{2}\right\rangle}{3 \rho_{0} c_{0}^{2}}-\frac{\rho_{0}\langle\mathbf{u} \cdot \mathbf{u}\rangle}{2}\right)
$$

Figura 5.2.2- Modelo numérico do sistema de levitação acústico com o potencial de Gor'kov relativo para a cavidade com transdutor e refletor de faces planas (COMSOL). Nesta figura, tanto o transdutor quanto o refletor possuem $7,5 \mathrm{~mm}$ de raio.

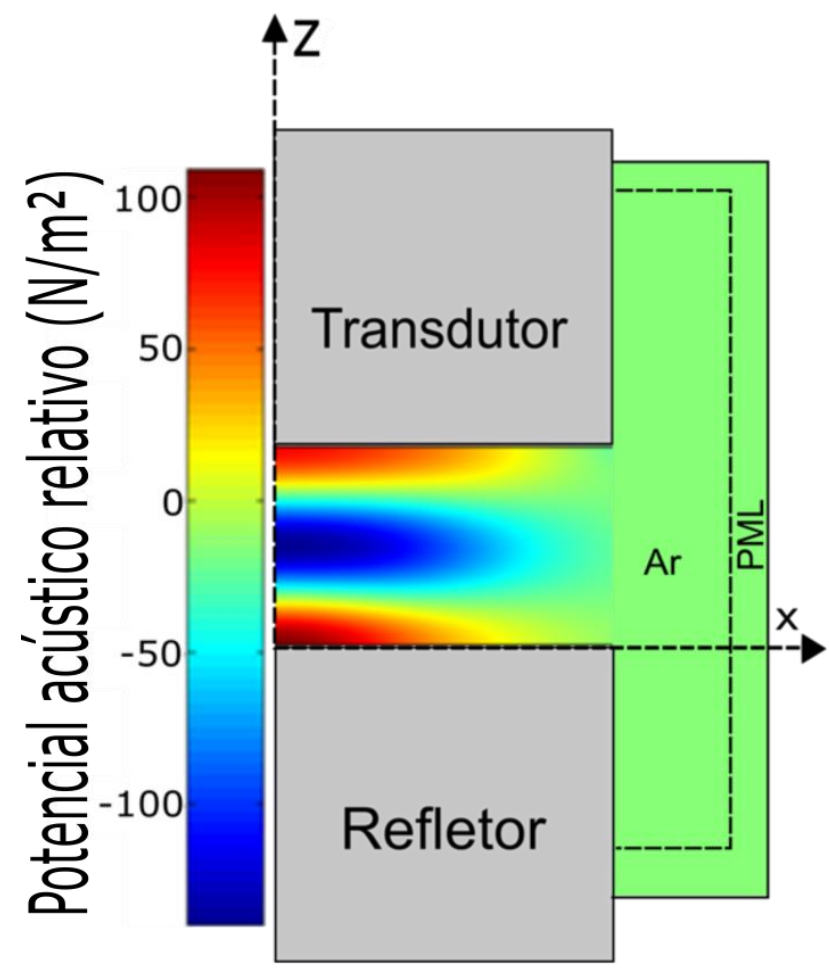

Fonte: Autor

A figura 5.2.2 apresenta o potencial acústico relativo para um caso específico onde o refletor e o transdutor possuem raios iguais. Utilizando um modelo similar ao da figura 5.2.1 foi realizada a simulação da força de radiação acústica que atua no refletor para diferentes valores de raio do refletor. Nestas simulações, o raio do transdutor foi mantido fixo em 7,5 mm e foram realizadas diversas simulações para o raio do refletor variando de $5 \mathrm{~mm}$ a $28 \mathrm{~mm}$. A partir das simulações, foram simulados os campos de pressão e de velocidade entre o transdutor e o refletor. A partir destes campos, e baseando-se no trabalho de Hong e coautores (HONG et al., 2014), foi determinada a pressão de radiação acústica sobre o refletor através da seguinte equação:

$$
p_{a c}=\frac{\left\langle p^{2}\right\rangle}{2 \rho_{0} c_{0}^{2}}-\frac{\rho_{0}\langle\mathbf{u} \cdot \mathbf{u}\rangle}{2}
$$


A partir da distribuição de pressão de radiação, dada pela equação 5.2.2, a força de radiação acústica sobre o refletor é obtida através da integração da pressão de radiação sobre a superfície do refletor. O gráfico da força de radiação sobre o refletor em função do raio do refletor dividido pelo comprimento de onda é apresentado na figura 5.2.3. Para cada valor de raio do refletor foi realizada uma varredura distanciando o transdutor do refletor para encontrar a posição de ressonância das cavidades e, como consequência, a força de radiação acústica máxima para cada valor de raio. A curva apresentada representa a força de radiação acústica máxima para cada raio de refletor. A finalidade deste estudo é encontrar a força de maior intensidade e compreender como a força de radiação acústica se comporta com a mudança da geometria da cavidade acústica na ressonância, região em que a força de radiação acústica é sensível a pequenas mudanças, como apresentado no capítulo 4, em que a força de radiação acústica altera sua intensidade de forma brusca na região de ressonância.

Na figura 5.2.3 nota-se que, para refletores com diâmetros menores que o diâmetro do transdutor, a intensidade da força de radiação acústica é pequena em comparação com a força de radiação acústica para o refletor com $8 \mathrm{~mm}$ de raio. Nesta configuração encontra-se a relação ótima entre o transdutor e o refletor. Para refletores com raios maiores, até $20 \mathrm{~mm}$ aproximadamente, foi observado uma queda da força de radiação acústica sobre o refletor, sendo que, por volta de 21 a 23 $\mathrm{mm}$ de raio constata-se que a força de radiação acústica possui uma intensidade próxima a força encontrada para o refletor com raio de $8 \mathrm{~mm}$. Deste modo, é esperado encontrar uma curva experimental próxima à encontrada no software COMSOL. 
Figura 5.2.3- Modelo numérico para a força de radiação acústica máxima em função de cada raio de refletor de face plana (COMSOL).

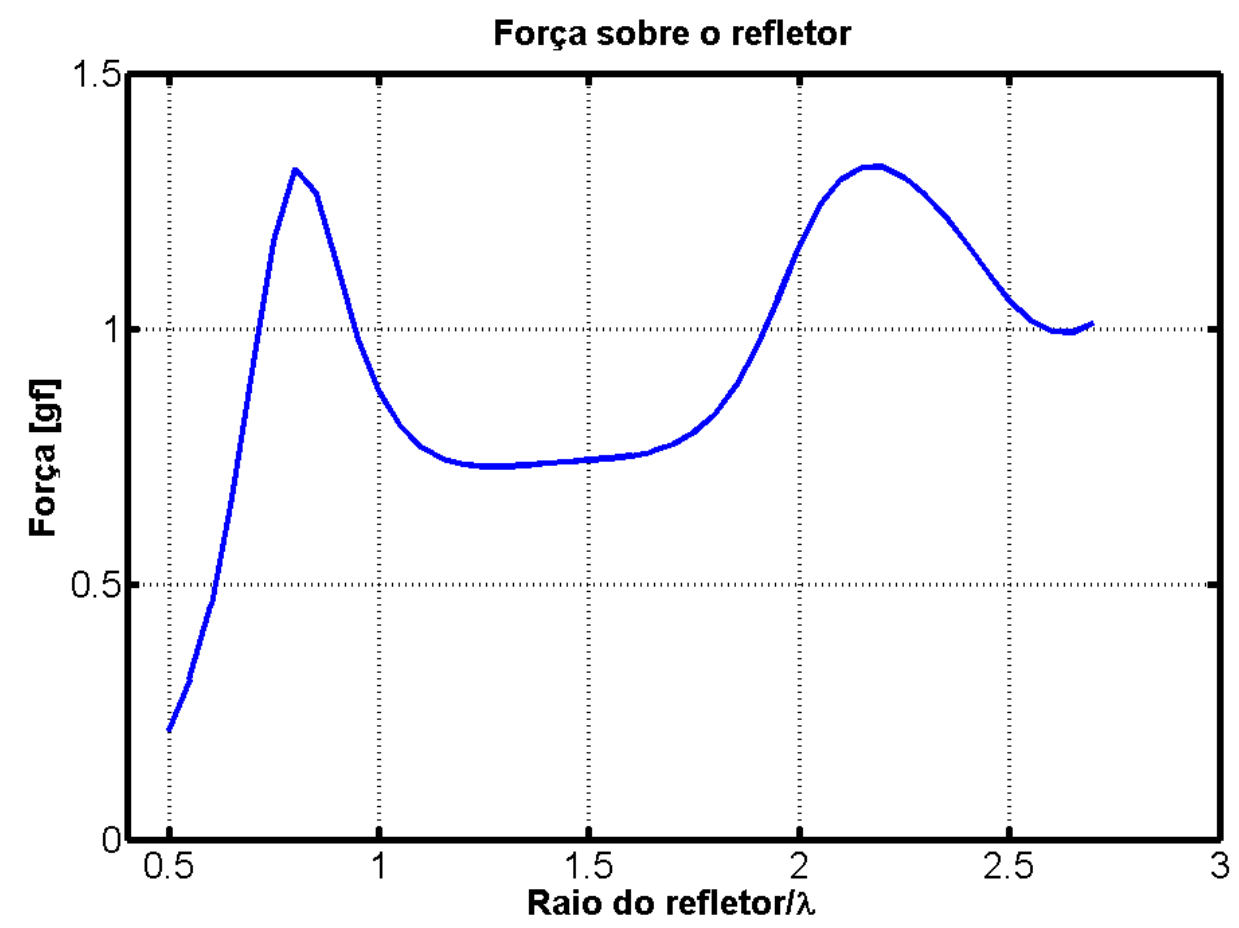

Fonte: Autor

A figura 5.2.4 apresenta o potencial de radiação acústica relativo para dois refletores, calculado pela equação de Gor'kov. O potencial de radiação acústico é calculado para todos os refletores, no entanto apresenta-se o resultado para dois refletores, sendo que uma curva refere-se ao refletor com o diâmetro de $16 \mathrm{~mm}$ e a outra para o refletor com o diâmetro de $24 \mathrm{~mm}$. Para as demais curvas o potencial de radiação acústica segue a tendência de sua respectiva força de radiação acústica apresentada na figura 5.2.3. As curvas apresentadas foram obtidas para as respectivas cavidades em ressonância, posição em que a cavidade possui a intensidade máxima da força de radiação acústica. Nota-se pela figura 5.2.4 que a curva com o menor potencial, $-10 \mathrm{~N} / \mathrm{m}^{2}$, é para o refletor com o diâmetro de $16 \mathrm{~mm}$, curva preta continua, e para este mesmo refletor a cavidade apresenta a maior intensidade da força de radiação acústica, tal efeito nota-se na figura 5.2.3. O potencial apresentado justifica que quanto maior a intensidade da força de radiação acústica sobre o refletor, maior o potencial acústico, o que indica que neste caso é possível levitar esferas mais densas. Vale lembrar que pela derivada segunda do potencial de radiação acústica permite obter a rigidez elástica que será maior para a cavidade que possui o refletor com diâmetro de $16 \mathrm{~mm}$. A curva vermelha tracejada 
da figura 5.2.4 representa o potencial de radiação acústica do refletor com diâmetro de $24 \mathrm{~mm}$, que possui um mínimo pontecial de aproximadamente $-5 \mathrm{~N} / \mathrm{m}^{2}$, em módulo menor que para o refletor de $16 \mathrm{~mm}$ de diâmetro.

Figura 5.2.4- Potencial de radiação acústica relativo, para refletores de faces planas com raios de 8 e $12 \mathrm{~mm}$, com as cavidades acústicas em ressonância.(COMSOL)

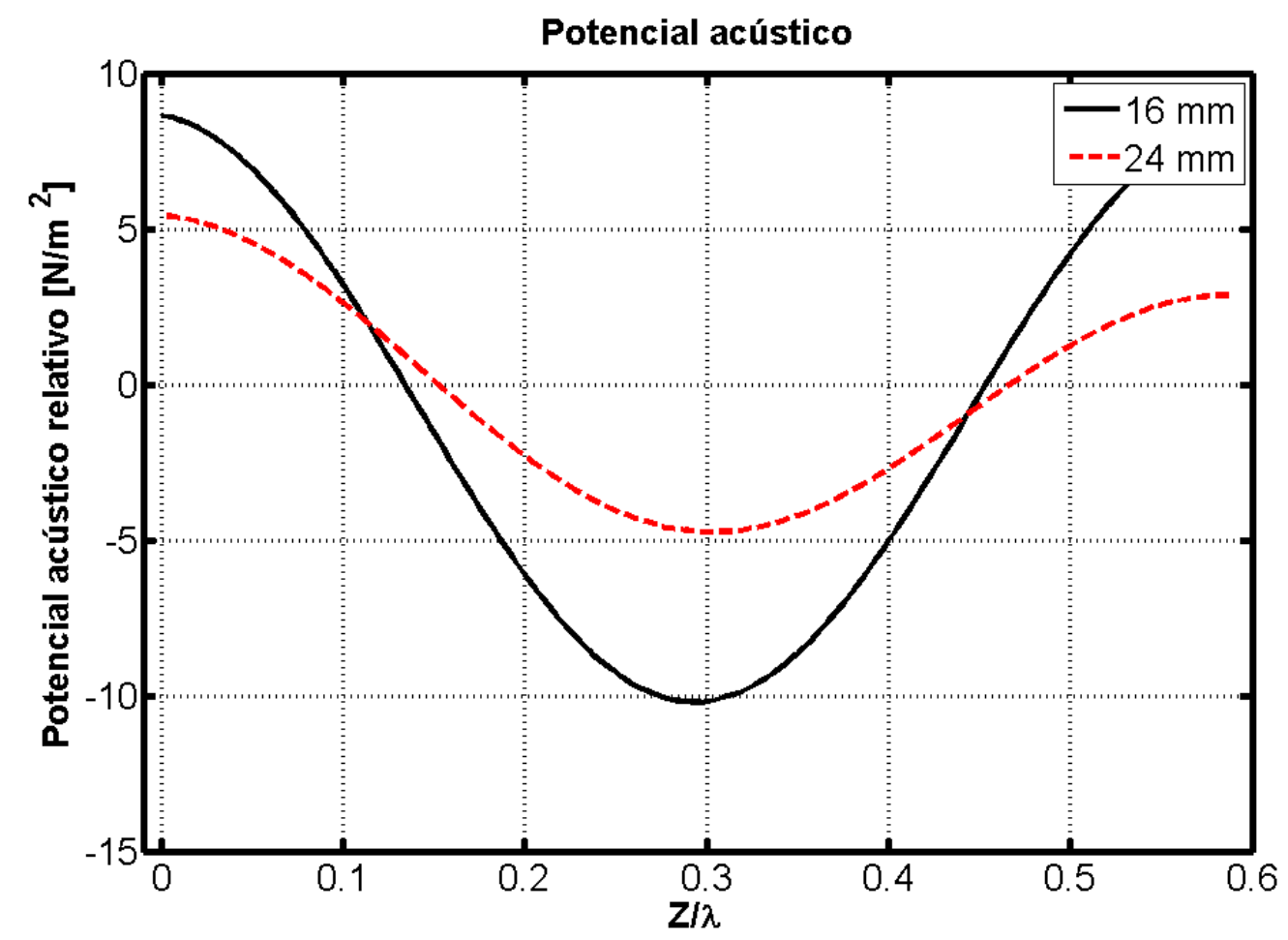

Fonte: Autor

Nas figuras a seguir apresenta-se o perfil da pressão de radiação sobre o refletor. A pressão de radiação acústica sobre o refletor é calculada por meio da equação (5.2.2). Esta equação apresenta dois termos, sendo que o primeiro depende da distribuição de pressão acústica ao longo da superfície do refletor e o segundo depende da distribuição de velocidades. O primeiro termo da equação (5.2.2) produz uma pressão positiva sobre a superfície do refletor, enquanto que o segundo termo é responsável pelo aparecimento de uma pressão negativa.

A figura 5.2.5 apresenta a pressão de radiação acústica total sobre o refletor em função da coordenada radial, na ressonância da cavidade, o que mostra que quanto mais próximo do centro da cavidade acústica, maior será a pressão de radiação 
acústica sobre o refletor. Este perfil é semelhante para todos os refletores utilizados na simulação, mas não com a mesma intensidade, pois cada cavidade acústica possui suas características próprias.

Figura 5.2.5- Pressão de radiação acústica qualitativa sobre o refletor de face plana plano com raio de $8 \mathrm{~mm}$. (COMSOL)

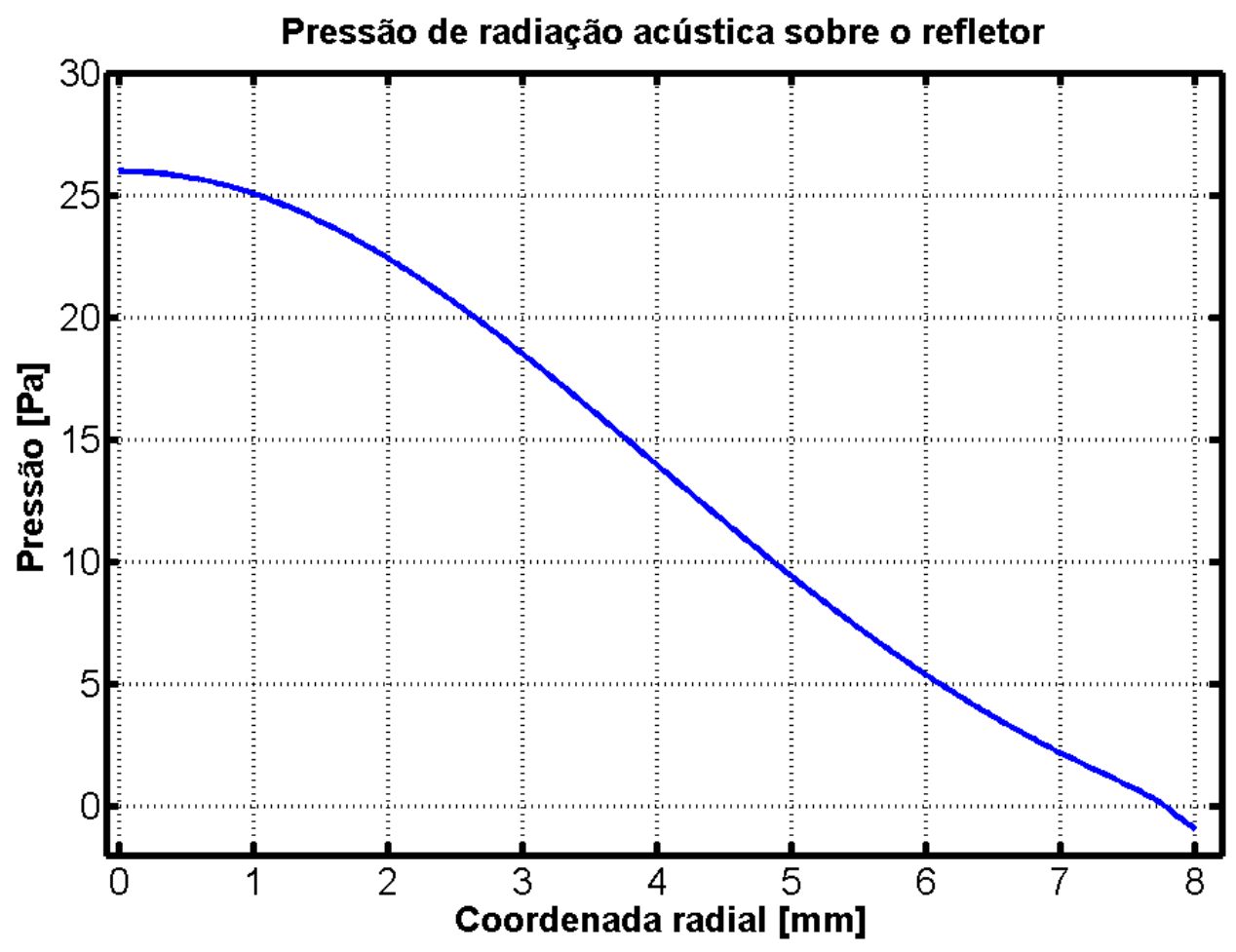

Fonte: Autor 
A partir da equação utilizada é possível notar que há dois termos: o primeiro que representa a energia potencial da cavidade acústica (LEE; WANG, 1993), que apresenta uma curva semelhante a pressão de radiação acústica total sobre o refletor dada na figura 5.2.5, isso indica que este primeiro termo tem maior influência sobre a equação da pressão total, mas com uma intensidade um pouco menor. $\mathrm{Na}$ figura 5.2.6 apresenta-se este perfil.

Figura 5.2.6- Modelo numérico qualitativo do primeiro termo da força de radiação acústica sobre o refletor de face plana com raio de $8 \mathrm{~mm}$ (energia potencial média temporal). (COMSOL)

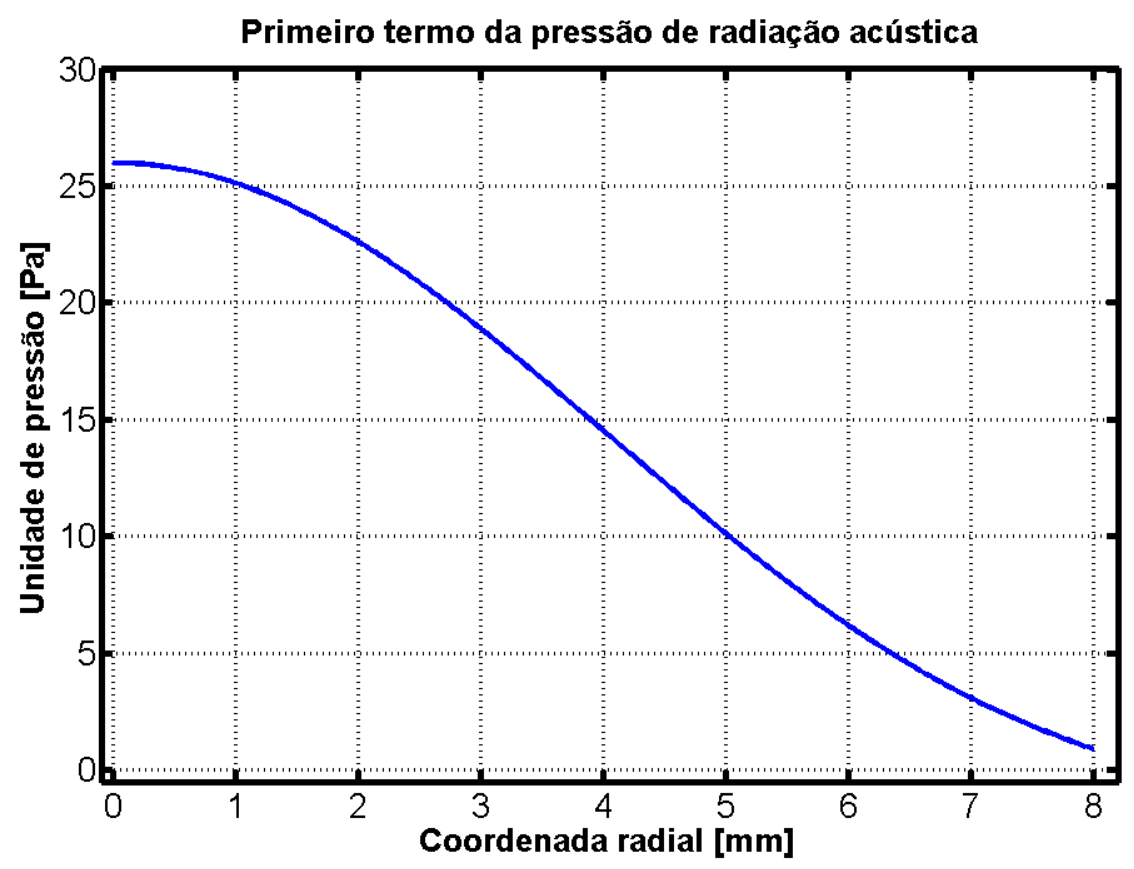

Fonte: Autor 
O segundo termo da equação (5.2.2) representa a energia cinética média da cavidade acústica (LEE; WANG, 1993). Na figura 5.2.7, é apresentada o segundo termo em valor absoluto. Na equação (5.2.2) é possível observar que este segundo termo apresenta um sinal negativo. Fisicamente, este sinal negativo pode ser interpretado como uma pressão negativa sobre a superfície do refletor. A figura 5.2.7, mostra o perfil deste segundo termo, que, quando próximo ao centro do refletor, a energia cinética é baixa e aumenta ao se aproximar da borda do refletor.

Figura 5.2.7- Modelo numérico qualitativo do segundo termo da pressão de radiação acústica sobre o refletor de face plana com raio de $8 \mathrm{~mm}$ (energia cinética média temporal). (COMSOL)

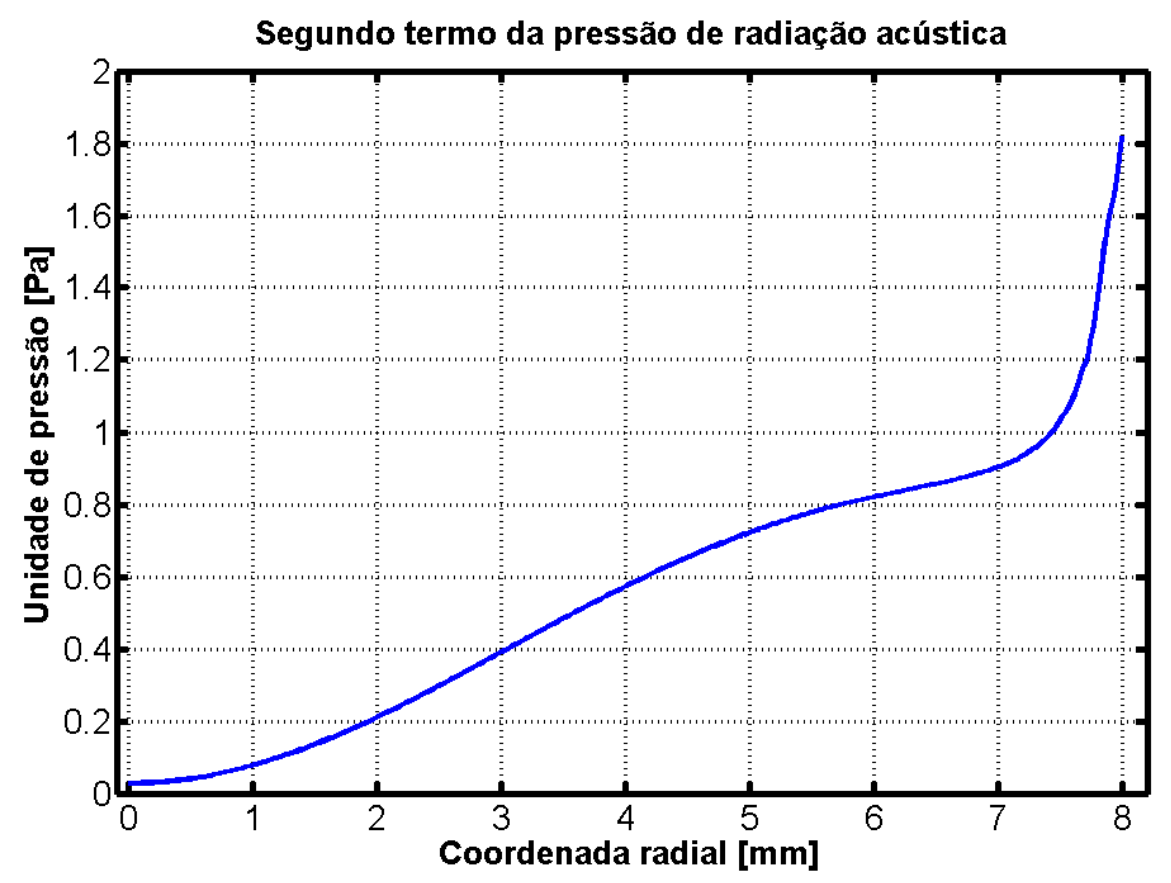

Fonte: Autor 
Observa-se na figura 5.2.8 a intensidade dos perfis apresentados sobre a face do refletor com um visão de topo do refletor, de tal modo que permite verificar como se dá a distribuição de pressão sobre a face do refletor na figura (a) e a distribuição de velocidade sobre a face do refletor na figura (b). Em razão da maior intensidade do primeiro termo, este exerce maior influência sobre a pressão de radiação acústica total sobre o refletor, principalmente na região central do refletor, nas bordas do refletor tem-se o predominio do campo de velocidade. Estes perfis apresentados são para o refletor de $16 \mathrm{~mm}$ de diâmetro na ressonância da cavidade.

Figura 5.2.8- Visão de topo qualitativo do primeiro e do segundo termo sobre o refletor de face plana e raio de $8 \mathrm{~mm}$. (COMSOL)

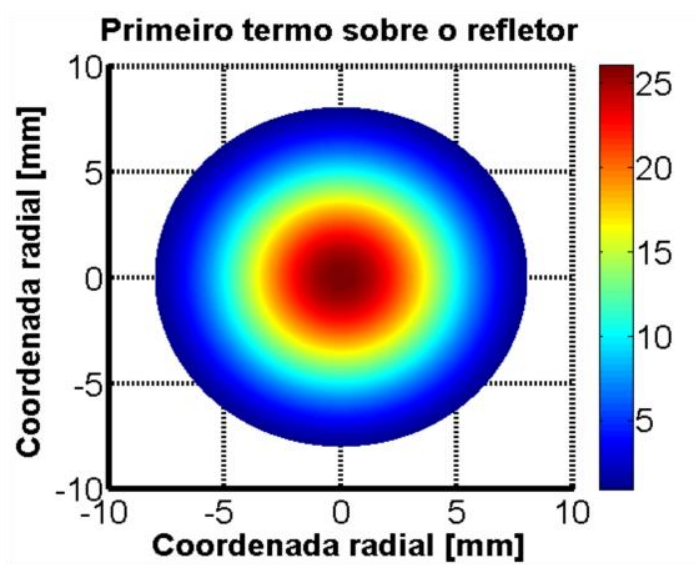

(a)

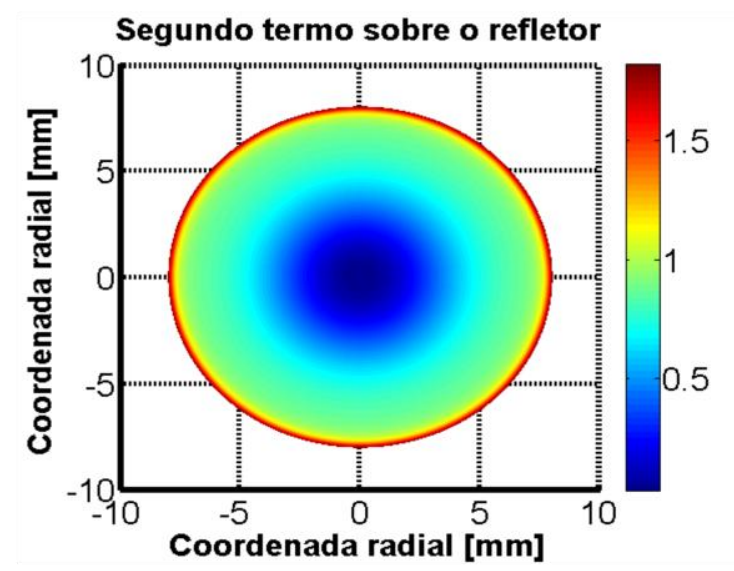

(b)

Fonte: Autor 


\subsection{Aparato experimental}

Na seção 5.2 foi utilizado um modelo numérico para determinar a força de radiação acústica sobre a face de um refletor. Experimentalmente, pode-se utilizar uma balança eletrônica para medir a força de radiação acústica sobre a face de um refletor. Na configuração experimental, assim como na simulação, mantem-se o raio do transdutor fixo, e altera-se o raio dos refletores, assim como a distância entre o transdutor e o refletor em torno da região de ressonância da cavidade acústica, cada refletor possui uma região de ressonância específica.

A figura 5.3.1 ilustra o aparato experimental utilizado para se medir a força de radiação acústica sobre o refletor em função da distância entre a face do transdutor e o refletor. Neste aparato experimental, o transdutor é fixado a um atuador linear motorizado, permitindo que a posição vertical do transdutor seja controlada de forma automática. Na face traseira do transdutor, é utilizado o sensor de fibra ótica (MTI) para monitorar a amplitude de deslocamento da face traseira do transdutor, neste experimento a amplitude foi mantida em torno de $2 \mu \mathrm{m}$. Neste experimento, foram utilizados diversos refletores com raio desde 5 até $52 \mathrm{~mm}$.

O aparato experimental ilustrado na figura 5.3.1 é conectado a um computador que possui códigos em Matlab que controlam o motor de passo e recebe os dados da balança. Este aparato é semelhante ao apresentado no capítulo 4, porém, com um transdutor diferente e sem a câmera de alta velocidade. 
Figura 5.3.1- Aparato experimental utilizado para medir a força de radiação acústica sobre o refletor em função da distância de separação entre a face do transdutor e o refletor.

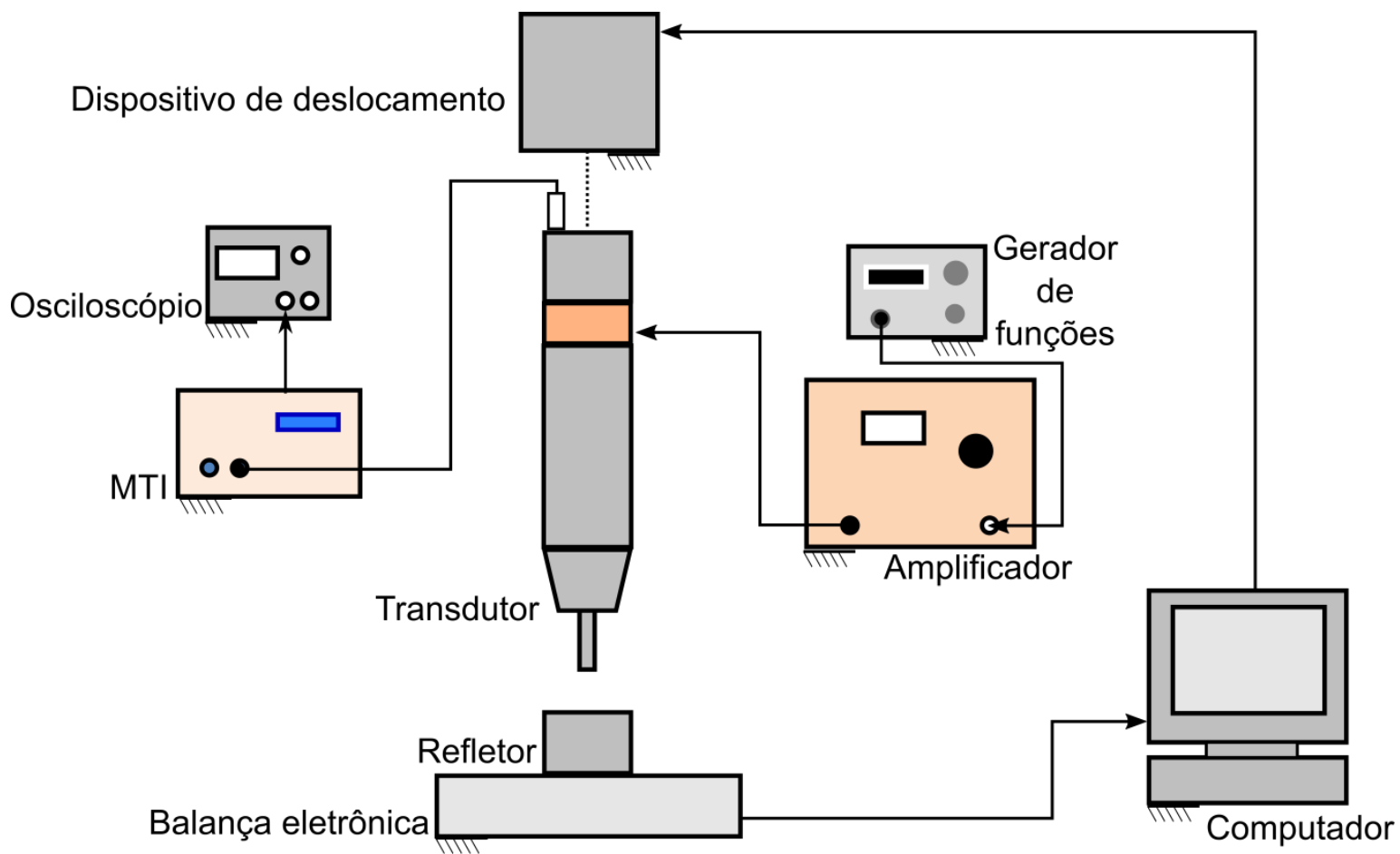

Fonte: Autor

Neste experimento foram utilizados um total 47 refletores. Para cada conjunto transdutor/refletor um alinhamento era realizado para manter o conjunto concêntrico. Lembrando que o transdutor foi mantido fixo e alterava-se o refletor sobre a balança. Assim como no experimento anterior uma proteção foi feita em torno do refletor para que nenhuma onda acústica espalhada pelo sistema atingisse o prato da balança. As varreduras foram repetidas até chegar em uma recorrência de resultados, eliminando qualquer efeito que alterasse a resposta do sistema. 


\subsection{Resultados e Discussão}

Nesta seção serão apresentados os resultados obtidos a partir da configuração experimental apresentada na figura 5.3.1.

A figura 5.4.1 apresenta o gráfico da força de radiação sobre um refletor em função da distância entre o transdutor e o refletor. Neste experimento especificamente, o raio do transdutor foi mantido fixo em $7,5 \mathrm{~mm}$ e o do refletor foi fixado em $11 \mathrm{~mm}$ de raio. Ressalta-se que todo o sistema de alimentação é semelhante ao utilizado para excitar o transdutor apresentado no capítulo 4.

Na realização deste experimento foi utilizado um sistema de levitação acústica com as seguintes características: um transdutor de $31 \mathrm{kHz}$ com uma face de radiação circular de raio $7,5 \mathrm{~mm}$. A face do transdutor possui uma amplitude de deslocamento 6.73 vezes maior em relação à face traseira, onde é realizado o monitoramento da amplitude de deslocamento do transdutor, o comprimento de onda emitida por este transdutor no ar é de 10,8 mm. Durante o experimento alterava-se a distância entre o transdutor e o refletor e, após o deslocamento esperava-se o equilíbrio do sistema e a coleta dos dados na balança era realizada, assim até cessar as requisições desejadas.

A varredura é importante ser realizada para localizar a posição onde a cavidade acústica encontra-se em ressonância, região onde a força de radiação acústica possui maior intensidade. Portanto, para cada refletor utilizado foi encontrado seu respectivo ponto de ressonância que é ligeiramente deslocado de um com relação ao outro refletor. Durante os experimentos e simulações notou-se que quanto maior o diâmetro do refletor, menor a distância encontrada entre o transdutor e o refletor.

Na figura 5.4.1 é apresentado o gráfico da força de radiação acústica sobre um refletor de $11 \mathrm{~mm}$ de raio em função da distância entre o transdutor e o refletor. Pode-se observar nesta figura, que a maior força de radiação acústica ocorre para o primeiro pico. Para os demais picos encontrados, a cavidade acústica também se encontra em ressonância, mas a intensidade da força de radiação acústica é menor. 
Examinando a figura 5.4.1 nota-se que os picos estão igualmente espaçados, em aproximadamente um múltiplo inteiro de meio comprimento de onda, diferente do que foi obtido no trabalho apresentado no capítulo 4 para o transdutor e refletor côncavos. Estes picos possuem uma grande quantidade de pontos, com o objetivo de observar se o comportamento seria semelhante ao do capítulo 4, onde se verificou a queda abrupta da força de radiação acústica, quando deslocado minimamente o transdutor do refletor na posição de ressonância da cavidade, neste experimento o passo de um ponto ao outro é de $5 \mu \mathrm{m}$. Na figura 5.4.1, observa-se que a curva é simétrica em torno do pico.

Figura 5.4.1- Varredura experimental completa para um refletor de face plana com $11 \mathrm{~mm}$ de raio.

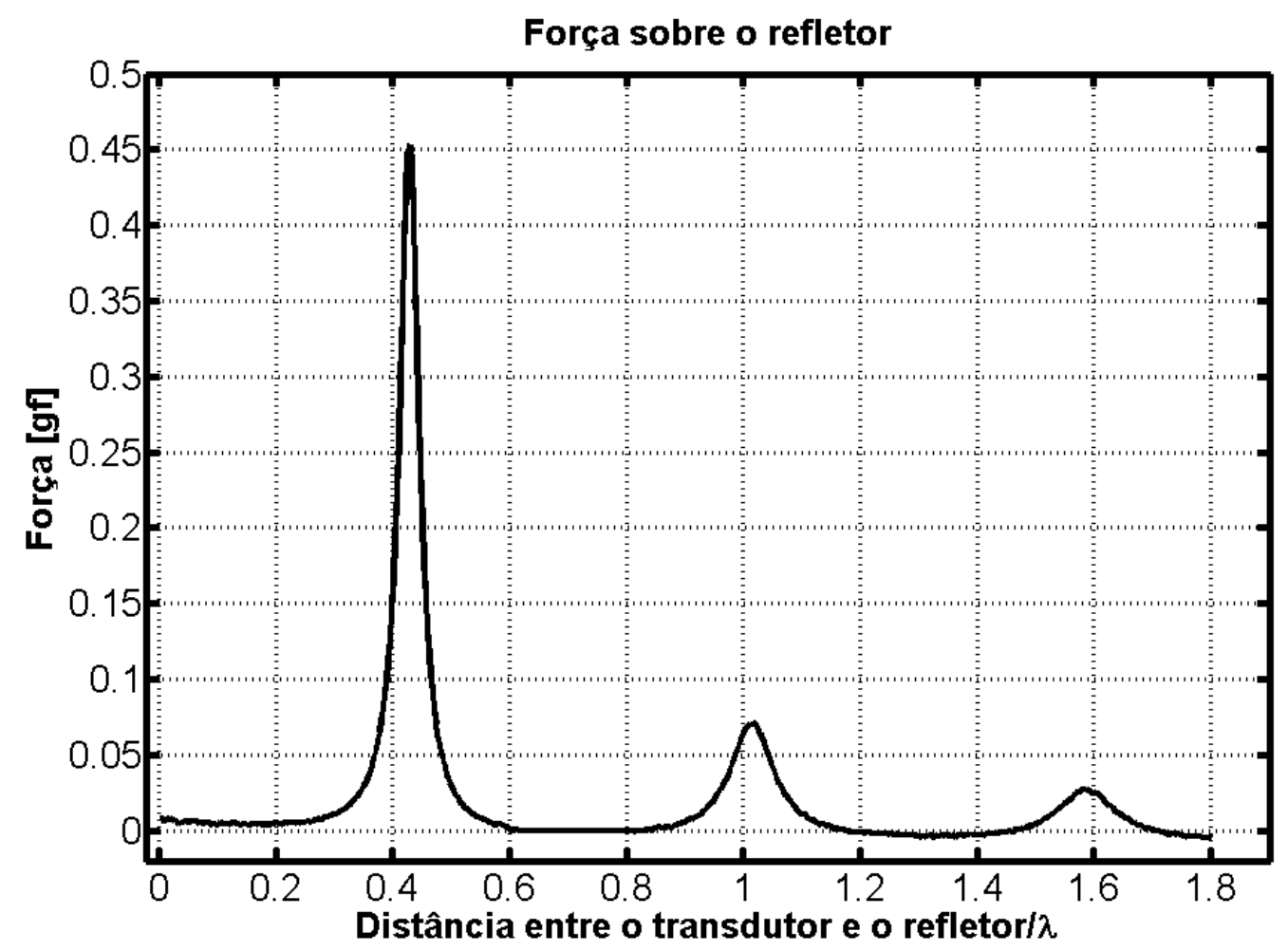

Fonte: Autor

O resultado experimental exposto na figura 5.4.1 permite afirmar que com o aumento da distância entre o transdutor e o refletor, menor será a intensidade da força de radiação acústica sobre o refletor. Este resultado experimental está em concordância com os resultados obtidos por Andrade (ANDRADE, 2010) e Xie e Wei (XIE; WEI, 2002). 
A figura 5.4.2 apresenta três curvas para três refletores de face plana com raios distintos. A curva de maior intensidade é para o refletor com diâmetro de $16 \mathrm{~mm}$, a segunda curva é para o refletor de diâmetro de $24 \mathrm{~mm}$ e, por fim a terceira curva se dá para o refletor com diâmetro de $28 \mathrm{~mm}$. No gráfico notamos que para o refletor de $16 \mathrm{~mm}$ de diâmetro têm-se a força de radiação acústica de maior intensidade, sendo que, para as outras duas curvas, a intensidade da força de radiação acústica é menor.

O refletor com diâmetro de $16 \mathrm{~mm}$ tem diâmetro $1 \mathrm{~mm}$ maior que o diâmetro do transdutor que é de $15 \mathrm{~mm}$, e as curvas experimentais foram obtidas com uma varredura em torno da posição de ressonância das respectivas cavidades. Nota-se pelas curvas apresentadas que a geometria da cavidade acústica possui grande influência sobre a intensidade da força de radiação acústica que atua sobre o refletor.

Figura 5.4.2- Resultado experimental da força de radiação acústica para três refletores de faces planas com diferentes diâmetros na ressonância das respectivas cavidades acústicas.

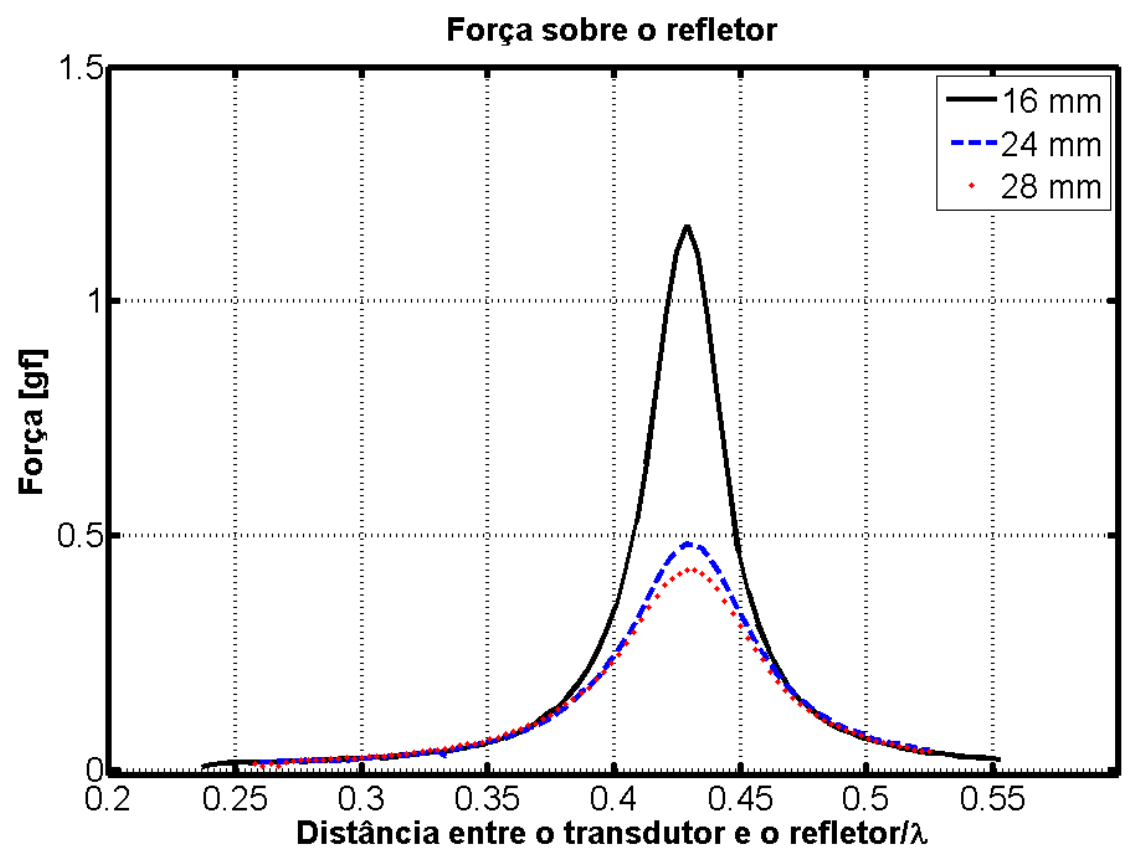

Fonte: Autor 
A figura 5.4.3 apresenta os resultados experimentais da força de radiação acústica máxima para refletroes de 5 a $28 \mathrm{~mm}$ de raio, na ressonância das respectivas cavidades. Estes resultados são utilizados com a finalidade de comparar com os resultados simulados. A região inicial da figura 5.2.3 possui curvatura semelhante ao da figura 5.4.3, onde refletores com raio menor que o raio do transdutor possuem força com intensidade menor, com relação ao refletor com raio de $8 \mathrm{~mm}$, configuração onde a força de radiação acústica possui maior intensidade, tanto no experimental quanto no simulado. Os resultados experimentais apresentados possuem semelhança com os resultados simulados até a configuração para o refletor de raio de $10 \mathrm{~mm}$ aproximadamente.

Após a região do pico, para o refletor de $8 \mathrm{~mm}$ de raio, a força também diminui sua intensidade, assim como ocorreu na simulação. Porém, no simulado a força volta novamente a aumentar sua intensidade, diversamente do resultado experimental obtido, em que a força diminui sua intensidade e oscila entre valores muito menores que o esperado pela simulação, não chegando a metade da força de radiação acústica máxima encontrada para o refletor de raio de $8 \mathrm{~mm}$. 
Na figura 5.4.3 a força tende a ganhar intensidade para um refletor com raio de aproximadamente $16 \mathrm{~mm}$, entretanto, não há correspondencia com o resultado que foi obtido na simulação, onde a força tende a ganhar intensidade novamente para refletores com raio maior que $20 \mathrm{~mm}$.

Figura 5.4.3- Força de radiação acústica máxima experimental para cada raio de refletor de face plana.

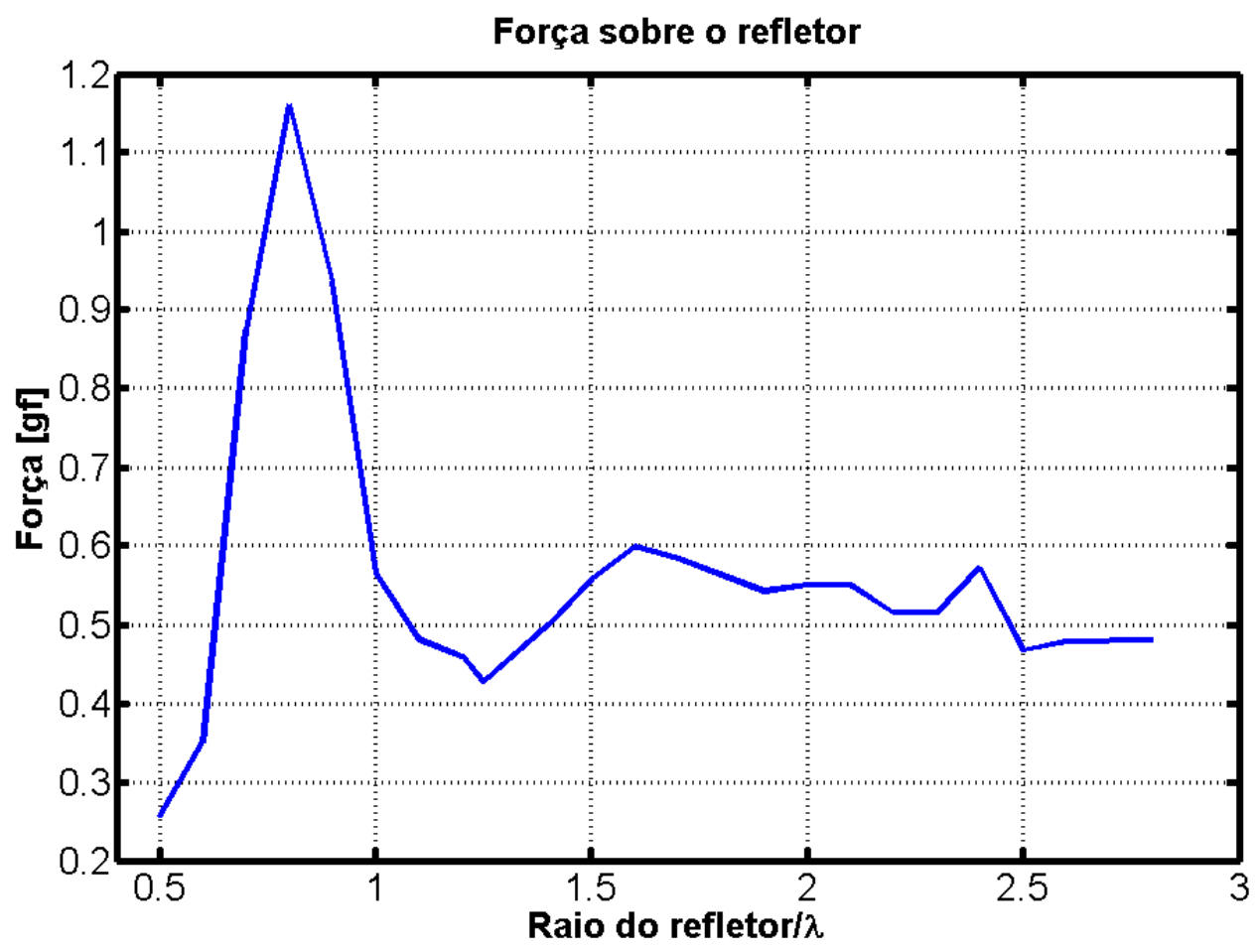

Fonte: Autor 
Na figura 5.4.4, são apresentadas as curvas simulada e experimental, em que temse a força de radiação acústica máxima, na região de ressonância para cada conjunto transdutor/refletor.

Figura 5.4.4- Força de radiação acústica máxima experimental e simulada para cada raio de refletor de face plana.

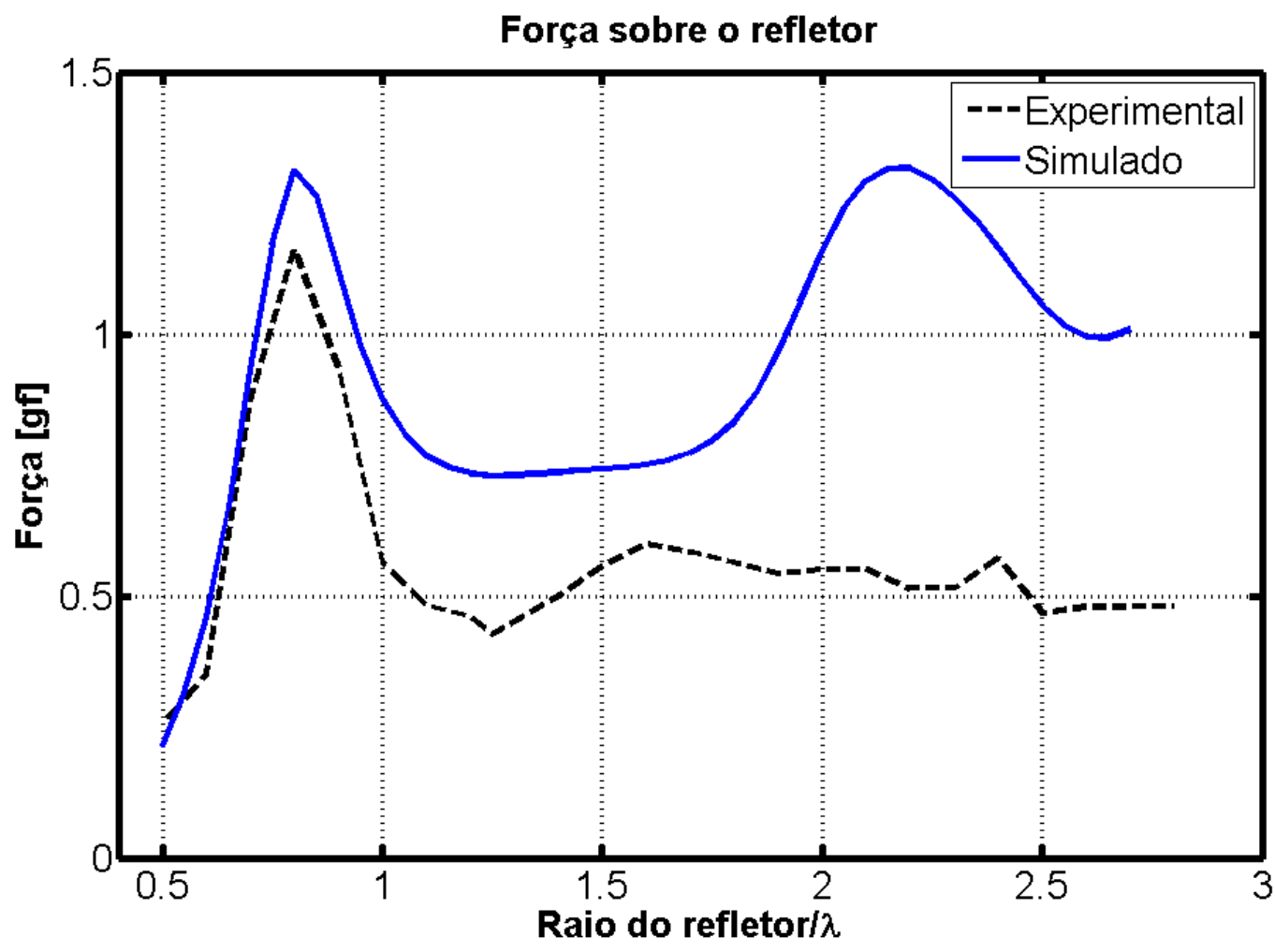

\subsection{Conclusão}

Os resultados encontrados não são intuitivos, pois a força sobre o refletor não é alterada de forma linear como o raio dos refletores. Analisando a região em que as curvas são semelhantes para os resultados simulados e experimentais, conclui-se que quanto maior a força de radiação acústica sobre o refletor, maior será o potencial acústico, em módulo, para o referido refletor. E, quanto maior a intensidade do potencial de radiação acústica, maior será a rigidez elástica da cavidade.

A configuração que se obtem a força de radiação acústica de maior intensidade é para um transdutor com raio de $7,5 \mathrm{~mm}$ e um refletor com raio de $8 \mathrm{~mm}$, com curvas 
semelhantes tanto experimentalmente como simulado. Para os demais refletores com raio maior que $10 \mathrm{~mm}$ as curvas são bem diferentes entre o simulado e o experimental, todavia, os valores númericos da força de radiação acústica simulada e experimental possui uma razoável diferença entre si.

Portanto:

- Os resultados não são intuitivos, provavelmente há a reflexão de ondas acústicas na borda do refletor, gerando ondas destrutivas na cavidade diminuindo a força de radiação acústica sobre o refletor;

- Com este experimento podemos afirmar que quanto maior a intensidade da força de radiação acústica sobre o refletor, maior o potencial de radiação acústico e maior será a rigidez elástica da mola acústica, sendo possível levitar esferas de maior densidade;

- A simulação possui razoável compatibilidade com os resultados experimentais para a faixa de refletores menores até aproximadamente $10 \mathrm{~mm}$;

- A maior força de radiação acústica ocorre para uma relação ótima entre o transdutor com diâmetro de $15 \mathrm{~mm}$ e do refletor de $16 \mathrm{~mm}$.

- Quanto maior o diâmetro do refletor mais próximo o transdutor deve ser posicionado do refletor para encontrar a região de ressonância do sistema acústico. 


\section{Levitação acústica de campo próximo}

\subsection{Introdução}

Levitação acústica de campo próximo é uma técnica onde um objeto plano pode ser levitado bem próximo à face emissora de um transdutor de ultrassom. Na levitação de campo próximo não há a necessidade de se utilizar um refletor, como apresentado nos trabalhos referentes aos capítulos 4 e 5 . Na levitação de campo próximo, o próprio objeto atua como "refletor" e tipicamente ele levita a uma altura de dezenas de micrometros de distância da superfície do transdutor, que possui uma face que vibra harmonicamente em uma determinada frequência. Na levitação de campo próximo usual, a onda gerada entre o transdutor e o objeto aplica uma pressão de radiação de radiação acústica positiva, fazendo com que o objeto levite afastando-se até certa distância da superfície do transdutor, isto ocorre para um transdutor com sua face emissora voltada para cima. Entretanto, existem resultados na literatura que mostram que dependendo da geometria do sistema de levitação também é possível gerar uma pressão negativa, fazendo com que o objeto seja atraído para próximo do transdutor. O intuito do trabalho realizado neste capítulo é identificar como força de radiação permuta de positiva para negativa.

Em grande parte dos trabalhos estudados, a face emissora do transdutor é apontada para cima (HASHIMOTO; KOIKE; UEHA, 1996), (HASHIMOTO; KOIKE; UEHA, 1998), (NOMURA; KAMAKURA, 2002), (HATANAKA, et al., 1999). Como o indicado na figura 6.1.1. Nesta técnica de levitação o transdutor e o objeto devem possuir suas faces planas, e devem ser dispostos paralelamente, face a face.

Nesta configuração, a dinâmica do sistema gera uma pequena camada de ar que mantém o transdutor e o objeto separados por uma pequena distância (NOMURA; KAMAKURA, 2002). Porém, também é possível levitar objetos planos com a configuração onde o transdutor dirige a sua face emissora para baixo. Entre o transdutor e o objeto levitado também surge uma fina camada de ar (BAO; YANG, 
2007), (YANO et al., 2011). A distância entre ambos é bem menor que o comprimento da onda emitida (LI et al., 2010).

Essa fina camada de ar entre o levitador e o objeto é de extrema importância para a dinâmica de diversos dispositivos tais como: micro acelerômetros, micro ressonadores, motores ultrassônicos, micro atuadores, e espelho de torção (LI, 1999), transporte e manipulação de amostras (TAKASAKI et al, 2010), (HATANAKA et al., 1999) maquinas de grande precisão sem contato (CHEN et al., 2014). A espessura da camada de ar tem grande influência na dinâmica do sistema de levitação de campo próximo (MINIKES; BUCHER, 2003).

Segundo Yano e colaboradores, a distância entre a face emissora e o objeto é proporcional à amplitude de vibração da face, isto para o trabalho apresentado com um transdutor na vertical com a face vibrante apontando para cima (YANO et al., 2011).

A figura 6.1.1 apresenta o esquema de levitação mais utilizado em pesquisas relacionadas a levitação de campo próximo, onde o transdutor está na região inferior e o objeto posicionado na parte superior. Conforme a figura 6.1.1, há a representação da força de radiação acústica repulsiva que atua sobre o objeto, região onde é possível observar experimentalmente uma fina camada de ar entre ambos. Tal efeito ocorre em função da dinâmica do sistema, da força de radiação acústica aplicada e do peso do objeto.

Figura 6.1.1- Esquema simplificado de levitação de campo próximo, com a face plana emissora direcionada pra cima, amostra de face plana.

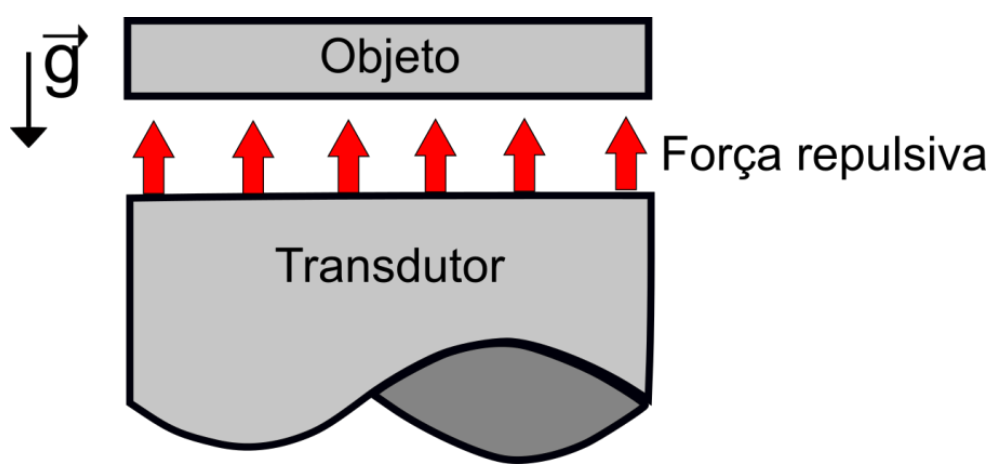

Fonte: Autor 
Hashimoto e coautores garantem que com essa técnica é permitido levitar objetos de até 10 kgf (HASHIMOTO; KOIKE; UEHA,1998). Na levitação de campo próximo, é possível levitar objetos maiores do que o comprimento de onda a uma altura de dezenas de micrometros da face do transdutor. Uma variação da técnica permite levitar grandes objetos a uma altura maior. Neste caso, é produzida uma onda estacionária entre um conjunto de transdutores e o objeto (ANDRADE; BERNASSAU; ADAMOWSKI, 2016).

Outro método de levitação acústica de campo próximo se dá por meio da utilização do transdutor com a face emissora direcionada para baixo. Nesta configuração é desejável que a força de radiação acústica atue de forma atrativa sobre o objeto e não de forma repulsiva, como no caso do transdutor com a face direcionada para cima.

Para Takasaki e coautores a força negativa atua em uma faixa de distância entre 20 e 40 micrometros, sendo esta proporcional à distância entre o transdutor e o objeto. Destacam os autores que a força atrativa deixa de atuar sobre o objeto quando a distância é de aproximadamente 200 micrometros entre a face emissora e o objeto, ao mesmo tempo em que, para uma distância menor que 20 micrometros a força atuante é repulsiva (TAKASAKI et al., 2010).

Com o objetivo de caracterizar o campo acústico na levitação de campo próximo, foi utilizado a equação apresentada por Hong (HONG et al, 2014), para determinar numericamente para quais diâmetros de transdutor, a força de radiação acústica é negativa e como o objeto ira se comportar submetido a força de radiação acústica em dada configuração. No entanto, as atuais soluções numéricas não possuem uma boa aproximação para os resultados experimentais, porém em casos muito específicos a solução numérica corresponde ao resultado analítico (MINIKES e BUCHER, 2006).

O modelo numérico utilizado é definido pela pressão radiação acústica total sobre a face de um anel, tal equação é a apresentada em 6.1.1 e elaborada por Lee e Wang (LEE; WANG, 1993). 


$$
p_{a c}=\frac{\left\langle p^{2}\right\rangle}{2 \rho_{0} c_{0}^{2}}-\frac{\rho_{0}\langle\mathbf{u} \cdot \mathbf{u}\rangle}{2}
$$

Na figura-se 6.1.2 apresenta a relação entre a força de radiação acústica e a distância entre o anel e o transdutor com a face direcionada para baixo, nesta simulação o transdutor é afastado gradativamente do anel. Foi utilizado um anel, pois no capítulo anterior deste trabalho, observou-se que a maior intensidade da pressão ocorre no centro do objeto, sendo assim, utiliza-se o anel para eliminar essa região central, e consequentemente obtendo uma maior influência do campo de velocidade que atua nas bordas dos objetos.

A figura 6.1.2 apresenta o resultado numérico, obtido por meio da utilização do software comercial COMSOL, que simula a força de radiação acústica aplicada sobre a face plana de um anel. $O$ anel utilizado no experimento possui $1 \mathrm{~mm}$ de espessura, $10 \mathrm{~mm}$ de diâmetro externo, $3 \mathrm{~mm}$ de diâmetro interno e força peso de $0.386 \mathrm{gf}$, o transdutor simulado também possui as mesmas características do transdutor utilizado experimentalmente, onde a face emissora possui $10 \mathrm{~mm}$ de diâmetro, a relação de amplitude de deslocamento de entre a face dianteira e traseira é de 18.8, semelhante ao que é esperado experimentalmente. 
O modelo simulado no software COMSOL apresentou uma força com grande intensidade negativa, -12 gf, quando o anel se encontra muito próximo da face emissora do transdutor e, na medida em que se simula o afastamento do transdutor do anel a intensidade da força de radiação acústica sobre a face do anel aproximase de zero. Com uma força de radiação acústica igual a zero, o sistema não é capaz de levitar objetos, seja atuando com uma força de radiação acústica atrativa ou repulsiva.

Figura 6.1.2- Modelo numérico da força de radiação acústica em função da distância entre o transdutor e o anel de faces planas. (COMSOL)

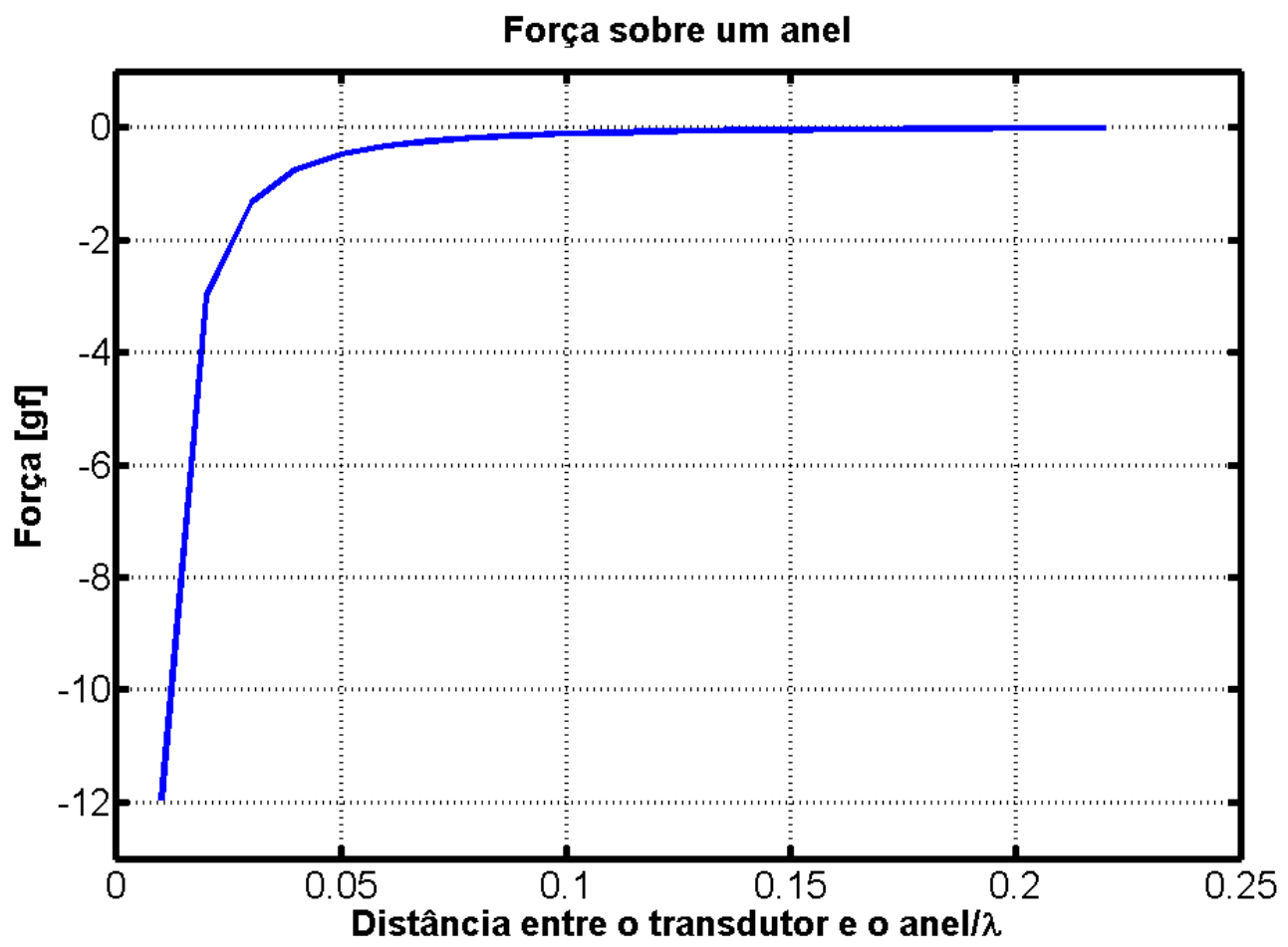

Fonte: Autor 
Nas figuras a seguir será apresentado o perfil dos termos da equação apresentada por Lee e Wang (LEE; WANG, 1993) de forma qualitativa, com o fim de possibilitar a compreensão de como estes parâmetros atuam sobre o objeto.

A figura 6.1.3 mostra um perfil da pressão de radiação acústica total sobre a face do anel. O conhecimento do perfil de pressão permite estimar como ocorrerá a levitação no experimento de campo próximo. Na simulação a face emissora do transdutor é direcionada para baixo.

Figura 6.1.3- Modelo numérico qualitativo da pressão de radiação acústica total sobre o raio do anel de face plana. (COMSOL)

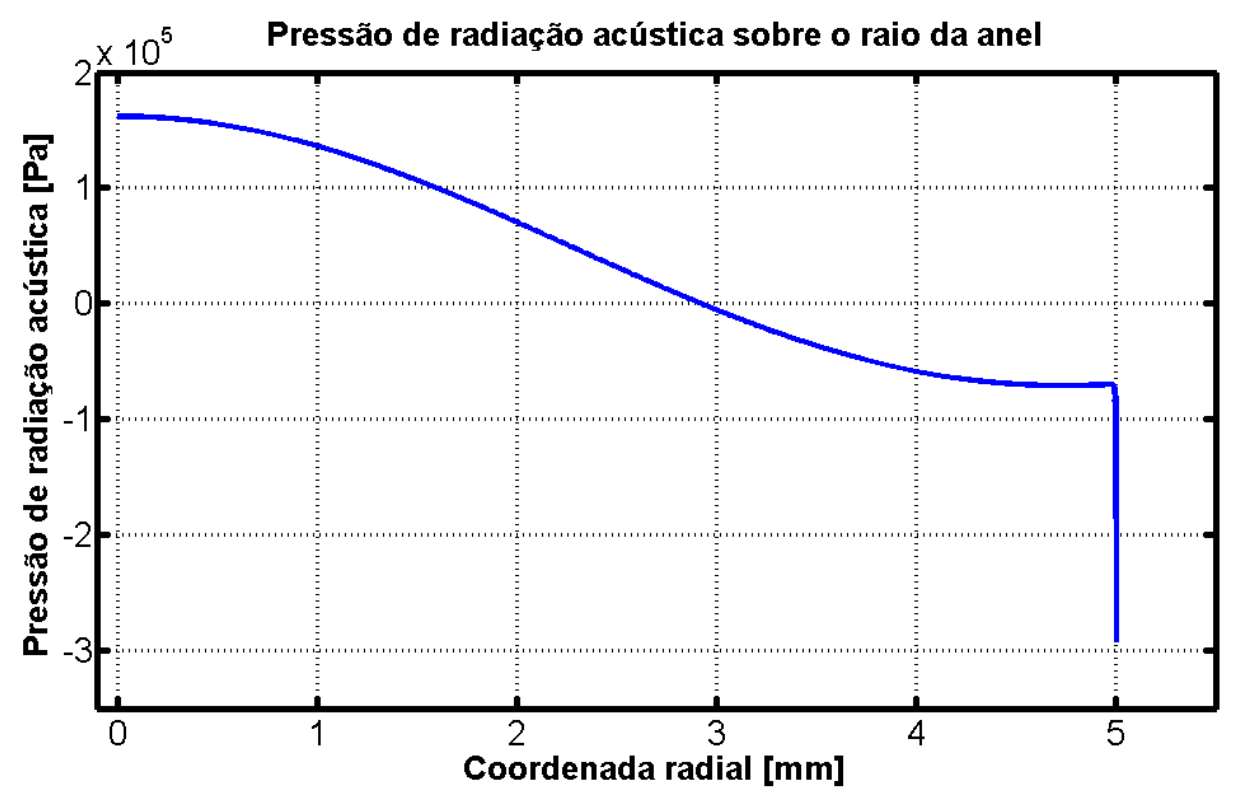

Fonte: Autor 
Na figura 6.1.4 temos o perfil do primeiro termo da equação utilizada por Hong e, neste caso, o perfil apresentado é ligeiramente diferente da pressão de radiação acústica, pois na imagem anterior notamos que há uma região negativa da pressão de radiação acústica. Pela figura 6.1.3 notamos que temos alta pressão no centro do refletor e uma baixa pressão na borda devido ao termo de velocidade.

Figura 6.1.4- Modelo numérico qualitativo do primeiro termo da pressão de radiação acústica total em função do raio do anel de face plana. (COMSOL)

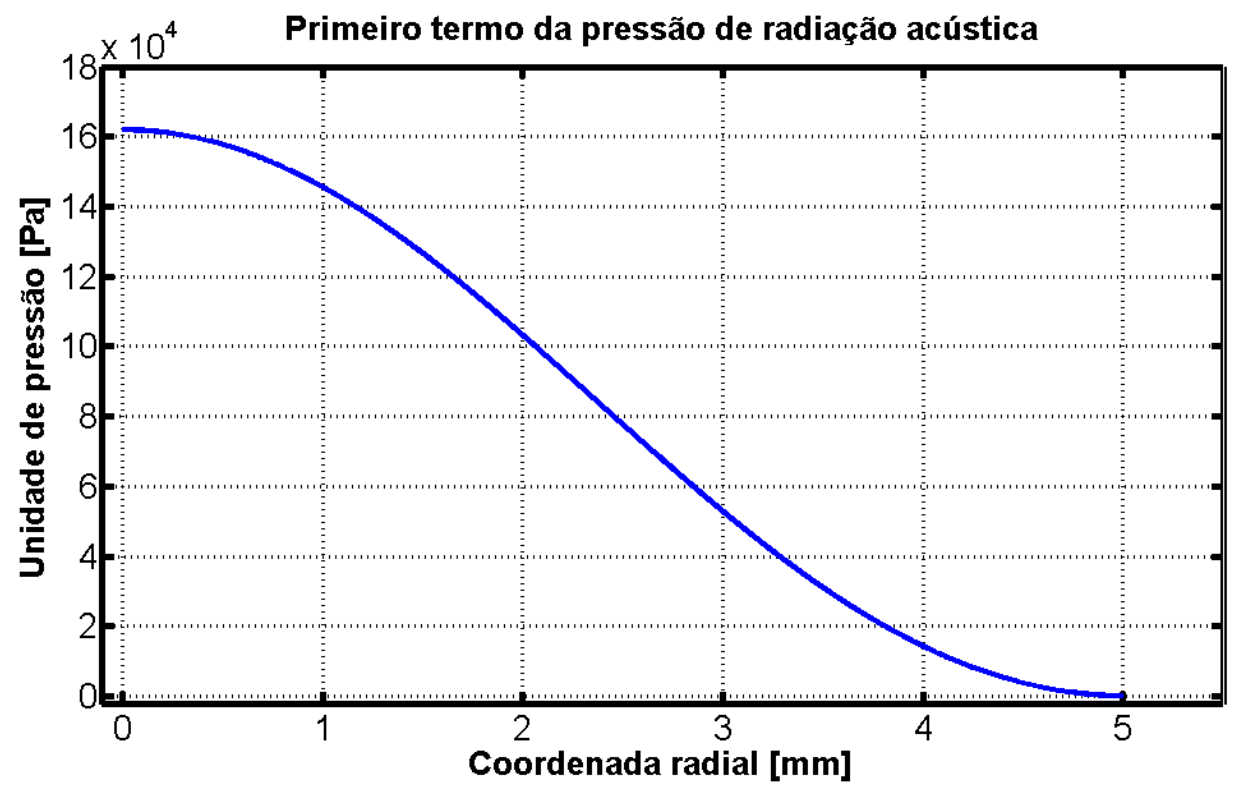

Fonte: Autor 
A figura 6.1.5 apresenta o segundo termo da pressão de radiação acústica sobre o anel, neste caso, tem-se qualitativamente o valor absoluto obtido na simulação pelo software COMSOL, o que permite notar que há uma grande velocidade nas bordas do anel e baixa velocidade no centro anel.

Figura 6.1.5- Modelo numérico qualitativo do segundo termo da pressão de radiação acústica em função do raio do anel de face plana. (COMSOL)

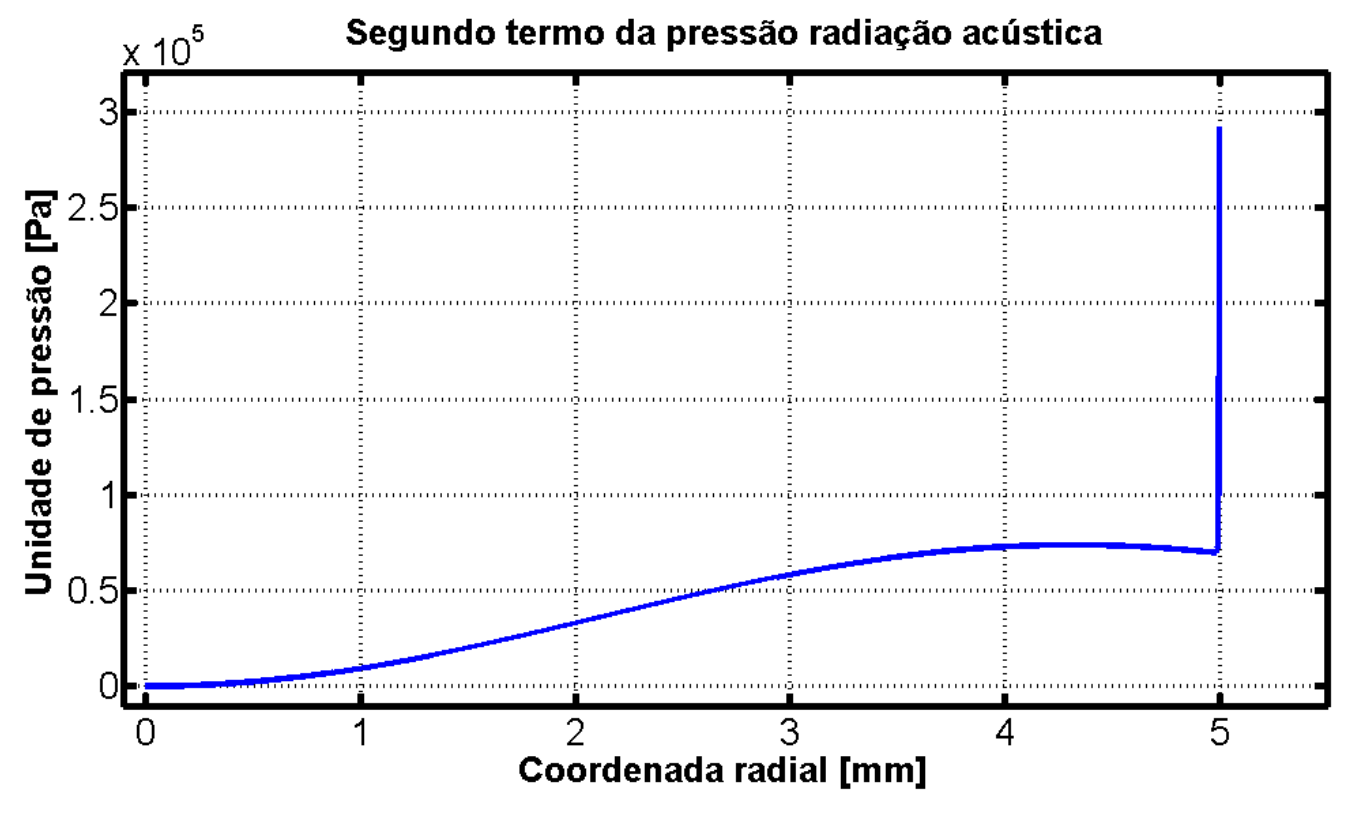

Fonte: Autor

Dos dados apresentados na figura 6.1.5, se pode compreender o porquê na figura 6.1.3, a pressão de radiação acústica total sobre o anel, tem valor negativo na borda do anel. Contudo, não se pode afirmar que a pressão de radiação acústica que atuará sobre o sistema experimental, seguirá exatamente as características apresentadas pelo modelo numérico. Minikes e Bucher também apresentam tal problemática da relação entre os modelos simulados e analíticos, com resultados experimentais (MINIKES; BUCHER, 2006). A equação apresentada por Hong e coautores (HONG et al., 2014) não apresentam resultados satisfatórios quando comparados com os resultados experimentais, neste trabalho. 


\subsection{Aparato experimental}

Para o desenvolvimento deste trabalho experimental foi utilizado um transdutor de $23090 \mathrm{~Hz}$, com um amplificador circular de $10 \mathrm{~mm}$ de diâmetro, capaz de amplificar a amplitude de deslocamento da face dianteira em $18.80 \mathrm{com}$ relação a face transeira onde monitora-se a amplitude de deslocamento do transdutor.

Neste experimento utilizamos um anel de face plana com $10 \mathrm{~mm}$ diâmetro externo e $3 \mathrm{~mm}$ de diâmetro interno, expessura de $1 \mathrm{~mm}$ e peso de $0.386 \mathrm{gf}$. A forma de levitação proposta foi de levitar 0 anel de forma diferente ao dos diversos experimentos encontrados na literatura, onde usualmente o transdutor encontra-se na vertical com a face emissora apontando para cima e o objeto é acomodado sobre o transdutor (MINIKES; BUCHER, 2002), (YANO et al., 2011).

No experimento proposto o transdutor é posicionado na vertical, porém, com a face sua emissora direcionada para baixo (CHINO et al., 2011) (TAKASAKI et al., 2010),(UCHIAGE et al., 2014) e (HATANAKA, et al., 1999). O objetivo deste experimento é observar se há uma força negativa que tenha intensidade suficiente para aproximar o objeto do transdutor. A força sobre o objeto em determinadas distâncias será negativa (TAKASAKI et al., 2010). 
A figura 6.2.1 apresenta um diagrama do sistema experimental utilizado para obter os resultados experimentais que serão apresentados nos resultados e discussões deste capítulo. Nesta configuração experimental o anel foi fixado sobre um refletor com um furo concêntrico ao anel e estes posicionados sobre a balança eletrônica para obter a força de radiação acústica que atua sobre a face deste anel.

Figura 6.2.1- Esquema simplificado do sistema de aquisição de dados da força de radiação acústica sobre o um anel de face plana, com uma balança eletrônica.

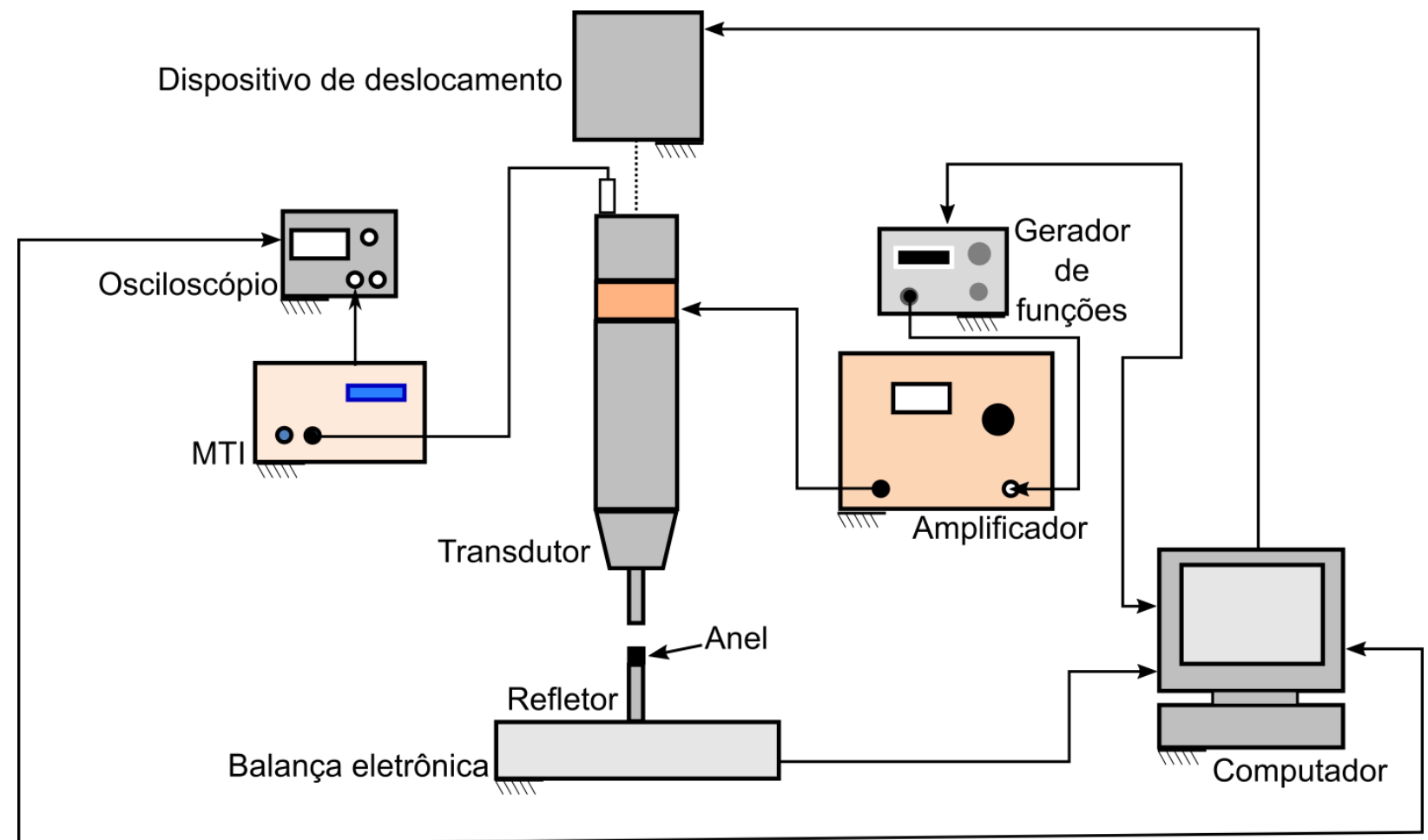

Fonte: Autor

A partir da montagem apresentada na figura 6.2.1 foi possível extrair os resultados experimentais da força de radiação acústica atuando sobre a face do conjunto em questão (anel-refletor), que serão apresentados no decorrer deste capítulo.

A fim de manter o controle da amplitude de deslocamento da face traseira do transdutor, um novo código em Matlab foi elaborado. Neste código realiza-se uma leitura do sinal no osciloscópio, visando verificar se a amplitude de deslocamento da face traseira encontra-se com o deslocamento pretendido. Se o deslocamento não 
possui a amplitude desejada, um sinal é enviado ao gerador de função para variar o sinal até atingir a amplitude desejada na face traseira do transdutor.

A relevância do referido mecanismo de controle se deve pelo fato de, a amplitude de deslocamento da face do transdutor variar muito durante a varredura e de forma repentina de uma posição para outra. Sem este controle as curvas eram distorcidas, apesar de melhorar o aspecto das curvas mantendo a amplitude da face do transdutor constante. Ainda assim, para algumas amplitudes as curvas ficam distorcidas.

Este controle garante que a todo instante, durante a varredura para a obtenção da força de radiação acústica sobre a face do anel terá exatamente a mesma amplitude de deslocamento da face traseira, como indicado nas curvas que serão apresentadas na seção 6.3. Por fim, ressalta-se que há uma relação entre a amplitude de deslocamento da face traseira e a dianteira, sendo possível obter a amplitude de deslocamento da face dianteira indiretamente. 


\subsection{Campo próximo força de radiação acústica positiva}

Diversos experimentos foram realizados com transdutores com amplificador de diâmetro maiores que $10 \mathrm{~mm}$. Com a finalidade de observar o comportamento da força de radiação acústica no campo próximo para os transdutores, a configuração do sistema de controle e alimentação do sistema de levitação foi mantida e os transdutores foram posicionados na vertical com a face emissora das ondas acústicas direcionado para baixo. Os transdutores utilizados nestes experimentos possuem diâmetros e frequências de trabalho diferentes entre si.

A figura 6.3.1 apresenta os resultados experimentais para um transdutor com amplitudes de deslocamento de 3,36 e 5,05 $\mu \mathrm{m}$. O transdutor possui um amplificador de $15 \mathrm{~mm}$ de diâmetro e um refletor de $16 \mathrm{~mm}$, ambos de faces planas, frequência de trabalho de $31 \mathrm{kHz}$, a relação entre a amplitude de deslocamento da face traseira com relação a amplitude de deslocamento da face dianteira é de 6.73 , e comprimento de onda de 10,8 mm. Para este experimento utilizou-se apenas duas amplitudes de deslocamentos, pois as curvas para outras amplitudes para o campo próximo ficaram distorcidas, com muita variação entre um ponto e outro. Nos resultados obtidos constatou-se, que o força de radiação acústica atua de forma positiva sobre o refletor, sendo condição ideal trabalhar com o transdutor direcionando sua face emissora da onda acústica para cima. 
Figura 6.3.1- Força de radiação acústica sobre um refletor de face plana, com diferentes amplitudes de deslocamento, para campo próximo, para o transdutor de $31 \mathrm{kHz}$ e $7.5 \mathrm{~mm}$ de raio. (experimental)

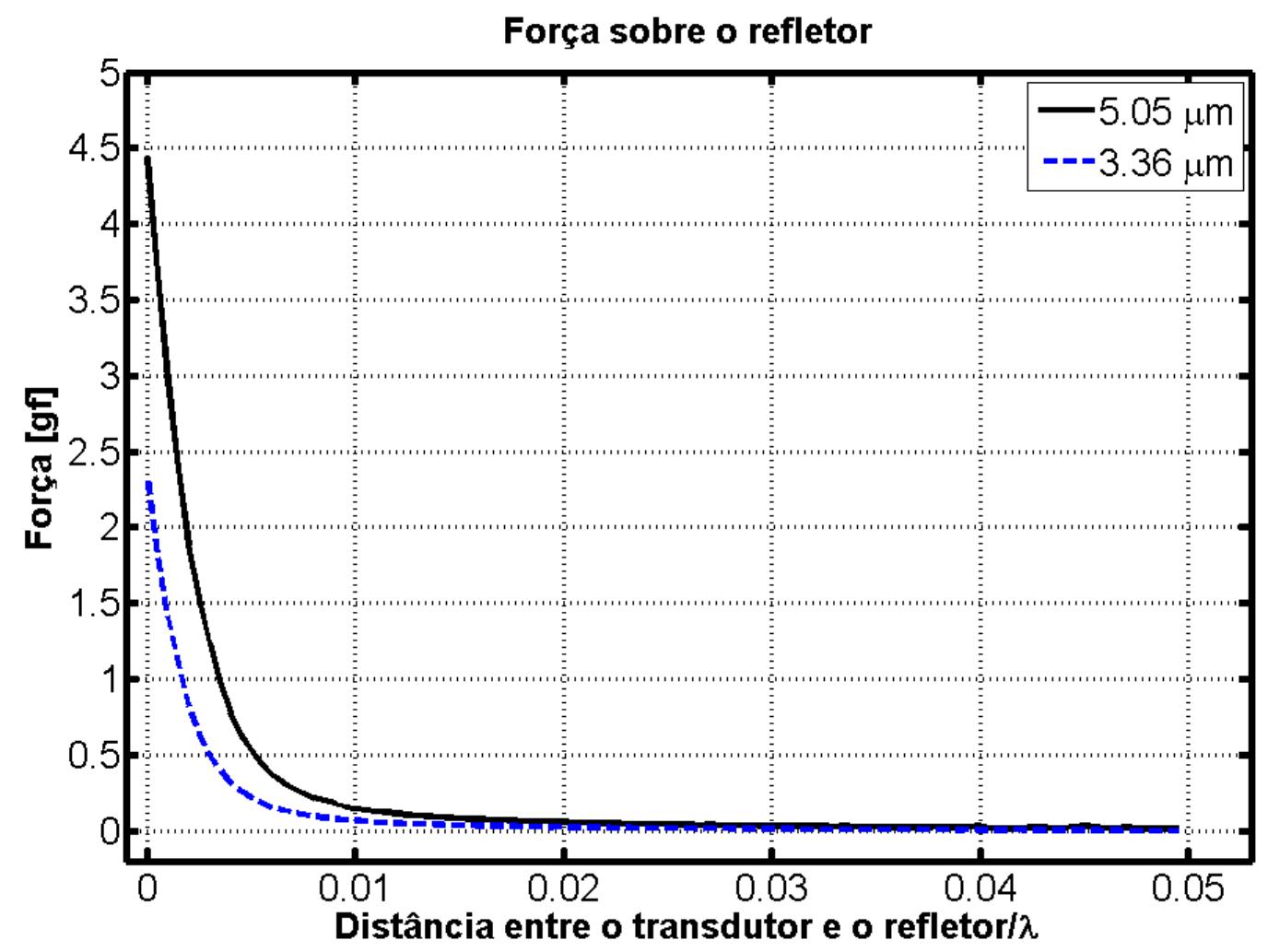

Fonte: Autor 
A figura 6.3.2 apresenta os resultados experimentais da força de radiação acústica atuando no campo próximo sobre um refletor de face plana, para amplitudes de deslocamento de 3,03, 4,05 e 5,06 $\mu \mathrm{m}$. O transdutor utilizado, neste experimento, possui um amplificador com diâmetro de $20 \mathrm{~mm}$, com face plana, frequência de $20440 \mathrm{~Hz}$, a relação entre de amplitude de deslocamento da face traseira com relação à amplitude de deslocamento da face dianteira é de 4.05, o refletor utilizado possui diâmetro de $20 \mathrm{~mm}$, o comprimento de onda é de 16,6 mm. Dos resultados apresentados permite concluir que a força de radiação acústica atua sobre o refletor com a intensidade positiva. Para este experimento, o ideal é trabalhar com o transdutor direcionado para cima, pois a força de radiação acústica repele o objeto da face emissora da onda ultrassônica.

Figura 6.3.2- Força de radiação acústica sobre um refletor de face plana, com diferentes amplitudes de deslocamento, para campo próximo, para o transdutor de $20 \mathrm{kHz}$ e $10 \mathrm{~mm}$ de raio. (experimental)

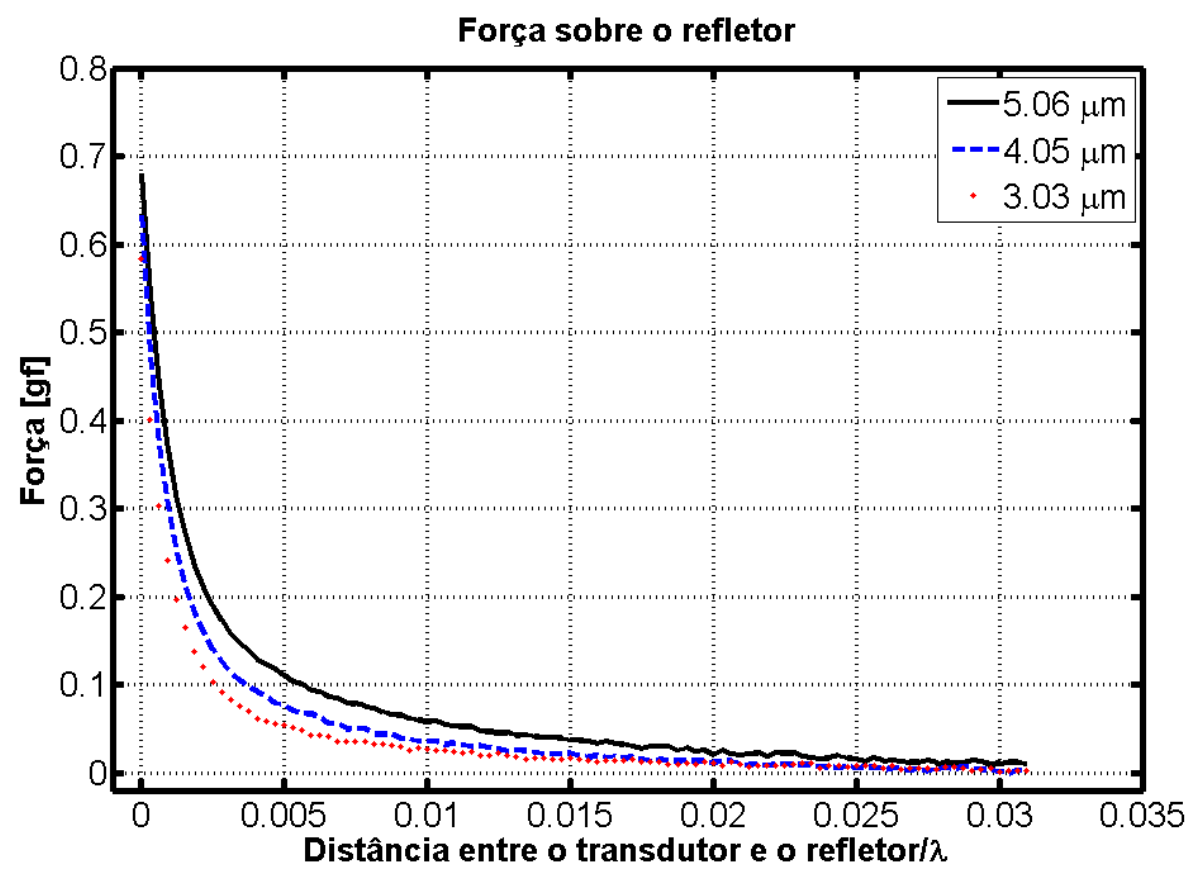

Fonte: Autor 
A figura 6.3.3 apresenta os resultados experimentais para as amplitudes de deslocamento de 1,69, 2,26 e 2,82 $\mu \mathrm{m}$, para um transdutor com um amplificador com $26 \mathrm{~mm}$ de diâmetro e um refletor com o mesmo diâmetro, $26 \mathrm{~mm}$, ambos de faces planas, a frequência de trabalho é $25250 \mathrm{~Hz}$, a relação entre a amplitude de deslocamento da face traseira e a amplitude da face dianteira é de 2.26 , e o comprimento de onda é de 13,4 mm. Assim como nos casos anteriores, a força de radiação acústica sobre o refletor também é positiva, o que é ideal para trabalhar com a face dianteira do transdutor direcionada para cima, pois a força de radiação acústica positiva repele os objetos da face do transdutor.

Figura 6.3.3- Força de radiação acústica sobre um refletor com diferentes amplitudes de tensão, para campo próximo, para o transdutor de $25 \mathrm{kHz}$ e $13 \mathrm{~mm}$ de raio. (experimental)

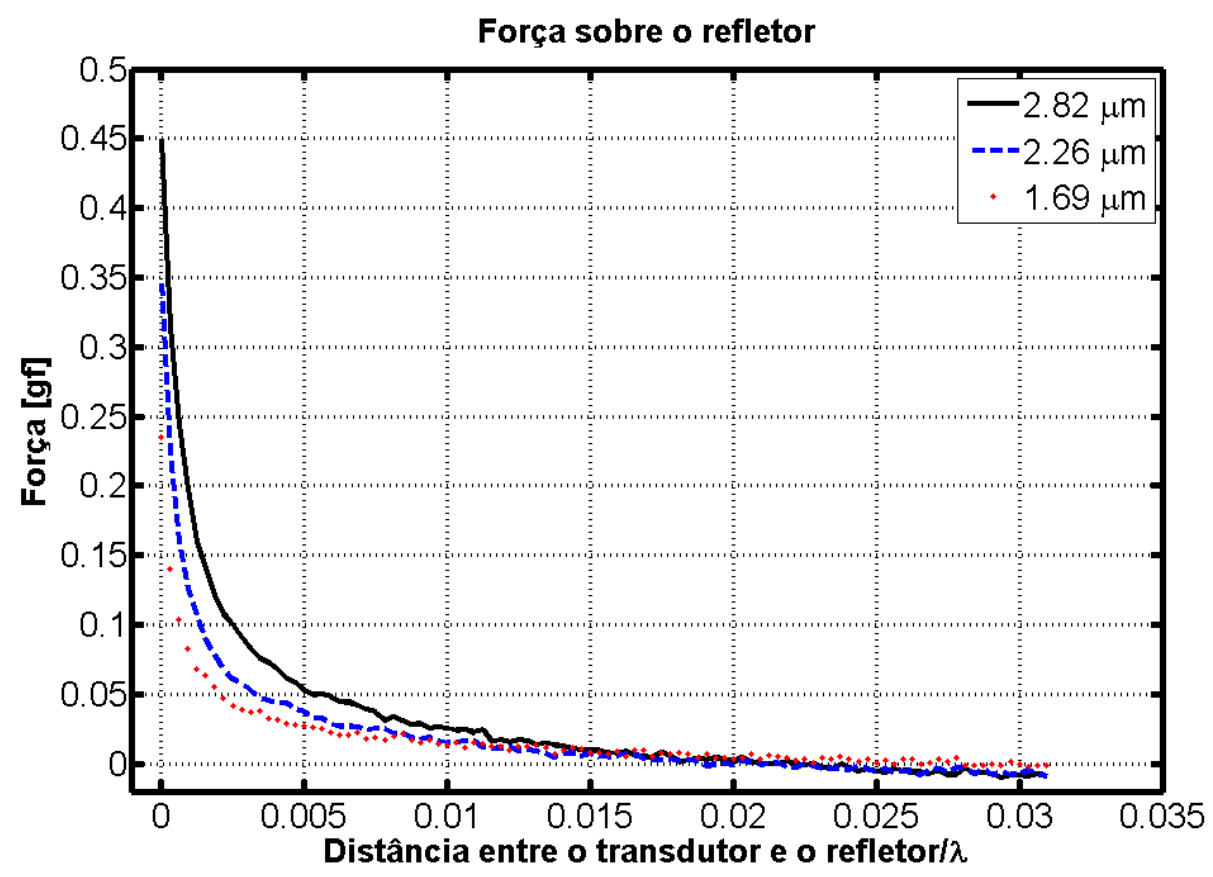

Fonte: Autor 


\subsection{Resultados e discussão}

A figura 6.4.1 apresenta o transdutor de face plana na região superior, uma fina camada de ar entre o transdutor e 0 anel, e por fim o anel de face plana sendo levitado pela força de radiação acústica que atua de forma atrativa. Nota-se, a partir da figura apresentada que não há um refletor abaixo do anel levitado, pois, nesta técnica, exige apenas o transdutor e o objeto de face plana que deseja-se levitar.

Figura 6.4.1- Imagem do experimento de levitação de campo próximo, com a ponta emissora do transdutor direcionada para baixo e um anel ambos com faces planas.

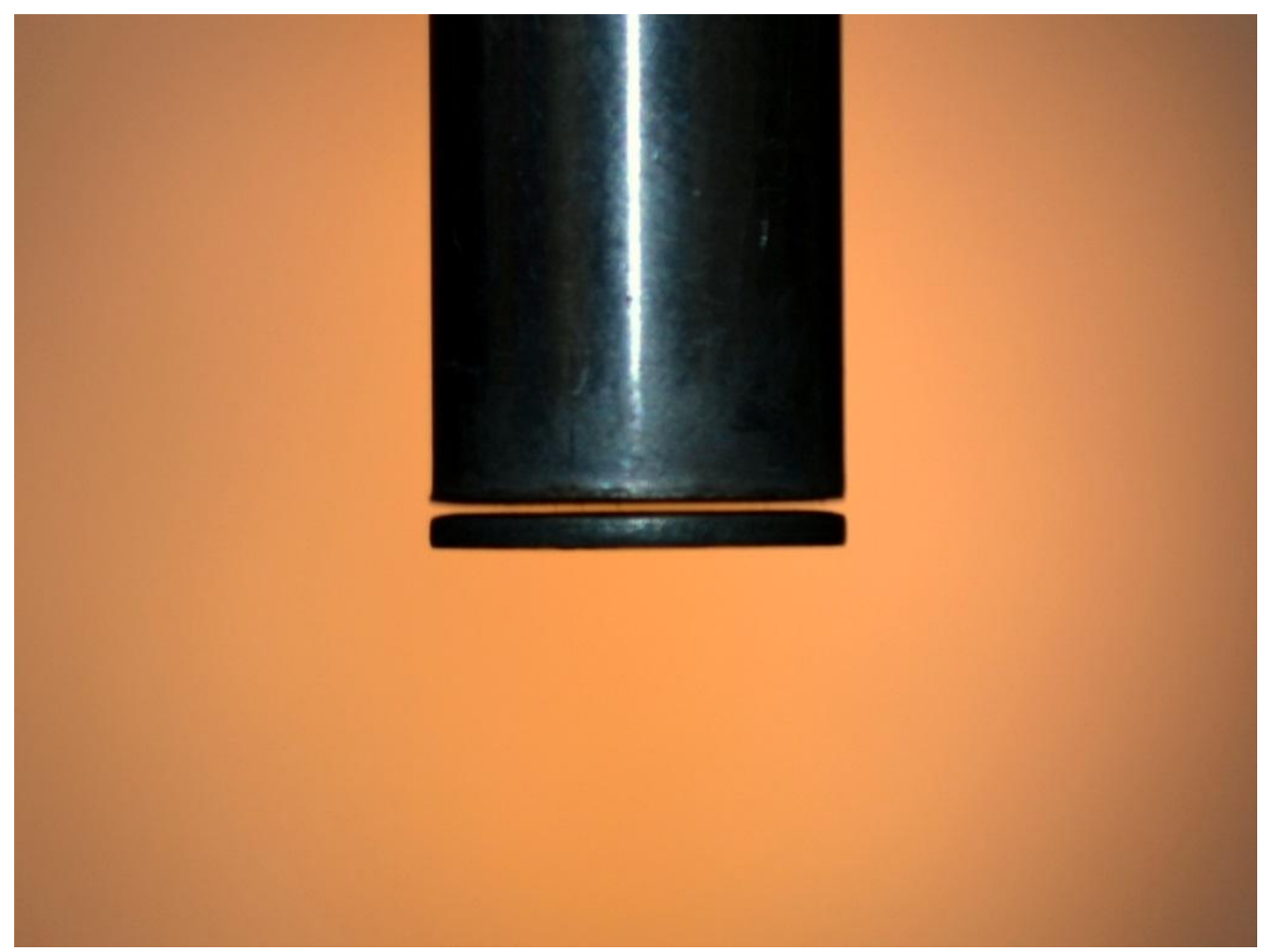

Fonte: Autor

A figura 6.4.2, mostra o resultado experimental para o transdutor de $23 \mathrm{kHz}$ e o anel de faces planas, o comprimento de onda é de $14,7 \mathrm{~mm}$, e a relação de amplitudes entre a face dianteira e traseira é de 18.80. A figura em questão é decomposta em três regiões: 1) a primeira onde temos uma força de grande intensidade por volta de 4 gf e que chega a zero, 2) a segunda região será de zero até o ponto onde temos a força de menor intensidade $0.301 \mathrm{gf}$, e 3) a terceira região onde a força de radiação acústica parte deste mínimo valor 0.301 gf em diante, mantendo a curva em aproximadamente zero. 
$\mathrm{Na}$ primeira região, a força de radiação acústica atua sobre o objeto de forma repulsiva, ou seja, a força de radiação acústica próxima da face do anel é positiva com 4 gf, nesta configuração o anel é afastado da face do transdutor, ideal para trabalhar com transdutor direcionando sua face emissora para cima, com o anel sendo acomodado sobre a face do transdutor.

A força de radiação acústica foi encontrada na segunda região da figura 6.4.2 para este transdutor. Onde definimos que a força é zero e alcança-se o menor valor experimental $0.301 \mathrm{gf}$. A característica desta região com a força negativa é atrair o anel para próximo da face emissora. Com tal condição é possível transportar objetos ou amostras de substância, que requerem manipulação, transporte ou mesmo separação retirando-o de um recipiente sem tocar no objeto.

O efeito da força de radiação acústica negativa é de atração sobre o objeto, o que, durante o experimento, se deu de forma satisfatória na configuração experimental elaborada na figura 6.4.1. O anel foi atraido para face emissora do transdutor e, como o esperado, a anel não encostou na referida face do transdutor, mantendo uma camada de ar de distância, conhecida como squeeze film, que é uma fina camada de ar que reside entre o transdutor e a amostra, conforme apresentamos na figura 6.4.1.

Já a terceira região, a qual se inicia com o valor mínimo da força de radiação acústica e aproxima-se de zero, não é possível levitar o anel, pois a força está diminuindo sua intensidade absoluta sobre o mesmo.

$\mathrm{Na}$ figura 6.4.2 apresentam-se curvas para três amplitudes distintas de deslocamento da face dianteira do transdutor, sendo que, para cada curva, existe um perfil de força de radiação acústica especifica para cada amplitude. Quanto maior a amplitude do sinal enviado pelo gerador de funções, mais intensa é força de radiação acústica atrativa sobre o anel, ou seja, menor tende a ser a região onde temos a camada de ar, salvo as características do anel. 
Como referência $40 \mathrm{mV}_{\mathrm{pp}}$ representa 1 micrometro de deslocamento da face traseira este valor é multiplicado pelo valor de 18.80, já mencionado. Portanto, enquanto temos a amplitude de $40 \mathrm{mV}_{\mathrm{pp}}$ na face traseira, na face frontal teremos $18.80 \mu \mathrm{m}$ de deslocamento, tal relação será utilizada para as demais amplitudes de 50 e $30 \mathrm{mV}_{\mathrm{pp}}$.

Figura 6.4.2- Força de radiação acústica sobre um anel de face plana com diferentes amplitudes de tensão, para campo próximo para o transdutor de $23 \mathrm{kHz}$ e $5 \mathrm{~mm}$ de raio. (experimental)

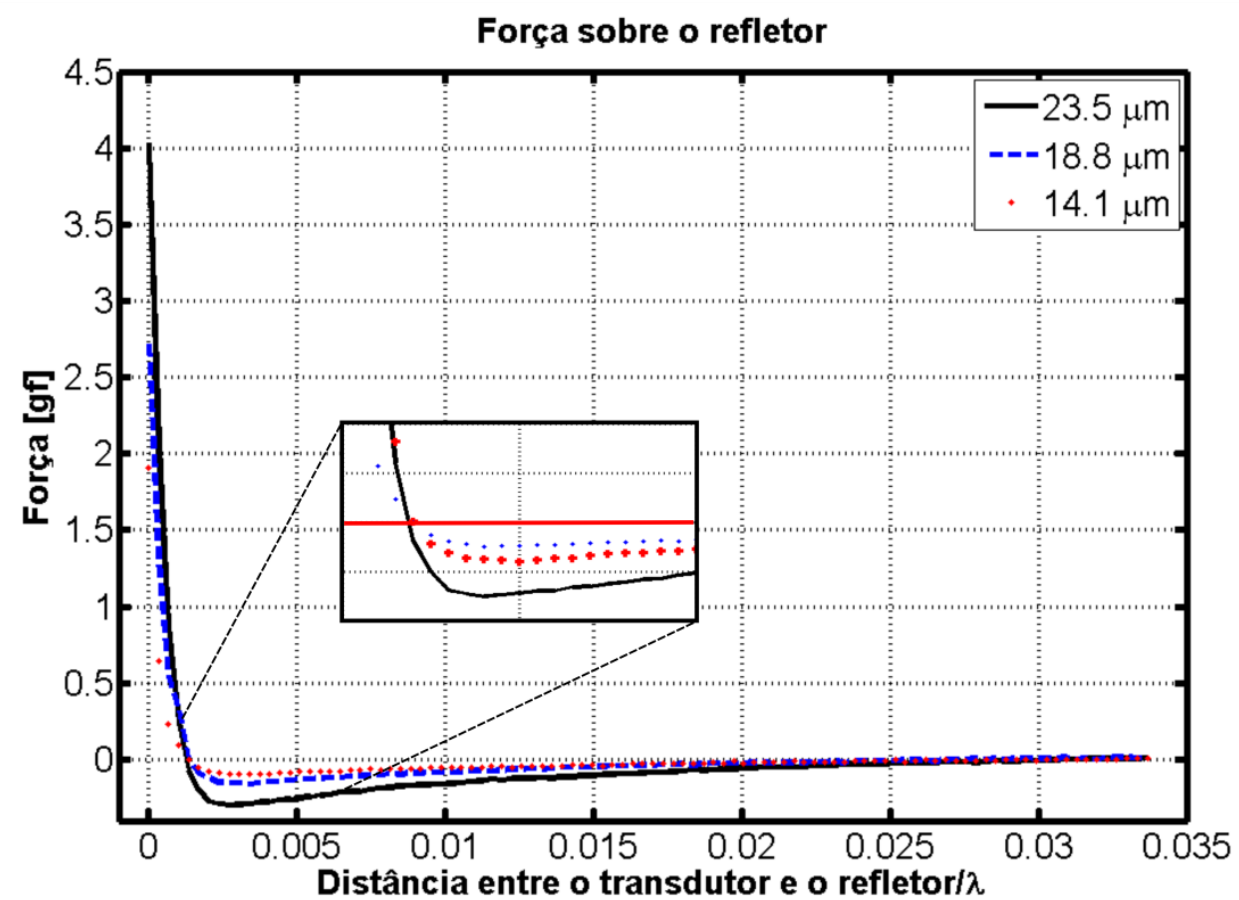

Fonte: Autor

A configuração para a força negativa é desejável em uma situação onde um objeto é colocado sobre uma bancada ou mesmo dentro de um recipiente e com a força de radiação acústica atuando de forma atrativa sobre o objeto, força de radiação acústica negativa, seja possível transportar, manipular e separar sem tocar no objeto. 


\subsection{Conclusão}

Os resultados simulados com software COMSOL apresentados no subcapítulo 6.1, foram gerados para comparar com os resultados experimentais presentes nos subcapítulos 6.3 e 6.4. A comparação entre os resultados simulados e experimentais para o transdutor com o amplificador de $10 \mathrm{~mm}$ foi bem discrepante, o mesmo ocorreu para os demais experimentos, o simulado sempre apresentando uma curva com uma força de radiação acústica negativa. As curvas para os demais experimentos não foram apresentadas, pois as curvas simuladas possuíam o perfil negativo, sendo que experimentalmente o perfil é positivo.

Para a curva com o transdutor que possui um amplificador de $10 \mathrm{~mm}$, os resultados apresentaram três regiões distintas. A primeira com uma força positiva de $4 \mathrm{gf}$, com o transdutor e o refletor bem próximos, a segunda região com a força negativa, o menor valor de $0.301 \mathrm{gf}$. Nesta segunda região tem-se a força de radiação acústica negativa, atraindo o anel para próximo da face emissora do transdutor e, a terceira região onde a força parte deste valor negativo e se aproxima de zero, nesta região o anel não levita.

Assim, com a utilização de um transdutor de $10 \mathrm{~mm}$ de diâmetro e frequência de $23090 \mathrm{~Hz}$ foi possível encontrar a região de atuação da força de radiação acústica atrativa para levitação o transdutor apontando para baixo.

Para os outros transdutores utilizados no experimento de campo próximo, com diâmetros de 15, 20 e 26 mm, a força de radiação acústica próximo do transdutor, possui intensidade positiva ideal para trabalhar com o transdutor direcionado para cima, configuração na qual o objeto é repelido da face emissora da onda ultrassônica.

Os transdutores utilizados neste experimento possuem diâmetros e frequências distintas, nota-se que a amplitude de deslocamento da face dianteira interfere na intensidade da força de radiação acústica. Nos resultados apresentados nota-se que 
quanto maior a relação da amplitude de deslocamento entre as faces dianteira maior a intensidade da força e mais rapidamente a força se aproximará de zero.

Pelos resultados simulados percebe-se que para obter a levitação atrativa é necessario que o objeto possua um furo central assim como o anel, para realizar a levitação de forma atrativa, pois assim eliminação o termo positivo de pressão, que possui grande intensidade no centro do objeto e tem-se maior influência do termo negativo de velocidade que possui grande influência nas bordas, tornando a força negativa, possibilitando a levitação de campo próximo com o transdutor apontando para baixo.

Portanto:

- Para o transdutor com o raio de $10 \mathrm{~mm}$, obtêm-se três regiões para a força de radiação acústica sendo: uma positiva, uma negativa e a ultima igual a zero. No intervalo onde a força é positiva o ideal é trabalhar com a face emissora do transdutor direcionada para cima. Para força de radiação acústica negativa o ideal é para trabalhar com o transdutor direcionando a face emissora para baixo;

- Para transdutores com raio maior que $15 \mathrm{~mm}$, obtêm-se a força de radiação é acústica positiva, ideal para trabalhar com o transdutor direcionando a face emissora para cima;

- A espessura da camada de ar não foi possível ser determinada. No entanto, notou-se que a distância aumenta com o aumento da amplitude de deslocamento em todos os experimentos.

- O efeito da força atrativa pode ter sido causa devido ao furo central na face do objeto, este efeito será melhor investigado posteriormente. 


\section{Conclusões}

Para obter resultados experimentais precisos, uma série de cuidados devem ser levados em consideração, todos os detalhes experimentais devem ser revisados ao término de cada varredura para que o resultado seja coerente, compatível e livre de interferências externas.

Os modelos numéricos utilizados para calcular o potencial de radiação acústica possuem grande confiabilidade, principalmente em experimentos onde se trabalha com campo distante, pois os resultados estão muito próximos dos resultados experimentais, como no caso da posição de levitação de esferas determinada pelo modelo do potencial de radiação acústica de Gor'kov.

No experimento da força de radiação acústica de campo distante, observou-se que as esferas de mesmo diâmetro na cavidade acústica apresentam o mesmo espalhamento do campo acústico. A diferença entre as curvas é o ponto de levitação devido à densidade da esfera, quanto mais densa maior deverá ser à força de radiação acústica para levitá-la, devido ao deslocamento proporcionado pela esfera, com relação à posição de referência para a cavidade sem esfera.

A partir das figuras do capítulo 4, que apresenta as oscilações das esferas, verificouse que quanto maior a densidade da esfera, mais suave será o aumento da oscilação da mesma, com o aumento da intensidade da força de radiação acústica, por outro lado, para as esferas menos densas as oscilações possuem mudanças bruscas de posição para posição.

Na posição em que a força de radiação acústica é máxima sobre o refletor, tem-se o maior potencial de radiação acústica, e como consequência deste potencial acústico, tem-se a maior rigidez elástica para a cavidade acústica.

O modelo utilizado por Hong (Hong et al.,2014), apresenta uma boa coerência para simulações de campo distante, (grandes distâncias comparadas com o comprimento de onda) entre o transdutor e o refletor. Antes de aplicar este modelo, foi 
reproduzida a simulação por eles apresentada, com o objetivo de garantir que os resultados obtidos estariam corretos. A equação utilizada apresentou boa coerência para o campo distante apresentando no capítulo 5. A simulação com a referida equação apresentou razoável compatibilidade para refletores com raios menores que $10 \mathrm{~mm}$. No entanto para refletores maiores a curva apresenta uma boa divergência entre os resultados simulados e experimentais.

Porém, utilizando a mesma equação para estimar a atuação da força de radiação acústica para o campo próximo, conforme apresentado no capítulo 6 , os resultados simulados comparados com os resultados experimentais não ficaram satisfatórios, uma vez que a comparação apresentou significativa discrepância. Deste modo, observa-se que para determinadas regiões a equação utilizada não é capaz de validar todos os intervalos de levitação, sendo eficiente em algumas configurações específicas, com em casos em que o transdutor e o refletor possuem razoável distância entre si.

Nos experimentos de campo próximo foi possível notar que muitos fatores interferem na atuação da força de radiação acústica sobre o objeto. No entanto, para o transdutor de $23 \mathrm{kHz}$, com amplificador de $10 \mathrm{~mm}$ obtém-se duas regiões, onde é possível realizar a levitação acústica, uma região onde a força de radiação acústica é positiva e uma região negativa, ideal para atrair objetos em que se deseja manipular com o transdutor direcionando sua face emissora da onda acústica para baixo. $O$ efeito da força negativa também pode ter ocorrido devido ao furo central do anel.

Para os transdutores de 31, 20 e $25 \mathrm{kHz}$ que possuem diâmetros de 15, 20 e 26, mm maiores do que o transdutor de $23 \mathrm{kHz}$, o ideal é trabalhar com os transdutores direcionando a face emissora da onda acústica para cima. Neste caso é necessário posicionar a amostra sobre a face do transdutor, pois a força de radiação acústica para estes transdutores atua de forma positiva, afastando as amostras da face do transdutor. 
Nos experimentos aqui apresentados, observou-se que a força de radiação acústica é bem sensível a: pequenas mudanças na geometria da cavidade acústica; diâmetro do transdutor; a distância entre o transdutor e o refletor ou o objeto para campo próximo; a inclinação do sistema de levitação; e o alinhamento e paralelismo das faces que confinam a cavidade acústica. Tais fatos apresentados interferem de forma crucial na intensidade da força de radiação acústica que atuará sobre o refletor ou sobre um objeto que se deseja levitar. A força de radiação acústica é ideal para trabalhar com objetos frágeis ou que não podem ter contato com outros recipientes para evitar contaminação, e não exige que a amostra tenha restrições como propriedades elétricas ou magnéticas.

Portanto:

- As esferas geram espalhamento do campo acústico sobre o refletor em uma cavidade acústica;

- Na configuração em que o refletor e transdutor possuem faces côncavas, há efeitos não lineares sobre a força de radiação acústica na face do refletor, na região de ressonância da cavidade acústica, efeitos observados: histerese e fenômeno de salto;

- Na configuração em que o refletor e transdutor possuem faces planas, a curva em torno do pico de ressonância da cavidade acústica não possui efeitos não lineares sobre a força de radiação acústica sobre o refletor, a curva é simétrica;

- Foi encontrada a relação ótima entre o transdutor e refletor de faces planas no campo distante 15 e 16 mm de diâmetro respectivamente;

- Para o transdutor com diâmetro de $10 \mathrm{~mm}$, a força de radiação acústica atua de forma negativa sobre o anel, aproximando o anel da face emissora da onda acústica; 
- Para transdutores com diâmetros maiores que $10 \mathrm{~mm}$ a força de radiação acústica atua de forma positiva sobre os objetos, afastando-os da face emissora da onda acústica do transdutor.

- Provavelmente o furo central apresentado pelo anel interfere na força de radiação acústica. 


\section{Trabalhos futuros}

Como sugestão para trabalhos futuros, existe a possibilidade de se investigar em que situações as esferas são ejetadas da cavidade acústica ou mesmo situações em que as esferas caem sobre o refletor. Outro efeito observado que não houve tempo para ser analisado é que com o aumento do diâmetro do refletor a distância entre o transdutor e refletor diminui, para a região de ressonância de dada cavidade acústica, que pelos resultados nota-se uma diminuição da força de radiação acústica sobre o refletor. A curva apresentada entre a força de radiação acústica e os diversos refletores não era esperada, e um possível trabalho futuro é analisar se existe efeito de ondas espalhadas pelo refletor retornando para a região central da cavidade acústica. Em relação ao experimento de campo próximo, pretende-se no futuro, medir a espessura da camada de ar entre o objeto e o transdutor e verificar qual a influência do furo central que 0 anel possui sobre a força de radiação acústica. 


\section{REFERÊNCIAS}

ALMEIDA, M, P. COSTA, U, M. Exemplo de histerese com um Sistema de massa-mola. Revista Brasileira de Ensino de Física, vol 22 (1),p 49-53, 2000.

ANDRADE, M. A. B.; BUIOCHI, F.; ADAMOWSKI, J. C. Finite Element Analysis and Optimization of a Single-Axis Acoustic Levitator. IEEE Transactions on Ultrasoinics, Ferroelectrics, and Frequency Control, vol 57 (2), p 469-479, 2010.

ANDRADE, M. A. B. Estudo da força de radiação acústica em partículas produzida por ondas progressivas e estacionárias. Tese (Doutorado), Escola Politécnica. Departamento de Engenharia Mecatrônica e de Sistemas Mecânicos, Universidade de São Paulo, São Paulo, 2010.

ANDRADE, M, A B., PEREZ, N., ADAMOWSKI, J, C., Experimental study of the oscillation of sphere in an acoustic levitator. Journal Acoustic Society of American, vol. 136 (4), p. 1518-1529, 2014.

ANDRADE, M. A. B.; RAMOS, T. S.; OKINA, F. T. A.; ADAMOWSKI, J. C.; Nonlinear characterization of a single-axis acoustic levitator. Review of Scientific linstruments, vol 85, 045125, 2014.

ANDRADE, M, A B., PEREZ, N., ADAMOWSKI, J, C., Particle manipulation by a non-resonant acoustic levitator. Applied Physics Letters, vol. 106, 014101, 2015.

ANDRADE, M, A B., PEREZ, N., ADAMOWSKI, J, C., Levitação acústica. Revista Brasileira de Ensino de Física, vol 37, n 2, 2304, 2015.

ANDRADE, M, A B., BERNASSAU, A, L., ADAMOWSKI, J, C. Acoustic levitation of a large solid sphere. Applied Physics Letters, vol 109, 044101, 2016.

ANDRADE, M, A B., ADAMOWSKI, J, C., Acoustic radiation force on a sphere in an acoustic levitation device. IEEE International Ultrasonics Symposium Proceedings, 2016.

BAER, S.; ANDRADE, M. A. B.; ESEN, C.; ADAMOWSKI, J. C.; SCHWEIGER, G; OSTENDORF, A. Analysis of the particle stability in a new designed ultrasonic levitation device. Review of Scientific Instruments, vol 82, 10511, 2011. 
BAO, M. YANG H. Squeeze film air damping in MEMS. Sensors and Actuators A Elsevier, vol. 136, p 3-27,2007.

BARMATZ, M.; COLLAS, P. Acoustic radiation potential on a sphere in plane, cylindrical, and spherical standing wave fields. Journal of the Acoustic Society America, vol 77(3), p. 928-945 1985.

BARNKOV, R. Acoustofluidics in microsystems: investigation of resonances. Master thesis, s032091, Department of Micro and Nanotechnology, Technical University of Denmark, 2009.

BENMORE, C.J.; WEBER, J.K.R. Amorphization of molecular liquids of pharmaceutical drugs by acoustic levitation. Physical Review X, vol. 1, 011004, 2011.

BEYER, R. T. Nonlinear acoustics. Brown University, 1974.

BEYER, R. T. Lord Rayleigh and nonlinear acoustics. Journal Acoustic Society America, vol 98, n 6, p. 3032-3034, 1995.

BORGNIS, F, E. Acoustic radiation pressure of plane compressional waves. Reviews of Modern Physics, vol 25 (3), p 653-664, 1953.

BRUUS, $\mathrm{H}$. Acoustofluidics 1: Governing equations in microfluidics. Lab Chip, The Royal Societ of Chemistry, vol.11, p 3742-3751, 2011.

BRUUS, $\mathrm{H}$. Acoustofluidics 7: the acoustic radiation force on small particles. Lab Chip, The Royal Societ of Chemistry, vol.12, p 1014-1021, 2012.

BUNKIN, F. V.; KRAVTSOV, Y. A.; LYAKHOV, G. A. Acoustic analogues of nonlinear-optics phenomena. Sov Physical usp, IOPscience, vol 29 (7) p. 607-619, 1986.

CHEN, C.; WANG, J.; JIA, B.; LI, F. Design of a noncontact spherical bearing based on near-field acoustic levitation. Journal of Intelligent Material Systems and Structures, vol. 25 (6), p 755-767 2014. 
CHINO, S.; ISHINO, Y.; TAKASAKI, M.; MIZUNO, T. Actuation force characteristics of ultrasonic suspension for minute object. IEEE International Ultrasonics Symposium Proceedings, 2001.

CHUN, Y.; KIM Y. Numerical analysis for nonlinear resonant oscillations of gas in axisymmetric closed tubes. Journal Acoustic Society America. vol 108 (6), p 2765-2774, 2000.

COLLAS, P.; BARMATZ, M. Acoustic radiation force on a particle in a temperatuer gradient. Journal Acoustic. Society of the America. vol 81 (5) p. 13271330, 1987.

COLLAS, P.; BARMATZ, M. SHIPLEY, C Acoustic levitation in the presence of gravity. Journal Acoustic. Society of the America. vol 86 (2) p. 777-787, 1989.

FIELD., C. R.; SCHEELINE, A. Design and implementation of an efficient acoustically levitated drop reactor for in still measurements. Review of Scientific Instruments. Vol 78 (12), 125102, 2007.

FORESTI, D.; BJELOBRK, N.; NABAVI, M.; POULIKAKOS, D. Contactless transport acoustically levitated particles. Applied Physics Letters, vol 97, 161904, 2010.

FORESTI, D.; BJELOBRK, N.; NABAVI, M.; POULIKAKOS, D. Investigation of a line-focused acoustic levitation for contactless transport of particles. Journal of Applied Physics, vol 109, 093503, 2011.

FORESTI, D.; NABAVI, M.; POULIKAKOS, D. On the acoustic levitation stability behaviour of spherical and ellipsoidal particles. Journal of Fluid Mechanics, p. 112, 2012.

FORESTI, D.; SAMBATAKAKIS, G.; BOTTAN, S.; POULIKAKOS, D. Morphing Surfaces Enable Acoustophoretic Contactless Transport of Ultrahigh-Density Matter in Air. Scientific Reports, p 1-6, 2013.

FORESTI, D.; POULIKAKOS, D. Acoustophoretic Contactless Elevation, Orbital Transport and Spinning of Matter in Air. Physical Review Letters, vol 112, 024301, 2014. 
GAITAN, D. F.; ATCHLEY, A. A. Finite amplitude standing waves in harmonic and anharmonic tubes. Journal Acoustic America, vol 93 (5), p. 2489-2495, 1993.

GALLEGO-JUÁREZ, J. A. Piezoelectric ceramics and ultrasonic transducer. Journal of Physics E: Scientific Instruments, vol 22, p 804-816, 1989.

GAO, J.R.; CAO, C.D.; WEI, B. Containerless processing of materials by acoustic levitation. Adv. Space Res., Elsevier, vol. 24 (10), p. 1293-1297, 1999.

GLYNNE-JONES, P.; DÉMORÉ, C. E. M; YE, C., QUI, Y., COCHRAN, S., HILL, M. Array-controlled ultrasonic manipulation of particles in planar acoustic resonator. IEEE Transactions on Ultrasonics, Ferroelectrics, and Frequency Control, vol 59 (6), p. 1258-1266, 2012.

GOR'KOV, L. P., On the forces acting on a small particle in an acoustical field in an ideal fluid, Soviet Physics - Doklady, vol. 6, p. 773-775, 1962.

HAAKE, A.; DUAL, J. Contactless micromanipulation of small particles by an ultrasound field excited by a vibrating body. Journal Acoustic Society of America, vol 117 (5), p. 2752-2760, 2005.

HAMILTON, M. F.; BLACKSTOCK, D. T. On the coefficient of nonlinearity $\boldsymbol{\beta}$ in nonlinear acoustics. Journal Acoustic Society America, vol 83 (1), p 74-77, 1988.

HASEGAWA, T., YOSIOKA, K., Acoustic-radiation force on a solid elastic sphere, Journal of the Acoustical Society of America, vol. 46(5), p. 1139-1143, 1969.

HASHIMOTO, Y.; KOIKE, Y.; UEHA, S. Near-field acoustic levitation of planar specimens using flexural vibration. Journal Acoustical Society of American, vol 100, p. 2057-2061, 1996.

HASHIMOTO, Y.; KOIKE, Y.; UEHA, S. Transporting objects wthout contact using flexural traveling waves. Journal Acoustical Society of American, vol 100, p. 2057-2061, 1998.

HATANAKA, T., KOIKE, Y., NAKAMURA, K., UEHA, S., HASHIMOTO, Y. Characteristics of underwater near-field acoustic radiation force acting on a planar object. Japanese Journal of Applied Physics, vol. 38, p. L1284-L1285, 1999.

HONG, Z. Y.; ZHAI, W.; YAN, N.; WEI, B. Measurement and simulation of acoustic radiation force on a planar reflector. Journal Acoustical Society America, vol 135 (5), p. 2553-2558, 2014. 
ILINSKII, Y. A.; LIPKENS, B.; LUCAS, T. S.; VAN DOREN, T. W.; ZABOLOTSKAYA E. A. Nonlinear standing waves in an acoustical resonator. Journal Acoustic Society America, vol 104 (5), p 2664-2674, 1998.

IULA, A. VAZQUEZ, F., PAPPALARDO, M., E GALLEGO, J. A. Finite element three-dimensional analysis of the vibrational behavior of the Langevin-type transducer. Ultrasonics, Elsevier Science, v 40, p 513-517, 2002.

KARLSEN, J. T., BRUUS, H. Forces acting on a small particle in an acoustical field in a thermoviscous fluid. Physical Review E, vol.92, p 043010, 2015.

KING, L. V. On the acoustic radiation pressure on spheres. The Royal Society of London. Series A, Mathematical and Physical Sciences. p.212-240, 1934.

KINO, G, S. Acoustic waves: devices, imaging, and analog signal processing. Prentice-Hall, Inc., Englewood Cliffs, NJ, Cap 3, p 154-317, 1987.

KOYAMA, D.; NAKAMURA, K. Noncontact Ultrasonic Transportation of Small Objects Over Long Distances in Air Using a Bending Vibrator and a Reflector. IEEE Transactions on Ultrasonics, Ferroelectrics, and Frequency Control, vol 57 (5), p 1152-1159, 2010.

LARENSON, C, C; LIPKENS, B., LUCAS, T. S., PERKINS, D. K., VAN DORE, T. W. Measurements of macrosonic standing wave in oscillating closed cavities. Journal Acoustic Society of America, vol 104 (2),p 623 636, 1998.

LEE, C. P.; WANG, T. G. Acoustic radiation pressure. Journal Acoustical Society of the America, vol. 94 (2), p. 1099-1109, 1993.

LI, J.; CAO, W., LIU, P., DING, H. Influence of gas inertia and edge effect on squeeze film in near field acoustic levitation. Applied Physics Letters, vol 96, 243507, 2010.

LI, W. Analytical modelling of ultra-thin gas squeeze film. Nanotechnology, IOP Publishing Ltd, vol 10, p. 440-446, 1999.

LI, X.; FINKBEINER, J.; RAMAN, G.; DANIELS, C.; STEINETZ, B. M.; Optimized shapes of oscillating resonators for generating high-amplitude pressure waves. Journal Acoustic Society of the America, vol 116 (5), p. 2814-2821, 2004. 
MANNEBERG, O. Multidimensional ultrasonic standing wave manipulation in microfluidic chips. Doctoral Thesis, Department of Applied Physics Royal Institute of Technology, Stockholm, Sweden, 2009.

MARZO, A.; GHOBRIA, A., COX, L., CALEAP, M., CROXFORD, A., DRINKWATER, $B$. W. Realization of compact tractor beams using acoustic delay-lines. Applied Physics Letters, vol 110, p. $014102,2017$.

MEURER, T.; QU, J.; JACOBS, L.J. Wave propagation in nonlinear and hysteretic Media a numerical study. International Journal of Solids and Structures, vol 39, p. 5585-5614, 2002.

MINIKES, A.; BUCHER, I. Coupled dynamics of a squeeze-film levitated mass and a vibrating piezoelectric disc: numerical analysis and experimental study. Journal of sound and Vibration, Elsevier, p. 241-268, 2003.

MINIKES, A.; BUCHER, I. HABER, S. Levitation force induced by pressure radiation in gas squeeze films. Journal Acoustical Society of American, vol 116 (1), p. 217-226, 2004.

MINIKES, A.; BUCHER, I. Comparing numerical and analytical solutions for squeeze-film levitation force. Journal Fluids and Structures, vol 22, p. 713-719, 2006.

MURRAY, I.F.; HEISTER, S.D. On a droplet's response to acoustic excitation. International Journal of Multiphase Flow, vol 25, p 531-550, 1999.

NOMURA, H.; MATSUDA, T, K, K. Theoretical and experimental examination of near-field acoustic levitation. Journal Acoustic Society of American, vol 111, p. 1578-1583, 2002.

NUSSENZVEIG, M. H. Curso de física básica. $4^{\circ}$ Edição São Paulo: Edgard Blücher, 2002.

PERÉZ, N., ANDRADE, M ,A, B., CANETTI, R., ADAMOWSKI, J, C. Experimental determination of the dynamics of na acoustically levitated sphere. Journal of Applied Physics, vol. 116, 184903, 2014. 
PERÉZ, N., CARDONI, A., CERISOLA, N., RIERA, E., ANDRADE, M ,A, B., CANETTI, R., ADAMOWSKI, J, C. Nonlinear dynamic modeling of Langevin-type piezoelectric transducers. Actuadors, vol. 4, p. 255-266, 2015.

RAMOS, TIAGO S.; ANDRADE, MARCO A. B.; ADAMOWSKI, JULIO C. Influence of Nonlinear Effects on the Acoustic Levitation of Small Spheres. IEEE Transactions on Ultrasonics, Ferroelectrics, and Frequency Control, vol. 1, p. 14321435, 2014.

RÖMER, H. Theoretical optics. WILEY-VCH Verlag GmbH \& Co. KGaA, 2005.

RUDNICK, J.; BARMATZ, M. Oscillational instabilities in single-mode acoustic levitators. Journal Acoustic Society America, vol (1) 87, p. 81-92, 1990.

SANTILLÁN, A. O.; BOULLOSA, R. R.; CUTANDA-HENRÍQUEZ, V.; LÓPEZ, A. P. Dependence of oscillational instabilities on the amplitude of the acoustic wave in single-axis levitators. $14^{\text {th }}$ International Congress on Sound \& Vibration, 2007.

SHUYU, L.. Study on the Langevin piezoelectric ceramic ultrasonic transducer of longitudinal-flexural composite vibrational mode. Ultrasonics, Elsevier Science, vol 44, p 109-114, 2006.

STINDT, A., ANDRADE, M ,A, B., ALBRECHT, M., ADAMOWSKI, J, C., PANNE, U., RIEDEL, J. Experimental and numerical characterization of the sound pressure in standing wave acoustic levitators. Review of Scientific Instruments, vol. 85, 015110, 2014.

TAKASAKI, M., TERADA, D., KATO, Y., ISHINO, Y., MIZUNO, T. Non-contact ultrasonica support of minute objetcs. International congress on ultrasonics, Physics Procedia 3, Elsevier, p. 1059-1065, 2010.

THALHAMMER, G., STEIGER, R., MEINSCHAD, M., HILL, M., BERNET, S., RITSCH-MARTE, M. Combined acoustic and optical trapping. Biomedical Optics Express, vol 2 (10), 2011.

TJØTTA, S. On some nonlinear effects in ultrasonic fields. Ultrasonics, Elsevier, vol 38, p. 278-283, 2000.

TORR,G. R. The acoustic radiation force. American Journal of Physics, vol 52 (5), p. 402-408 1984. 
UCHIAGE, K.; ISHINO, Y.; TAKASAKI, M.; MIZUNO, T. Enlargement of floator size in ultrasonic suspension by arranging the shape of vibrating surface. International Ultrasonics Symposium Proceedings, 2014.

VANDAELE, V.; LAMBERT, P.; DELCHAMBRE, A. Non-contact handling in microassembly: Acoustic levitation. Precision Engineering, Elsevier,vol 29, p. 491505, 2005.

VANHILLE, C.; CONDE C.; CAMPOS-POZUELO. C. Finite-difference and finitevolume methods for nonlinear standing ultrasonic waves in fluid media. Ultrasonics, Elsevier, vol 42, p. 315-318, 2004.

VANHILLE, C.; CAMPOS-POZUELO, C. Numerical and experimental analysis of strongly nonlinear standing acoustic waves in axisymmetric cavities. Ultrasonics, Elsevier, vol 43, p. 652-660, 2005.

VANHILLE, C.; CAMPOS-POZUELO, C. Nonlinear ultrasonic resonators: A numerical analysis in the time domain. Ultrasonics, Elsevier, vol 44, p. 777-781, 2006.

VORONOV, B. B.; KOROBOV, A. I.; RUDENKO, O. V. Nonlinear acoustic waves in media with absorption and dispersion. Sov. Phys. Usp, IOPscience, vol 35 (9), p. 769-804, 1992.

XIE ,W. J.; WEI, B. Dependence of acoustic levitation capabilities on geometric parameters. Physical Review E, Vol. 66, 026605, 2002.

XIE ,W. J.; CAO ,C. D.; LÜ ,Y. J.; WEI, B. Levitation of iridium and liquid mercury by ultrasound. Physical Review Letters, vol. 89 (10), 104304, 2002.

YANO, R.; AOYAGI, M.; TAMURA, H.; TAKANO, T. Novel transfer method using Near-Field acoustic levitation and its application. Japanese Journal of Applied Physics, 50, p. 07HE29, 2011.

YARIN, A.L.; PFAFFENLEHNER, M.; TROPEA, C. On the acoustic levitation of droples. Journal Fluid Mechanical,Cambridge University Press, vol.356, p. 65-91, 1998.

YARIN, A.L.; WEISS, D.A.; BRENN, G.; RENSINK, D. Acoustically levitated drops: drop oscillation and break-up driven by ultrasound modulation. International Journal of Multiphase Flow, Elsevier, vol 28 p. 887-910, 2002. 
YOSIOKA, K., E KAWASIMA, Y. Acoustic radiation pressure on a compressible sphere. Acoustica, vol.5, p 167-173, 1955.

WESTERVELT, P. J. Acoustic radiation pressure. Journal of the Acoustical Society of America, vol.29, p 26-29, 1957. 